International Scientific-Technical and Production Journal

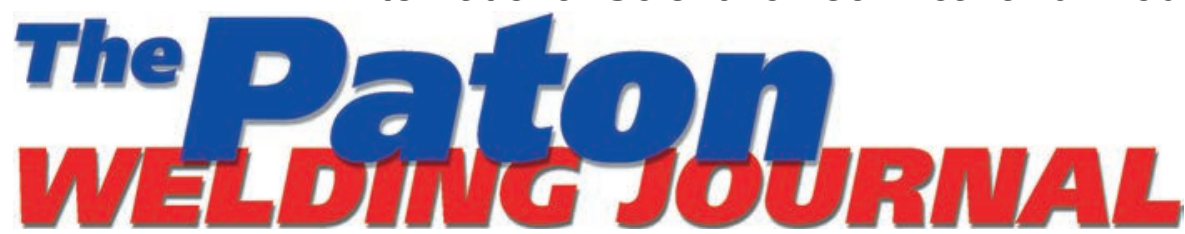

English Translation of the Monthly «Avtomatychne Zvaryuvannya»

(Avtomaticheskaya Svarka/Automatic Welding) Journal Published in Ukrainian and Russian Since 1948

\section{EDITORIAL BOARD}

E.O. Paton Electric Welding Institute, Kyiv, Ukraine: B.E. Paton (Editor-in-Chief),

S.I. Kuchuk-Yatsenko (Deputy Editor-in-Chief),

V.M. Lipodaev (Deputy Editor-in-Chief),

O.M. Berdnikova, Yu.S. Borisov,

V.V. Knysh, V.M. Korzhyk, I.V. Krivtsun,

Yu.M. Lankin, L.M. Lobanov, S.Yu. Maksimov,

M.O. Pashchin, V.D. Poznyakov,

I.O. Ryabtsev, K.A. Yushchenko; V.V. Dmitrik, NTUU

«Kharkiv Polytechnic Institute», Kharkiv, Ukraine; V.V. Kvasnitsky, NTUU

«lgor Sikorsky Kyiv Polytechnic Institute», Kyiv, Ukraine;

E.P. Chvertko, NTUU

«Igor Sikorsky Kyiv Polytechnic Institute», Kyiv, Ukraine;

M.M. Student, Karpenko Physico-Mechanical Institute, Lviv, Ukraine;

M. Zinigrad, Ariel University, Israel;

Ya. Pilarczyk, Welding Institute, Gliwice, Poland;

U. Reisgen, Welding and Joining Institute, Aachen, Germany

\section{Founders}

E.O. Paton Electric Welding Institute International Association «Welding» Publisher

International Association «Welding» Translators

A.O. Fomin, I.M. Kutianova Editor

N.G. Khomenko

Electron galley

D.I. Sereda, T.Yu. Snegiryova Address

E.O. Paton Electric Welding Institute, International Association «Welding» 11 Kazimir Malevich Str. (former Bozhenko), 03150, Kyiv, Ukraine

Tel.:/Fax: (38044) 2008277

E-mail: journal@paton.kiev.ua

www://patonpublishinghouse.com/eng/journals/tpwj

\section{State Registration Certificate KV 4790 of 09.01 .2001} ISSN 0957-798X

DOI: http://dx.doi.org/10.15407/tpwj Subscriptions

12 issues per year, back issues available. $\$ 384$, subscriptions for the printed (hard copy) version, air postage and packaging included.

$\$ 312$, subscriptions for the electronic version (sending issues of Journal in pdf format or providing access to IP addresses).

Institutions with current subscriptions on printed version

can purchase online access to the electronic versions of any back issues that they have not subscribed to.

Issues of the Journal (more than two years old)

are available at a substantially reduced price.

All rights reserved

This publication and each of the articles contained herein are protected by copyright.

Permission to reproduce material contained in this journal must be obtained in writing from the Publisher.

\section{CONTENTS}

Borys Evgenovych Paton - IEEE Hononary Member! 2

\section{SCIENTIFIC AND TECHNICAL}

Poznyakov V.D., Gaivoronskyi O.A., Kostin V.A., Berdnikova O.M. and Shmygelskyi S.V. Influence of thermal cycle of surfacing on mechanical properties and resistance of HAZ metal of rail steel M76 to brittle fracture

Boyi Wu and Krivtsun I.V. Processes of nonconsumable electrode welding with welding current modulation (Review). Part II. Effects of arc impact on the metal being welded

Maksymov S.Yu., Sydoruk V.S. and Krazhanovskyi D.M. Features of arc with pulsed self-regulation of electrode melting process in manual arc welding

\section{INDUSTRIAL}

Krivtsun I.V., Korzhik V.N., Khaskin V.Yu., Lo Z. and Illyashenko E.V.

Hybrid laser-microplasma welding of stainless steels

Lobanov L.M., Makhlin N.M., Vodolazsky V.E., Popov V.E. and

Oliyanenko D.S. Modernization of heads of automatic welding machines

for orbital TIG-welding of pipelines of NPP power units

Marchenko A.E., Gnatenko M.F. and Skorina N.V. Effect of extrusion modifiers of coating mixture on electrode coating thickness difference 48

Gruzevich A.V. and Nikiforov D.L. Experience of repair of parts of TPS power unit equipment

CALENDAR OF DECEMBER 61 


\section{BORYS EVGENOVYCH PATON — IEEE HONONARY MEMBER!}

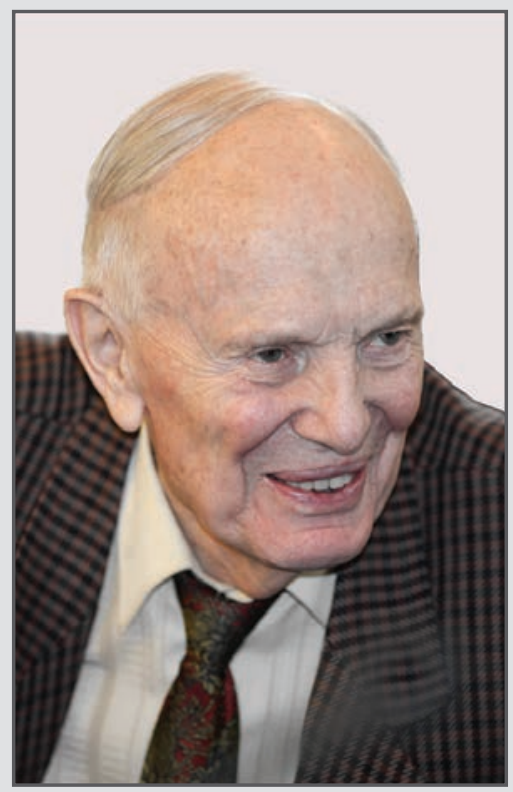

Honorary membership of the Institute of Electrical and Electronics Engineers (IEEE) is given to a person for life. It is awarded by IEEE Board of Directors to people, who, not being IEEE members, have made

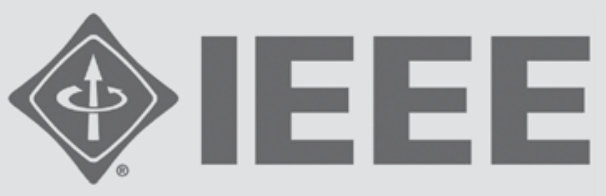
Advancing Technology for Humanity an outstanding contribution into progress of humanity in IEEE fields of interest.

IEEE Ukraine Section is proud to announce that Professor Borys Paton, President of the National Academy of Sciences of Ukraine, Director of the E.O. Paton Electric Welding Institute of the NAS of Ukraine, was selected to receive the 2020 IEEE Honorary Membership Award. This is a recognition of his achievement within IEEE engineering fields, which had an impact on development of electrometallurgy, materials science, electric welding of metals and biological tissues.

At the end of this year, IEEE Board of Directors meeting approved a decision on granting Prof. Borys Paton, President of the National Academy of Sciences of Ukraine, Director of the Electric Welding Institute of the NAS of Ukraine, a special award - IEEE Honorary Membership with the following definition «For achievements in IEEE engineering fields that have an impact on development of electrometallurgy, materials science, electric welding of metals and biological tissues».

The title of Honorary Member is awarded by IEEE for outstanding contribution into development of engineering sciences, designated by IEEE. The Institute of Electrical and Electronics Engineers has more than 400 thou members from 160 countries of the world. However, there are not more than 50 Honorary Members. The recipients of this title are presented with the Certificate, «Honorary Member» pin and crystal sculpture.

In the previous years, the IEEE Honorary Membership recipients were Telle Whitney (2019), Anton Zeilinger (2018), Rodolfo Stefano Zich (2016), Elon Musk (2015), Shirley Marie Tilghman (2014) and others.

\section{Dear Professor Paton}

It is a great pleasure to inform you that the IEEE Board of Directors selected you to receive the 2020 IEEE Honorary Membership Award, which is given elected by the Board of Directors from among those individuals, not members of IEEE, who have rendered meritorious service to humanity in IEEE's designated fields of interest.

The award comes with the following citation:

"For lifetime achievements within IEEE technical fields of interest in the development of processes of electrometallurgy, materials science, electric welding of metals, and biological tissues."

For nearly a century, the IEEE Awards Program has paid tribute to researchers, inventors, innovators, and practitioners whose exceptional achievements and outstanding contributions have made a lasting impact on technology, society, and the engineering profession. Each year the IEEE Awards Board recommends a small number of outstanding individuals for IEEE's most prestigious honors. You now join this select group.

Details regarding the award presentation will be sent separately via electronic mail by the IEEE Awards Staff.

Congratulations on your achievement, and thank you for your commitment to IEEE and its mission of advancing technology to benefit humanity.

Very truly yours,

Jose' manuel Forsece de moura

Jose' Moura

IEEE President 


\title{
INFLUENCE OF THERMAL CYCLE OF SURFACING ON MECHANICAL PROPERTIES AND RESISTANCE OF HAZ METAL OF RAIL STEEL M76 TO BRITTLE FRACTURE
}

\author{
V.D. POZNYAKOV, O.A. GAIVORONSKYI, V.A. KOSTIN, \\ O.M. BERDNIKOVA and S.V. SHMYGELSKYI \\ E.O. Paton Electric Welding Institute of the NAS of Ukraine \\ 11 Kazymyr Malevych Str., 03150, Kyiv, Ukraine. E-mail: office@paton.kiev.ua
}

\begin{abstract}
Increasing the life of railway wheels is an urgent problem. The solution to this problem is associated with the optimization of the structural state of metal of railway wheels. In the work the influence of cooling rate during melting on mechanical properties, resistance to brittle fracture and structural changes of the HAZ metal of wheel steel with carbonitride strengthening with a carbon content of $0.63 \%$ were investigated. It is shown that in the process of surfacing, a hardening bainite-martensitic structure is formed, the volume fraction of structural components in which is determined by the cooling rate. The hardened HAZ metal of wheel steel with carbonitride strengthening has a high strength and a low ductility with a high susceptibility to brittle fracture. 12 Ref., 2 Tables, 11 Figures.
\end{abstract}

Keyw ords : arc surfacing, carbonitride strengthening, heat-affected-zone, thermal cycle, brittle fracture

Today in Ukraine for manufacture of wheels of freight cars, wheel steel of grade 2 with a carbon content of $0.55-0.65 \%$ is used $[1,2]$. During operation, wheels wear out along the rolling profile. Due to the specifics of operation of the friction-rolling pair «wheel-rail», the working surface of a wheel flange has a more intensive wear, and on the rolling surface of a wheel, defects of a «shelled tread» type are often formed.

The modern trends in the development of mainline rail transport in Ukraine are aimed at increasing the axle load up to $27.5 \mathrm{t}$ and the speed of freight trains up to $150 \mathrm{~km} / \mathrm{h}$, which predetermines the use of wheels of increased strength and wear resistance. The most promising direction for achieving this aim is based on microalloying of the existing wheel steel with carbide- and nitride-forming elements, due to which it is possible to provide a dispersion of the metal structure. This will promote the increase in ductile properties of a wheel metal at a higher level of its strength [3-5]. To reduce the probability of «shelled treads» formation on the rolling surface of a wheel, the carbon content in the steel should be limited.

It is necessary to foresee whether after the wear it will be possible to restore them by surfacing in the conditions of domestic production. Therefore, the development of a scientifically based technology for surfacing wheels manufactured of the new wheel steel, which would be based on the results of investigations of the influence of thermal deformation processes of arc surfacing on structural changes and properties of the new high-strength wheel steel, is an urgent problem.

The idea of the surfacing technology is based on the increased strength, hardness, ductile properties and cyclic crack resistance of the metal, deposited during restoration of a worn rolling profile of new rail wheels by forming a tiny bainite-martensite structure in the deposited metal, which has a good ability to resist wear during friction of a pair «wheel-rail».

Investigation procedures. Investigation of influence of cooling rate during surfacing on mechanical properties of the HAZ metal. The investigations were carried out using the simulation method in the installation MSR-75 [6]. As an object of investigations wheel steel with carbonitride strengthening (abbreviation is KS-TRZ - wheel steel - thermally hardened) with the following composition, wt.\% : $0.63 \mathrm{C} ; 0.35 \mathrm{Si}$; $1.15 \mathrm{Mn} ; 0.16 \mathrm{Cr}$; 0.11 V, 0.019 S, 0.027 P was used. The results of investigations of wheel steel KS-TRZ were compared with the results of similar investigations of wheel steel of grade 2, GOST 10791-2004 (abbreviation is KS2) of the following composition, wt.\% : $0.58 \mathrm{C}$; $0.44 \mathrm{Si} ; 0.77 \mathrm{Mn} ; 0.05 \mathrm{Cr} ; 0.01 \mathrm{~V}$, $0.015 \mathrm{~S}, 0.020 \mathrm{P}$, which are given in [7]. 


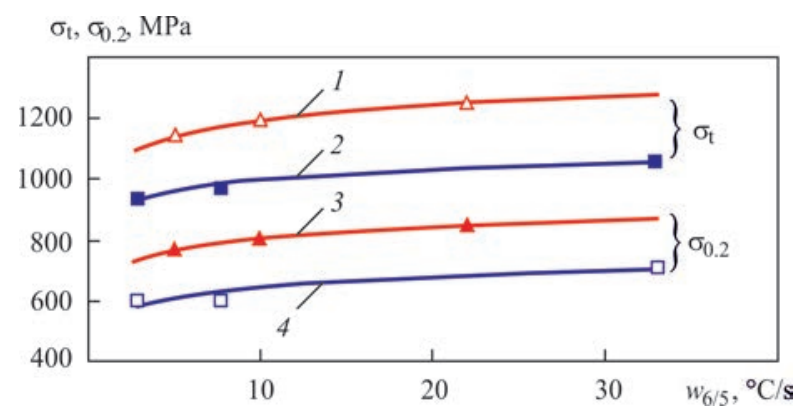

Figure 1. Influence of cooling rate on strength of HAZ metal of wheel steels KS-TRZ $(1,3)$ and $\operatorname{KS} 2(2,4)$

The specimens with the dimensions of $120 \times 12 \times 12 \mathrm{~mm}$ were used, which were heated by electric current according to a set cycle on the base of $60 \mathrm{~mm}$. The maximum heating temperature of the specimens was $1200-1250{ }^{\circ} \mathrm{C}$, the heating rate was 200-210 ${ }^{\circ} \mathrm{C} / \mathrm{s}$. In the central part of the specimens, a $40 \mathrm{~mm}$ wide area of metal was formed, which was homogeneous as to its structure. The cooling rate $w_{6 / 5}$ (in the temperature range of $600-500{ }^{\circ} \mathrm{C}$ ) amounted to 5,10 and $22{ }^{\circ} \mathrm{C} / \mathrm{s}$. Such cooling rates were selected based on the conditions of forming the most characteristic structures for the metal of the HAZ overheating region. After simulation of thermal cycle of arc surfacing, the special specimens were made from the specimens for evaluation of mechanical properties under static tension (specimen of type II, GOST 1497-84) and tests on impact bending (specimen of type 1, GOST 9454-78) were carried out. The investigations were carried out at a temperature of $20^{\circ} \mathrm{C}$ and $-40^{\circ} \mathrm{C}$.

Investigations of influence of cooling rate in surfacing on resistance of the HAZ metal to brittle fracture. Investigations were performed using model specimens of $100 \times 20 \times 10 \mathrm{~mm}$, which were treated according to the thermal deformation cycle of arc surfacing. At the first stage of investigations, the specimens were subjected to heat treatment in the installation MSR-75. The heating rate of the notched specimens was $150^{\circ} \mathrm{C} / \mathrm{s}$. The maximum heating temperature was $1250^{\circ} \mathrm{C}$. The cooling rates of the metal in the temperature range of $600-500{ }^{\circ} \mathrm{C}\left(w_{6 / 5}\right)$ were selected based on the conditions of forming the most

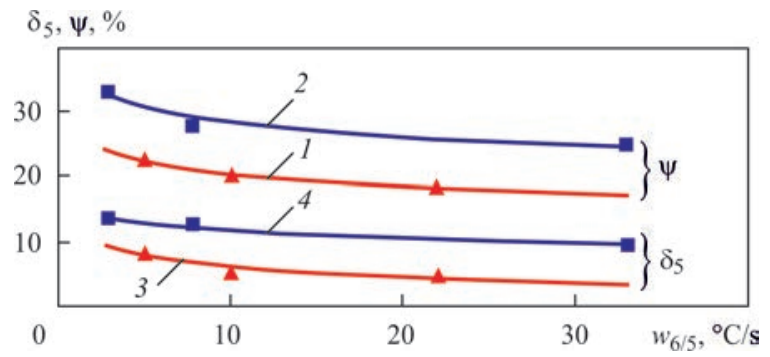

Figure 2. Influence of cooling rate on ductile properties of HAZ metal of wheel steels KS-TRZ $(1,3)$ and $\operatorname{KS} 2(2,4)$ characteristic metal structures of the HAZ overheating region of wheel steel KS-TRZ (according to the results of preliminary dilatometric investigations):

- $w_{6 / 5}=5^{\circ} \mathrm{C} / \mathrm{s}$ - bainitic-martensitic structure $95 \% \mathrm{~B}_{1}, 5 \% \mathrm{M}$;

- $w_{6 / 5}=22^{\circ} \mathrm{C} / \mathrm{s}-$ martensitic structure $-18 \% \mathrm{~B}_{\mathrm{l}}$, $82 \% \mathrm{M}$.

Further, in the heat treated specimens a notch with a depth of $7 \mathrm{~mm}$ was mechanically made, from the top of which a fatigue crack with a depth of $3 \mathrm{~mm}$ was then grown. At the same time, a symmetrical load cycle with a frequency of $35 \mathrm{~Hz}$ and a stress cycle of $120 \mathrm{MPa}$ were used. The load was performed in a low-power fatigue testing machine UMP-1. Then, the specimens with cracks were tested at a three-point bending in the Friedland installation.

The loading of specimens was carried out at a constant force when moving the punch at a speed of $1 \mathrm{~mm} / \mathrm{min}$. The value of the load at which the fracture of specimens occurs, was determined on indications of the dynamometer. The temperature of specimens during the tests was $20^{\circ} \mathrm{C}$. According to the obtained data, the critical factor of stress intensity $K_{1 c}$ was calculated [8, 9].

The fractures of specimens after testing were investigated by the methods of scanning electron emission in the scanning microscope SEM-515 of Philips Company, equipped with an energy-dispersive spectrometer of the «LINK» system.

Investigations of influence of thermal surfacing cycle on structural changes in the HAZ metal. The investigations were performed on the model specimens with a diameter of $6.0 \mathrm{~mm}$ and a length of 80 $\mathrm{mm}$, which were made of wheel steel KS-TRZ, the chemical composition of which is indicated above. In accordance with the test method, the rigidly fixed specimens were heated to a temperature of $1250^{\circ} \mathrm{C}$ at a rate of $210^{\circ} \mathrm{C} / \mathrm{s}$ (heating time is $6 \mathrm{~s}$ ) and then cooled at different rates according to the thermal cycles of surfacing [8]. The time of staying of the metal at the temperatures higher than $A_{c 3}$, depending on the cooling rate, was 7-10 s.

The temperature of beginning and end of the overcooled austenite transformation was determined according to the point of deviation of the tangent from the dilatometric curve, and the ratio of the phases formed as a result of transformations was determined by the method of sections [11, 12]. Subsequently, the structure of the specimens was examinated by optical metallography methods, and according to their results the correlations of structural components and their properties were specified. 


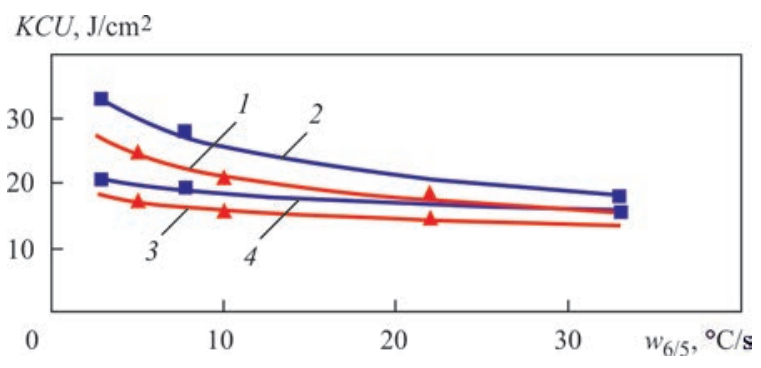

Figure 3. Influence of cooling rate on impact toughness of HAZ metal of wheel steels $\mathrm{KS}$-TRZ $(1,3)$ and $\operatorname{KS} 2(2,4)$ at testing temperature of $20^{\circ} \mathrm{C}(1,2)$ and $-40{ }^{\circ} \mathrm{C}(3,4)$

The metallographic examinations were performed by using Neophot-32 microscope, microhardness of separate structural components and integral hardness of the metal was measured in LECO M-400 hardness tester at the loads of $100 \mathrm{~g}\left(H V_{1}\right)$ and $1 \mathrm{~kg}\left(H V_{10}\right)$ respectively. The specimens for examinations were prepared by the standard method using diamond pastes of different dispersions, the reveal of microstructure was performed by chemical etching in the $4 \%$ alcoholic solution of a nitric acid.

Results of experiments and their analysis. The generalized comparative mechanical properties of the HAZ metal of wheel steels KS-TRZ and KS2 are shown in Figures 1-3.

As is seen from the mentioned data, at high cooling rates, the hardened HAZ metal of wheel steel KS-TRZ has the highest values of strength and a low ductility. As compared to wheel steel KS2, the tensile and yield strength of the HAZ metal of steel KS-TRZ is approximately $21 \%$ higher and the relative elonga-

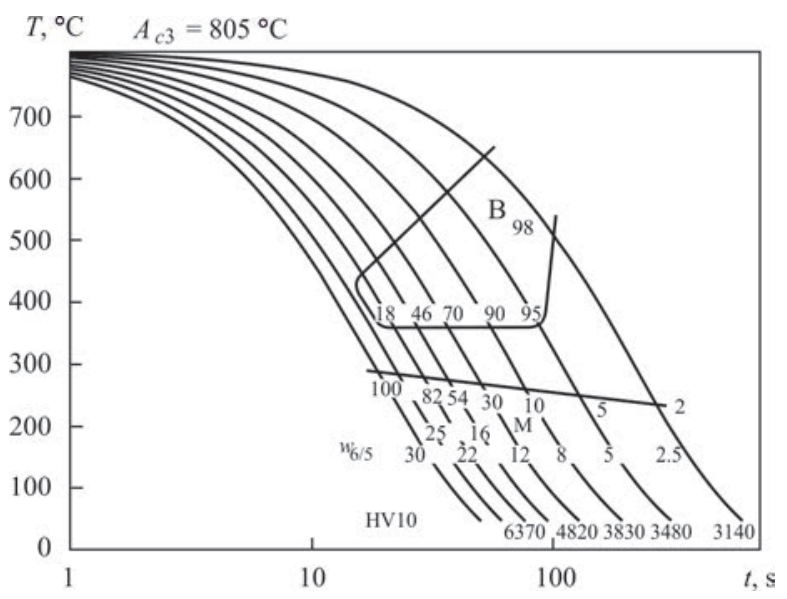

Figure 4. Diagram of transformation of overcooled austenite in HAZ metal of wheel steel KS-TRZ $(0.63 \% \mathrm{C})$ in arc surfacing tion and reduction in area are respectively lower by 50 and $26 \%$.

The strength and ductility of the HAZ metal of both wheel steel of grade KS2 as well as KS-TRZ are significantly affected by the cooling rate after heating. Thus, at $w_{6 / 5}=22{ }^{\circ} \mathrm{C} / \mathrm{s}$, the strength of the hardened metal of KS-TRZ is $1250 \mathrm{MPa}$, the relative elongation is only $4.7 \%$, the reduction in area is $18.3 \%$. When the cooling is slowed down to $w_{6 / 5}=5.0^{\circ} \mathrm{C} / \mathrm{s}$, the values of ductility of the hardened metal can be improved by 1.2-1.8 times. But even under such cooling conditions, the values of impact toughness in the metal do not exceed $8.8 \mathrm{~J} / \mathrm{cm}^{2}$. It is obvious, that such a metal will have a relatively low deformation capacity under the action of external loading, and therefore an increased susceptibility to brittle fracture.
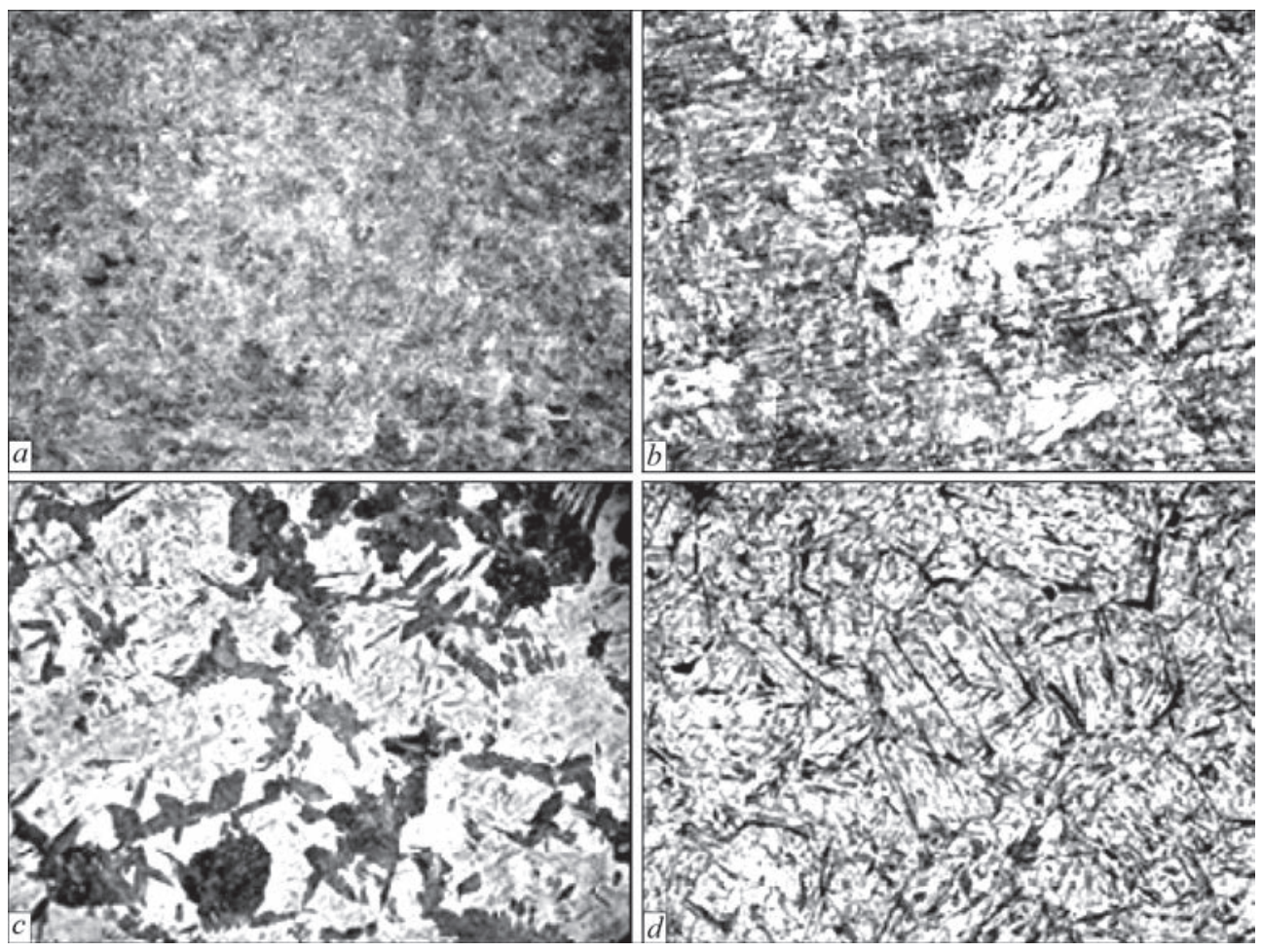

Figure 5. Microstructure $(\times 500)$ of HAZ metal of wheel steel KS-TRZ: $a-$ metal in the initial state; $b-w_{6 / 5}=5 ; c-22 ; d-30{ }^{\circ} \mathrm{C} / \mathrm{s}$ 


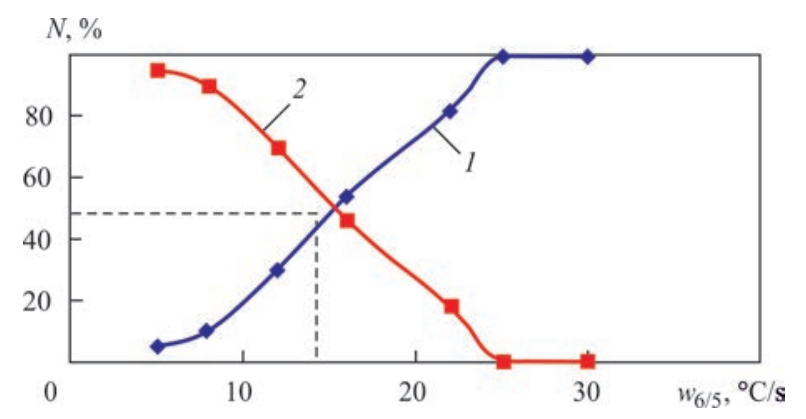

Figure 6. Influence of cooling rate on change of structure components in HAZ metal of wheel steel KS-TRZ: 1 - martensite; 2 - bainite

The mentioned changes in mechanical properties of the HAZ metal of steel KS-TRZ are most likely associated with the influence of continuous heating and cooling according to the thermal cycle of surfacing on the structure formation in the given metal. This is evidenced by the results of metallographic examinations.

In Figure 4, the generalized results of the investigations are shown in the form of a diagram of the overcooled austenite transformation in the metal of the HAZ overheating region, depending on the cooling rate in accordance with the thermal cycles of surfacing, and the metal structure is shown in Figure 5.

The structure of wheel steel KS-TRZ in its initial state is represented by a pearlite-ferrite mixture (Figure 5, a), the grain size is $16-32 \mu \mathrm{m}$, the microhardness of the structural components is $H V_{1}-1990$ $2450 \mathrm{MPa}$. At the grain boundaries the ferrite fringes of 5-10 $\mu \mathrm{m}$ are located. Under the action of thermal cycle of surfacing, the structure of the metal changes significantly.

At a cooling rate of $w_{6 / 5}=5.0-12.0^{\circ} \mathrm{C} / \mathrm{s}$, a bainitic-martensitic structure is formed in the metal of the HAZ overheating region, in which the major part is formed by the bainitic component (Figure 4). It is mainly a lower bainite with the microhardness $H V_{1}$ 3360-3780 MPa (Figure 5, b). As the cooling rate increases in this range, the fraction of martensite grows from 5 to $30 \%$ and the hardness $H V_{10}$ of the hardened metal increases from 3480 to $4820 \mathrm{MPa}$.

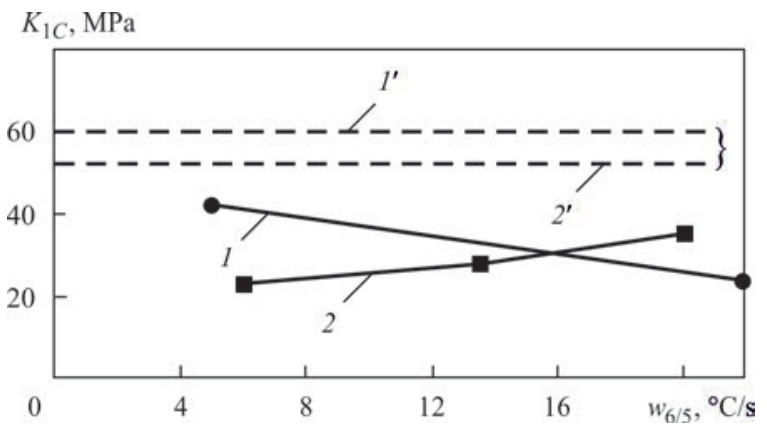

Figure 7. Resistance of HAZ metal of wheel steels KS-TRZ (1) and KS2 (2) to brittle fracture. Dashed lines - steel in the initial state
The upper bainite $\left(H V_{1}-2970-3220 \mathrm{MPa}\right)$ is the main component of the HAZ metal structure at a cooling rate of $2.5^{\circ} \mathrm{C} / \mathrm{s}$. As the cooling rate increases to $5.0^{\circ} \mathrm{C} / \mathrm{s}$, its fraction decreases to $20 \%$ with a corresponding increase in the fraction of lower bainite.

Depending on the cooling rate, the martensitic transformation in the HAZ metal of wheel steel KSTRZ begins at a temperature of $240-280{ }^{\circ} \mathrm{C}$, and its microhardness varies from 4250 to $7830 \mathrm{MPa}$. As the cooling rate of the metal increases in the range $w_{6 / 5}=12.0-22.0^{\circ} \mathrm{C} / \mathrm{s}$, its fraction increases from 30 to $82 \%$ (Figure $5, c$ ). The amount of martensitic component of the structure at $50 \%$ corresponds to the conditions of cooling, when the cooling rate will be approximately $w_{6 / 5} \approx 15.0^{\circ} \mathrm{C} / \mathrm{s}$ (Figure 6 ). In this case the hardness of the hardened HAZ metal will be at the level of $5000 \mathrm{MPa}$.

The generalized results of investigations of the influence of cooling rate $w_{6 / 5}$ on the resistance of the HAZ metal of wheel steel KS-TRZ to brittle fracture are shown in Figure 7. For comparison, this Figure shows also the previously obtained results of investigations of resistance of the HAZ metal of wheel steel KS2 to brittle fracture [7].

Depending on the cooling rate of specimens, the factor $K_{1 c}$ during fracture of the HAZ metal of steel KS2 can vary in the range from 23 to $35 \mathrm{MPa} \vee \mathrm{m}$. The base metal of the mentioned steel has the values of $K_{1 c}$ at the level of $51-52 \mathrm{MPa} \sqrt{\mathrm{m}}$. The lowest value of stress intensity $\left(K_{1 c}=23 \mathrm{MPa} \sqrt{\mathrm{m}}\right)$ is in the HAZ metal, whose cooling rate was $6.0^{\circ} \mathrm{C} / \mathrm{s}$. At that time a structure was formed, consisting of upper bainite by $98 \%$.

At the increase in the cooling rate $w_{6 / 5}$ to $20{ }^{\circ} \mathrm{C} / \mathrm{s}$, the resistance of the HAZ metal of steel KS2 to brittle fracture grows by 1.5 times $\left(K_{1 c}=35 \mathrm{MPa} \sqrt{\mathrm{m}}\right)$. Under the mentioned cooling conditions, a more dispersed structure of lower bainite and martensite is formed in an equal ratio.

The factor $K_{1 c}$ during the fracture of the HAZ metal of wheel steel KS-TRZ, depending on the cooling rate of specimens, i.e. their structural state, varies from 24 to $42 \mathrm{MPa} \sqrt{\mathrm{m}}$. At this time, the metal with a structure of predominantly lower bainite $\left(w_{6 / 5}=5.0{ }^{\circ} \mathrm{C} / \mathrm{s}\right)$ has the highest resistance to brittle fracture, similar to the $\mathrm{HAZ}$ metal of steel $\mathrm{KS} 2$ at $20{ }^{\circ} \mathrm{C} / \mathrm{s}$. When forming a predominantly martensitic structure (at $22{ }^{\circ} \mathrm{C} / \mathrm{s}$ ), the value $K_{1 c}$ for the HAZ metal of wheel steel KS-TRZ is the lowest.

According to the results of studying fracture of specimens, the general and specific conditions of their fracture were established. The common feature for 
them is that in the fracture three characteristic areas are distinguished (Figure 8):

- area I - initiation and propagation of fatigue crack;

- area II - propagation of the main crack under the static bending load;

- area III - final fracture.

The comparative analysis of fracture surfaces of the specimens showed that irrespective of the type of wheel steel and the structural state of the HAZ metal, the initiation and propagation of fatigue cracks has a brittle nature. In the zone of initiation of a fatigue cracks a brittle intergranular fracture was formed (Figure $9, a, b$ ), and in the zone of propagation - a brittle transgranular fracture (Figure 9, $c, d$ ). The differences in the propagation of fatigue cracks depending on the type of wheel steel and a structural state of the HAZ metal are as follows. In the HAZ metal of steel KS2 with the structure of upper bainite $\left(w_{6 / 5}=6.0^{\circ} \mathrm{C} / \mathrm{s}\right)$, the size of brittle fracture facets is $30-100 \mu \mathrm{m}$, and in the fracture of the HAZ metal of steel KS-TRZ during forming the structure of predominantly lower bainite $\left.w_{6 / 5}=5.0{ }^{\circ} \mathrm{C} / \mathrm{s}\right)$ it is $30-70 \mu \mathrm{m}$. In the area I of the

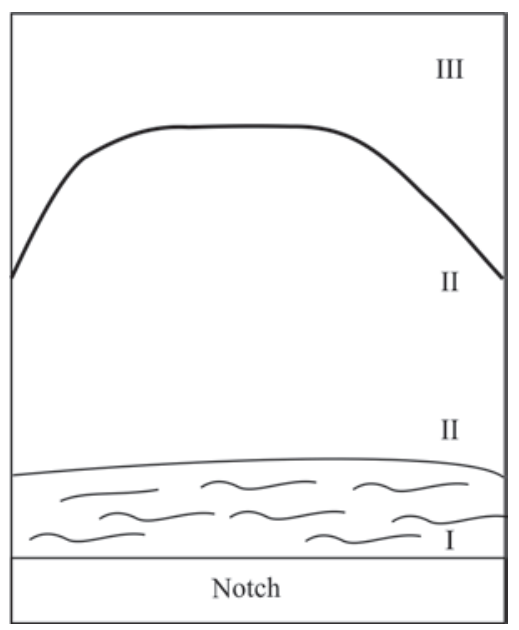

Figure 8. Conditional scheme of distribution of characteristic areas on the fracture surface of specimens during tests (description I-III see in the text)

fractures, the secondary cracks were revealed, which were located along the boundaries of the grains, they are clearly seen in Figure 9, $a, b$. Their sizes also depend on the type of steel. It was established that in the metal of the HAZ overheating region of wheel steel KS2 at the mentioned cooling rates, the length of the

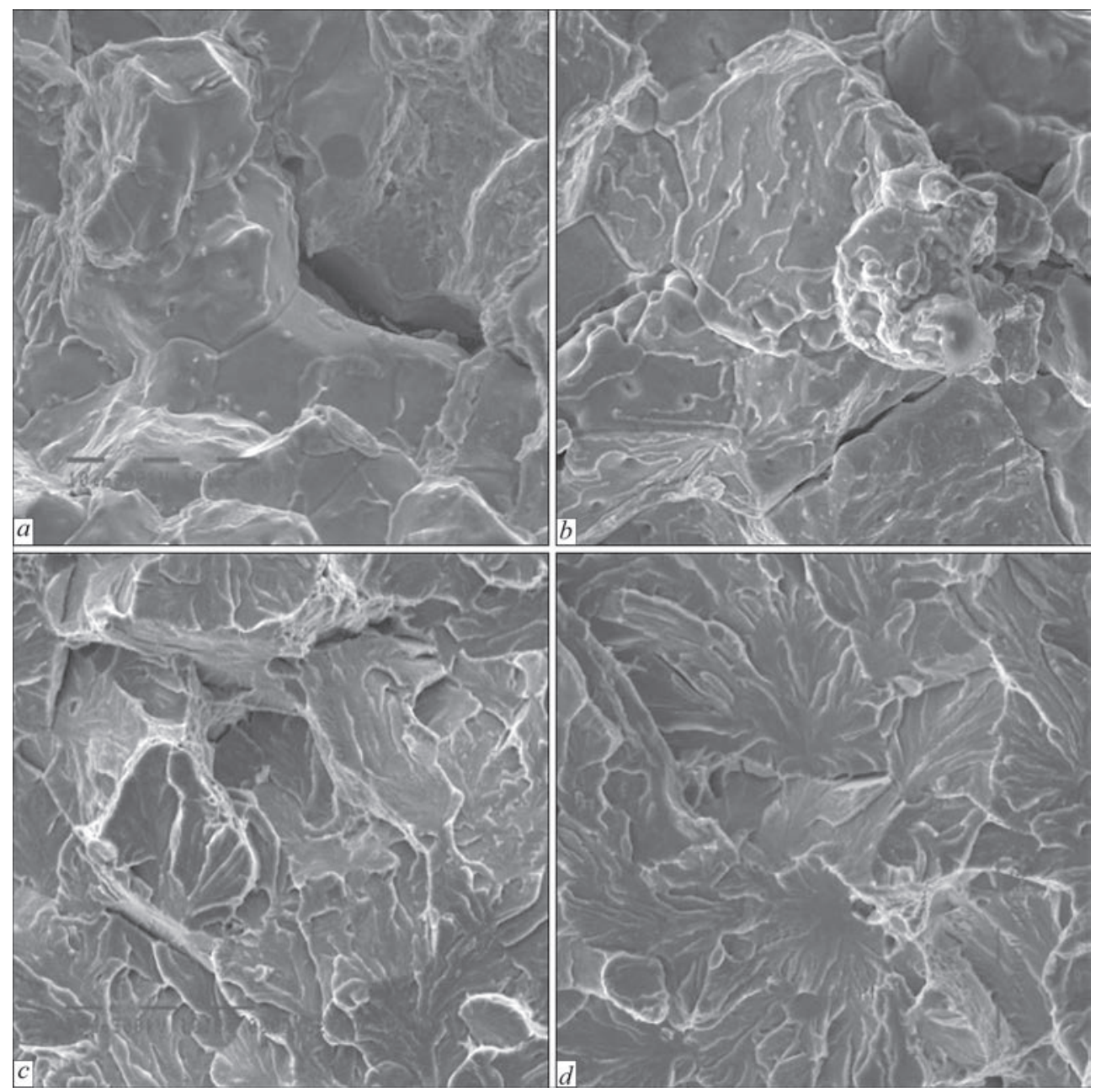

Figure 9. Typical surface of fracture of HAZ metal of wheel steels $\mathrm{KS} 2\left(w_{6 / 5}=6.0^{\circ} \mathrm{C} / \mathrm{s}\right)$ and $\mathrm{KS}-\mathrm{TRZ}\left(5.0^{\circ} \mathrm{C} / \mathrm{s}\right)$ in the area of initiation $(a, b)$ and propagation $(c, d)$ of fatigue crack (x1010): $a, c-\mathrm{KS} 2$ [7]; $b, d-\mathrm{KS}-\mathrm{TRZ}$ 

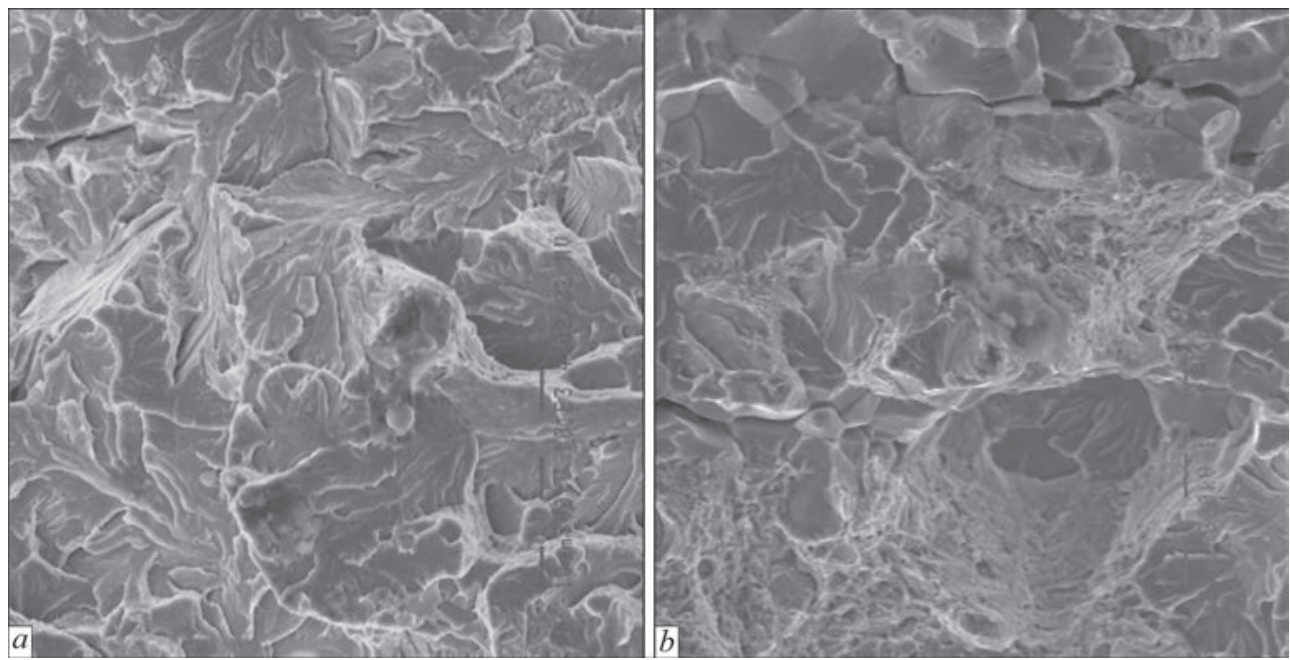

Figure 10. Typical fracture of HAZ metal of wheel steel KS-TRZ in the area of main crack propagation $(\times 1010): a-w_{6 / 5}=5.0 ; b-$ $22^{\circ} \mathrm{C} / \mathrm{s}$

Table 1. Character of fracture of HAZ metal of wheel steel KS2 [7] and steel KS-TRZ in the area of main crack propagation

\begin{tabular}{|c|c|c|c|c|c|c|c|}
\hline \multicolumn{4}{|c|}{ Steel KS2 $(\mathrm{C}=0.58 \%)$} & \multicolumn{4}{|c|}{ Steel KS-TRZ $(\mathrm{C}=0.63 \%)$} \\
\hline \multicolumn{2}{|c|}{$w_{6 / 5}=6.0^{\circ} \mathrm{C} / \mathrm{s}$} & \multicolumn{2}{|c|}{$13.5^{\circ} \mathrm{C} / \mathrm{s}$} & \multicolumn{2}{|c|}{$5.0^{\circ} \mathrm{C} / \mathrm{s}$} & \multicolumn{2}{|c|}{$22^{\circ} \mathrm{C} / \mathrm{s}$} \\
\hline \multicolumn{2}{|c|}{$98 \% \mathrm{~B}_{\mathrm{u}}$} & \multicolumn{2}{|c|}{$25 \% \mathrm{~B}_{\mathrm{u}}, 50 \% \mathrm{~B}_{1}, 23 \% \mathrm{M}$} & \multicolumn{2}{|c|}{$95 \% \mathrm{~B}_{1}, 5 \% \mathrm{M}$} & \multicolumn{2}{|c|}{$18 \% \mathrm{~B}_{1}, 82 \% \mathrm{M}$} \\
\hline$\frac{\mathrm{BTF}, \%}{L_{\mathrm{sec}}, \mu \mathrm{m}}=\frac{100}{40}$ & $\frac{\mathrm{BIF}, \%}{L_{\mathrm{sec}}, \mu \mathrm{m}}-\mathrm{N} / \mathrm{D}$ & $\frac{\mathrm{BTF}, \%}{L_{\mathrm{sec}}, \mu \mathrm{m}}=\frac{100}{5}$ & $\frac{\mathrm{BIF}, \%}{L_{\mathrm{sec}}, \mu \mathrm{m}}-\mathrm{N} / \mathrm{D}$ & $\frac{\mathrm{BTF}, \%}{L_{\mathrm{sec}}, \mu \mathrm{m}}=\frac{100}{30}$ & $\frac{\mathrm{BIF}, \%}{L_{\mathrm{sec}}, \mu \mathrm{m}}-\mathrm{N} / \mathrm{D}$ & $\frac{\mathrm{BTF}, \%}{L_{\mathrm{sec}}, \mu \mathrm{m}}=\frac{85}{60}$ & $\frac{\mathrm{BIF}, \%}{L_{\mathrm{sec}}, \mu \mathrm{m}}=\frac{15}{60}$ \\
\hline
\end{tabular}

secondary crack is $L_{\text {sec }}=50-100 \mu \mathrm{m}$, and that of steel KS-TRZ does not exceed $60 \mu \mathrm{m}$.

Unlike the fractures of the HAZ metal of steel KSTRZ, which was heat treated at a cooling rate $w_{6 / 5}=$ $=5.0^{\circ} \mathrm{C} / \mathrm{s}$, the secondary cracks in the zone of initiation and propagation of fatigue cracks of specimens, which predominantly had a martensitic structure $\left(22{ }^{\circ} \mathrm{C} / \mathrm{s}\right.$ ) were $L_{\text {sec }} \leq 200 \mu \mathrm{m}$ in length.

At the fracture area II, at a cooling rate $w_{6 / 5}$ at the level of $6.0^{\circ} \mathrm{C} / \mathrm{s}$ and $13.5^{\circ} \mathrm{C} / \mathrm{s}$, the crack size is, respectively, not more than 40 and $5 \mu \mathrm{m}$ [7]. In the HAZ metal of wheel steel KS-TRZ under the action of stat- ic loading, the crack propagates with a brittle nature on the grains body (brittle transgranular fracture BTF) at $w_{6 / 5}=5.0^{\circ} \mathrm{C} / \mathrm{s}$, and also on the grain boundaries (brittle intergranular fracture - BIF) at $22^{\circ} \mathrm{C} / \mathrm{s}$. The secondary cracks with the length $L_{\mathrm{sec}} \leq 30-60 \mu \mathrm{m}$ were also found in the fracture structure (Figure 10).

In the area of final fracture (area III), irrespective of the type of wheel steel and structural HAZ metal, the fracture of specimens has a tough nature (Figure 10). On the fractures surface, the phase formations of up to $1-3 \mu \mathrm{m}$ in size with a higher content of $\mathrm{Mn}$, $\mathrm{Ti}, \mathrm{Si}, \mathrm{Al}$ and $\mathrm{Ca}$ are revealed.

Table 2. Parameters of thermal cycle in HAZ metal during arc surfacing of wheel steel (thickness is $20 \mathrm{~mm}, T_{\max }=1250-1350{ }^{\circ} \mathrm{C}$ ) [10]

\begin{tabular}{|c|c|c|c|c|}
\hline \multirow{2}{*}{$\begin{array}{l}\text { Input energy of surfacing } \\
\qquad Q_{w}, \mathrm{~kJ} / \mathrm{cm}\end{array}$} & \multirow{2}{*}{$\begin{array}{l}\text { Temperature of preheating } \\
\qquad T_{\mathrm{ph}},{ }^{\circ} \mathrm{C}\end{array}$} & \multicolumn{3}{|c|}{ Parameters of thermal cycle } \\
\hline & & Cooling rate $w_{6 / 5},{ }^{\circ} \mathrm{C} / \mathrm{s}$ & $\begin{array}{l}\text { Cooling time from } 800 \\
\text { to } 500{ }^{\circ} \mathrm{C} \tau_{8 / 5}, \mathrm{~s}\end{array}$ & $\begin{array}{l}\text { Cooling time from } 800 \\
\text { to } 100{ }^{\circ} \mathrm{C} \tau_{8 / 1}, \mathrm{~s}\end{array}$ \\
\hline \multirow{7}{*}{8.6} & 20 & $25-30$ & 8 & 170 \\
\hline & 50 & $20-25$ & 10 & 230 \\
\hline & 70 & $15-20$ & 11 & 250 \\
\hline & 100 & $12-15$ & 12 & 450 \\
\hline & 150 & $8-10$ & 14 & 760 \\
\hline & 200 & $5-7$ & 18 & 890 \\
\hline & 250 & $3-4$ & 25 & 1050 \\
\hline \multirow{3}{*}{11.5} & 20 & $15-17$ & 14 & 245 \\
\hline & 50 & $12-14$ & 16 & 360 \\
\hline & 100 & $6-8$ & 20 & 850 \\
\hline 15.0 & 20 & $10-12$ & 17 & 290 \\
\hline
\end{tabular}


The generalized results of investigations of the HAZ metal fractures of steels KS2 and KS-TRZ are given in Table 1.

The carried out investigations showed that the HAZ metal of the studied wheel steel KS-TRZ due to the formation of hardening structures, has an increased susceptibility to brittle fracture. As compared to the initial state, the resistance of the HAZ metal to brittle fracture decreases by 1.4-2.5 times. At the same time, the change in the stress intensity factor $K_{1 c}$ during propagation of the main crack is significantly influenced by the structure-phase composition of the hardened metal. When forming predominantly the structure of the lower bainite in the HAZ metal, the $K_{1 c}$ value is the highest. Such conditions of structure formation in the HAZ can be provided in arc surfacing when the cooling rate is $w_{6 / 5} \leq 5.0^{\circ} \mathrm{C} / \mathrm{s}$.

The generalized parameters of the thermal cycle are given in Table 2.

Thus, during the investigations it was found that in the process of arc surfacing in the HAZ metal of the studied wheel steel KS-TRZ, the carbon content of which is $0.63 \%$, a hardening bainitic-martensitic structure is formed, the volume fraction of structural components in which is determined by the rate of cooling. As the rate of cooling of the metal increases from 5.0 to $22^{\circ} \mathrm{C} / \mathrm{s}$, the fraction of martensite increases from 5 to $82 \%$, and the fraction of lower bainite decreases from 95 to $18 \%$. At the same time, the hardness of the hardened metal is increased by 1.8 times. The cooling rate $w_{6 / 5}$, when in the structure of HAZ metal $50 \%$ of martensite is formed, is $15{ }^{\circ} \mathrm{C} / \mathrm{s}$. The formation of predominantly upper bainite in the structure during cooling, which is undesirable in terms of providing a relatively high level of resistance of the HAZ metal of wheel steel KS-TRZ to brittle fracture, is possible only at a cooling rate $w_{6 / 5}=2.5^{\circ} \mathrm{C} / \mathrm{s}$.

\section{Conclusions}

During investigations, it was established that:

1. In the process of arc surfacing in the HAZ metal of the studied wheel steel with carbonitride strengthening, the carbon content in which is $0.63 \%$, a hardening bainitic-martensitic structure is formed, the volume fraction of structural components in which is determined by the cooling rate. As the cooling rate of the metal increases from 5.0 to $22{ }^{\circ} \mathrm{C} / \mathrm{s}$, the fraction of martensite increases from 5 to $82 \%$ and the fraction of lower bainite decreases from 95 to $18 \%$. In this case, the hardness of hardened metal is increased by 1.8 times. The cooling rate $w_{6 / 5}$ during formation of $50 \%$ of martensite in the HAZ metal structure is $15^{\circ} \mathrm{C} / \mathrm{s}$.

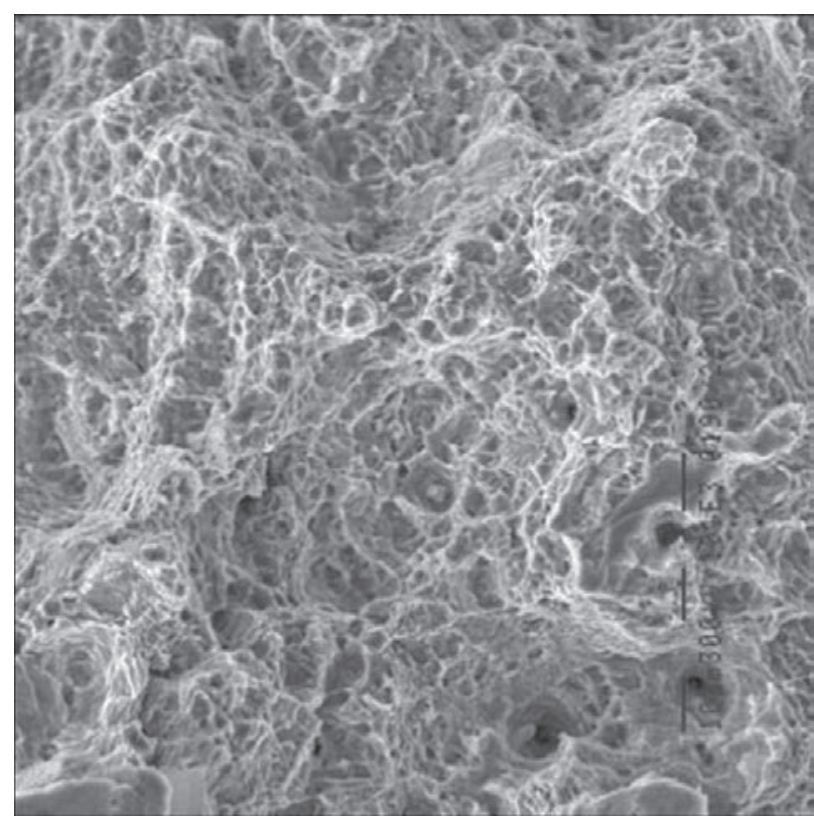

Figure 11. Fracture surface of specimens in the area of final fracture $(\times 1010)$

2. A hardened HAZ metal of wheel steel with carbonitride strengthening has a high strength and a low ductility. As compared to wheel steel of grade 2, the tensile and yield strength of the HAZ metal with carbonitride strengthening are approximately $21 \%$ higher and the relative elongation and reduction in area are lower by 50 and $26 \%$, respectively.

3. To increase the ductility values of a hardened HAZ metal of wheel steel with carbonitride strengthening by 1.2-1.8 times is possible due to slowing down the cooling to $w_{6 / 5}=5.0^{\circ} \mathrm{C} / \mathrm{s}$, when the structure of the lower bainite is predominantly formed in the metal.

4. HAZ metal of the studied wheel steel with carbonitride strengthening due to the formation of hardening structures has an increased susceptibility to brittle fracture. As compared to the initial state, the resistance of the HAZ metal to brittle fracture is by 1.4-2.5 times reduced. At the same time, the structural-phase composition of the hardened metal is significantly influenced by the change of the stress intensity factor during propagation of the main crack. When a predominant structure of the lower bainite is formed in the HAZ metal, the value $K_{1 c}$ is the highest. Such conditions of structure formation in the HAZ can be provided by arc surfacing, when the cooling rate will be $w_{6 / 5}<5.0^{\circ} \mathrm{C} / \mathrm{s}$.

1. Uzlov, I.G. (2003) Advanced processes of manufacturing and quality of railway wheels. Stal, 5, 69-72 [in Russian].

2. Railway wheels and tyres KLW (Interpipe NTZ Ukraine). www.interpipe.biz [in Russian].

3. Uzlov, I.G., Babachenko, A.I., Dementieva, Zh.A. (2005) Influence of steel microalloying on fracture toughness of rail- 
way wheels. Metallurgiya i Gornorudnaya Promyshlennost, 5, 46-47 [in Russian].

4. Babachenko, A.I., Litvinenko, P.L., Knysh, A.V. et al. (2011) Improvement of chemical composition of steel for railway wheels ensuring the increase of their resistance to defect formation on roll surface. In: Fundament. i Prikl. Problemy Chyorn. Metallurgii, Transact. of IFM, NANU, 23, 226-233 [in Russian].

5. Ivanov, B.S., Filipov, G.A., Demin, K.Yu. et al. (2007) Modification of wheel steel by nitrogen. Stal, 9, 22-25 [in Russian].

6. Sarzhevsky, V.A., Sazonov, V.Ya. (1981) Installation for simulation of welding thermal cycles on the base of MSR-75 machine. Avtomatich. Svarka, 5, 69-70 [in Russian].

7. Gajvoronsky, A.A., Poznyakov, V.D., Markashova, L.I. et al. (2016) Brittle fracture resistance of HAZ metal in arc-welded joints of high-strength steels with carbon content of 0.55$0.65 \%$. The Paton Welding J., 9, 2-8.
8. (1972) New methods for evaluation of brittle fracture resistance of metals. Ed. by Yu.N. Robotnov. Moscow, Mir [in Russian].

9. (1985) GOST 25.506-85: Methods of mechanical testing of metals. Determination of fracture toughness characteristics under the static loading. Moscow, Izd-vo standartov [in Russian].

10. Gajvoronsky, A.A. (2014) Resistance to cold crack formation of HAZ metal of welded joint of high-strength carbon steels. The Paton Welding J., 2, 2-11.

11. Cherepin, V.T. (1968) Experimental technique in physical metal science. Kiev, Tekhnika [in Russian].

12. Vasiliev, V.G., Sarzhevsky, V.A., Kornienko, T.A., Gajvoronsky, A.A. (1997) Attachment to dilatometer for examination of phase transformations at low temperatures. Avtomatich. Svarka, 5, 55-57 [in Russian].

WORLD TRADE FAIR FOR WELDINGEENGINEERING JOINING, CUTTING, SURFACING

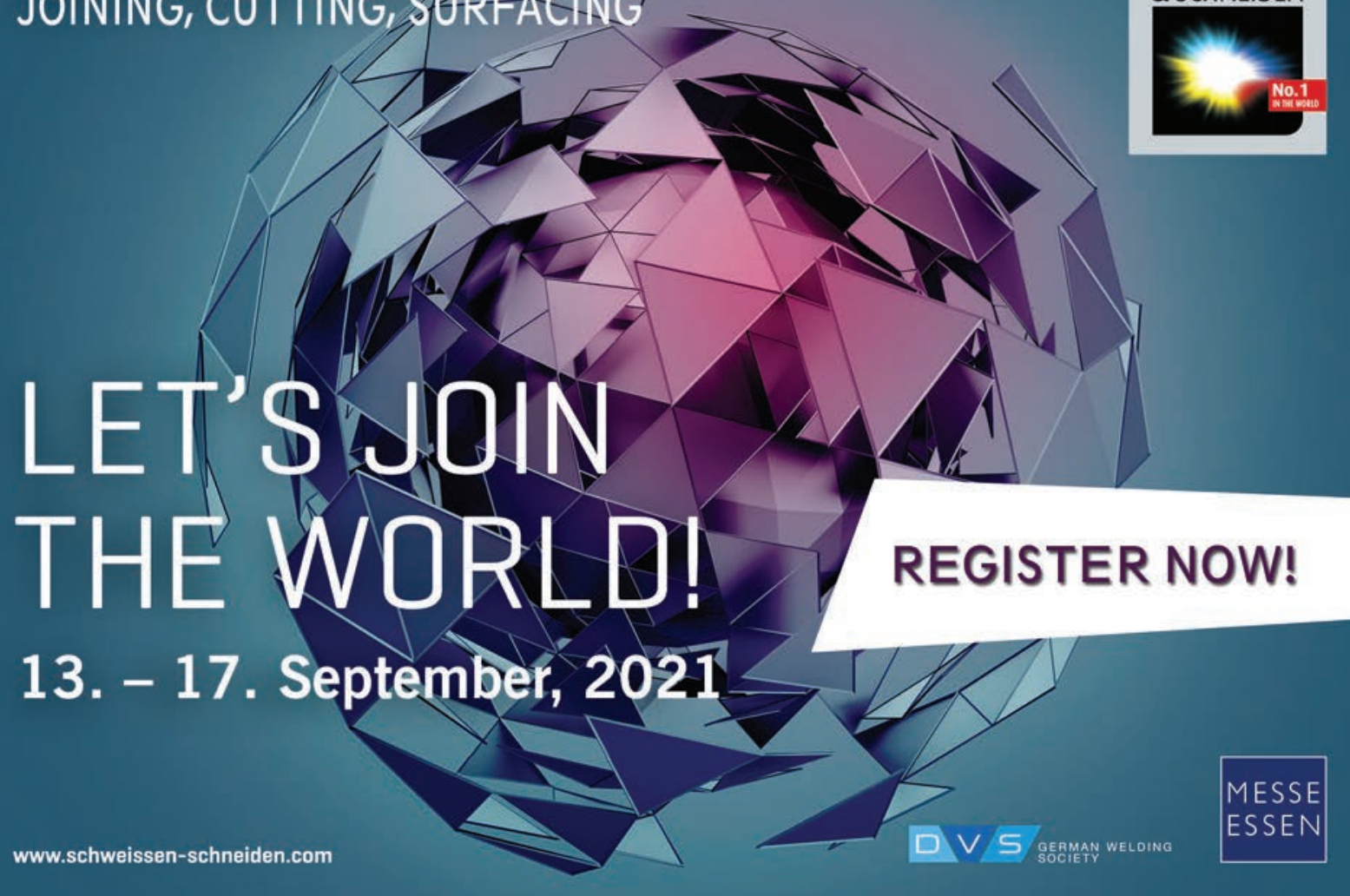




\title{
PROCESSES OF NONCONSUMABLE ELECTRODE WELDING WITH WELDING CURRENT MODULATION (Review). Part II. Effects of arc impact on the metal being welded
}

\author{
BOYI WU ${ }^{1}$ and I.V. KRIVTSUN ${ }^{2}$ \\ ${ }^{1}$ Guangdong Institute of Welding (China-Ukraine E.O.Paton Institute of Welding) \\ 363 Chiansin Str., 510650, Guangzhou, Tianhe. E-mail: wuby@gwi.gd.cn \\ ${ }^{2}$ E.O. Paton Electric Welding Institute of the NAS of Ukraine \\ 11 Kazymyr Malevych Str., 03150, Kyiv, Ukraine. E-mail: office@paton.kiev.ua
}

\begin{abstract}
A review of studies, devoted to the processes of nonconsumable electrode inert-gas welding with welding current modulation was performed. The second part of the review is devoted to analysis of the works, dealing with the features of metal penetration (aluminium alloys, stainless steels, high-temperature nickel-chromium alloys) and weld formation in TIG welding with modulated current. 12 Ref., 16 Tables, 19 Figures.
\end{abstract}

Keywords : arc with refractory cathode, TIG welding, metal being welded, penetration, weld, welding current modulation, pulse, frequency, fill factor, amplitude

Features of burning of a nonstationary arc in nonconsumable electrode welding with current modulation, described in the first part of this review [1], cause considerable changes of the characteristics of thermal and dynamic impact of the arc on the metal being welded, and, therefore, of the processes of its penetration and formation of welds compared to the respective processes at DC TIG welding.

Work [2] is one of the first studies, devoted to comparative analysis of the quality and mechanical properties of welds, made at single-pass TIG welding of samples from aluminium alloy 2219 of thickness of $0.125 ; 0.250 ; 0.350 \mathrm{in}$. (3.2; 6.4 and $8.9 \mathrm{~mm}$ ) at SPDC and with pulse modulation of current. Two power sources were used during the experiments: for high-frequency (HFP) and low-frequency (LFP) pulse modulation of welding current. The first of them ensured HFP modulation of current by rectangular pulses up to values of $500 \mathrm{~A}$, with pulse repetition rate $f=2-25 \mathrm{kHz}$ and adjustable fill factor $\delta$ in the range from 20 up to $80 \%$, that allowed variation of average current value from 100 up to $400 \mathrm{~A}$. The second source ensured additional LFP modulation of high-frequency arc current by rectangular pulses with the frequency of $1-10 \mathrm{~Hz}$ and fill factor from 10 up to $100 \%$. The base current was equal to $3 \mathrm{~A}$ in all the cases. It should be noted that in addition to feeding single-polarity current pulses, such a system also allows realization of welding current modulation (including combined one) by pulses of straight and reverse polarity.

I.V. KRIVTSUN — http://orcid.org/0000-0001-9818-3383

(C) BOYI WU and I.V. KRIVTSUN, 2019
Overlay and butt welds (in the downhand position, unsupported) were made on all the samples in two modes of current modulation: high-frequency and combined (high-frequency + low-frequency modulation), as well as at DC TIG welding. Produced welds were subjected to radiographic inspection. X-ray images were analyzed at tenfold magnification and the number of defects (pores and oxide inclusions) of more than 0.005 in. $(0.13 \mathrm{~mm})$ size was determined along the entire weld length. Figures 1, 2 show the dependencies of the length of discontinuities (defects) on the length of welds on samples from aluminium alloy 22198.9 and $3.2 \mathrm{~mm}$ thick, respectively, at different modulation modes. Experimental data given in these figures are indicative of the fact that application of HFP modulation of current essentially (up to $80 \%)$ lowers the number of pores and nonmetallic inclusions per a unit of weld length, whereas appli-

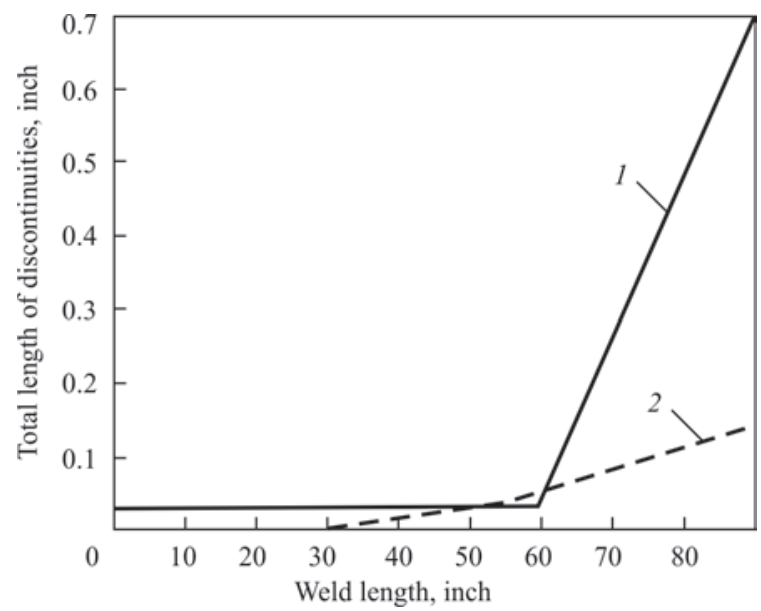

Figure 1. Total length of discontinuities (inches), depending on weld length (inches) in TIG welding of samples $8.9 \mathrm{~mm}$ thick at direct current (1) and with HFP modulation of current (2) [2] 


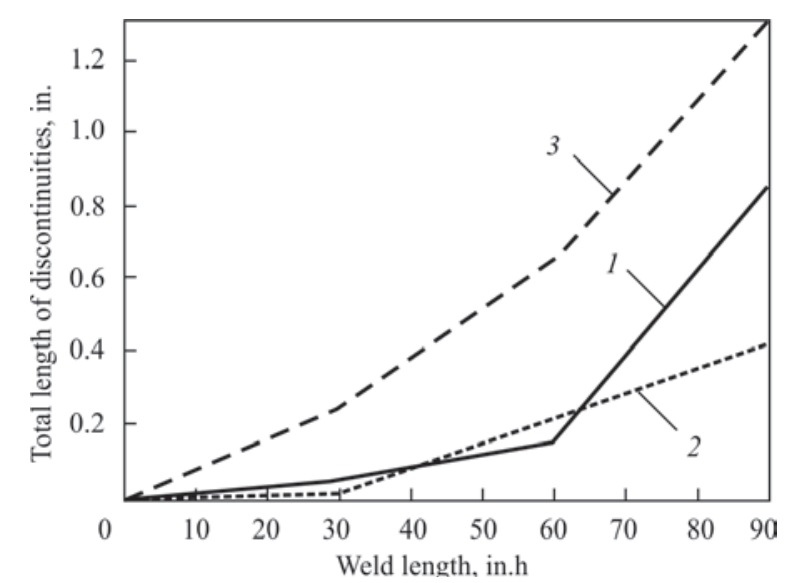

Figure 2. Total length of discontinuities, depending on weld length at TIG welding of samples $3.2 \mathrm{~mm}$ thick at direct current (1), with HFP modulation of current (2) and with combined modulation (3) [2]

cation of the combined mode markedly impairs this characteristic.

The author of [2] showed that high-frequency pulse modulation of welding current can also be effectively used for destruction of nonuniform cast structure of metal found in welds made by nonconsumable electrode DC welding. As a result, the microstructure of weld metal in welding aluminium alloy 2219 with HFP modulation of current is homogeneous both in the longitudinal and transverse section of the weld. Therefore, such welds are characterized by $10-15 \%$ higher fracture values than in DC TIG welding.

Low-frequency modulation of arc current in combination with high-frequency modulation does not lead to formation of a homogeneous microstructure in welds on aluminium alloy 2219. It can be used only to control the weld geometry in single-pass TIG welding of samples of $0.125 \mathrm{in}$. (3.2 mm) thickness with free formation. This allows performing quality welding of thinner materials that ensures reduction of welded structure weight.

Work [3] presents experimental studies of the impact of five parameters of the mode of TIG welding of stainless steel samples with low-frequency $(1-5 \mathrm{~Hz})$ modulation of current by rectangular pulses, namely: amplitude (depth) and frequency of current modulation, fill factor and maximum current value, as well as welding speed on penetration depth, weld form

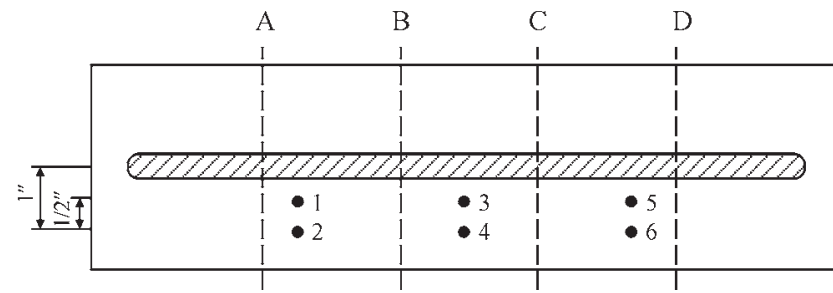

Figure 3. Arrangement of thermocouples on sample surface, points $1,3,5$ at the distance of $1 / 2$ in. (12.7 mm); 2, 4, 6- 1 in. (25.4 mm) from weld center line [3]
Table 1. Parameters of the studied welding modes [3]

\begin{tabular}{|c|c|c|c|}
\hline Parameter & \multicolumn{3}{|c|}{ Values } \\
\hline Depth of current modulation $I_{L} / I_{H}, \%$ & 80 & 50 & 20 \\
\hline Modulation frequency $f, \mathrm{~Hz}$ & 5 & 3 & 1 \\
\hline Fill factor $\delta, \%$ & 75 & 50 & 25 \\
\hline Maximum current value $I_{H}, \mathrm{~A}$ & 175 & 125 & 75 \\
\hline Welding speed $S$, in./min & 9 & 6 & 3 \\
\hline
\end{tabular}

factor and thermocycles in the metal being welded. In order to analyze such an impact, 46 combinations were selected on three levels of the above parameter values, given in Table 1, by the method of mathematical planning of the experiment, for which full-scale experiments were performed.

All the experiments were performed with application of water-cooled welding torch with a refractory cathode from thoriated tungsten of 3/32 in. $(2.38 \mathrm{~mm})$ diameter, arc length was set equal to $0.05 \mathrm{in}$. $(1.27 \mathrm{~mm})$ and a mixture of $75 \% \mathrm{He}+25 \%$ Ar was used as shielding gas. Overlay welds were made on samples of stainless steel 304 of $1 / 4$ in. ( $6.35 \mathrm{~mm}$ ) thickness, the length of all the welds was the same and equal to 10 in. $(25.4 \mathrm{~cm})$. Temperature was measured by chromel-alumel thermocouples in six points on the sample surface, shown in Figure 3.

Characteristic time dependencies of temperature in the respective points are shown in Figure 4. Maximum temperature values in points $1,3,5$, as well as in points 2, 4, 6 turn out to be practically the same.

Measured values of maximum temperature in the selected points were correlated with the rate of energy input $X(\mathrm{~J} / \mathrm{in}$.) of the welding process. In the case of pulse modulation of current it was calculated as follows $X=0.6 U\left[I_{H} \delta+I_{L}(100-\delta)\right] / S$, where $U$ is the arc voltage, which was selected constant (independent on pause current and maximum current values) and equal to $11.75 \mathrm{~V}$, and designations of the other parameters and their dimensions correspond to those used in Table 1. The given in Figure 5 dependencies

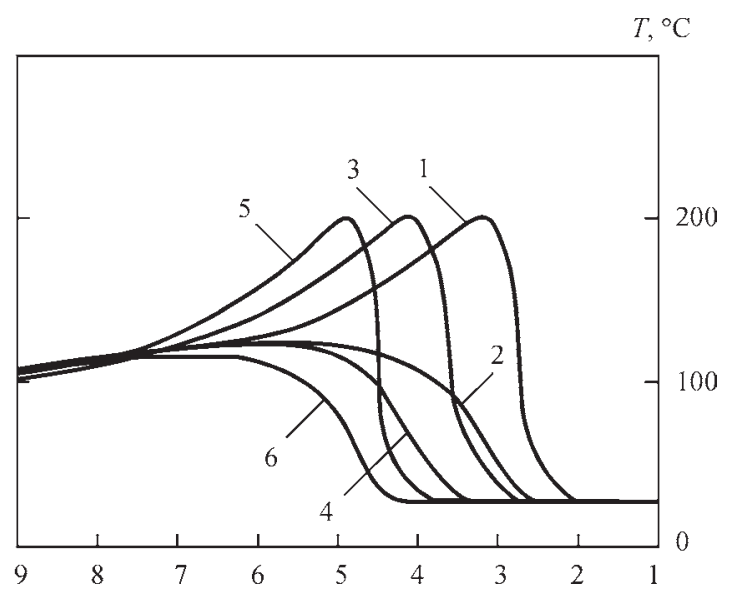

Figure 4. Thermal cycles in different points of sample surface [3] 


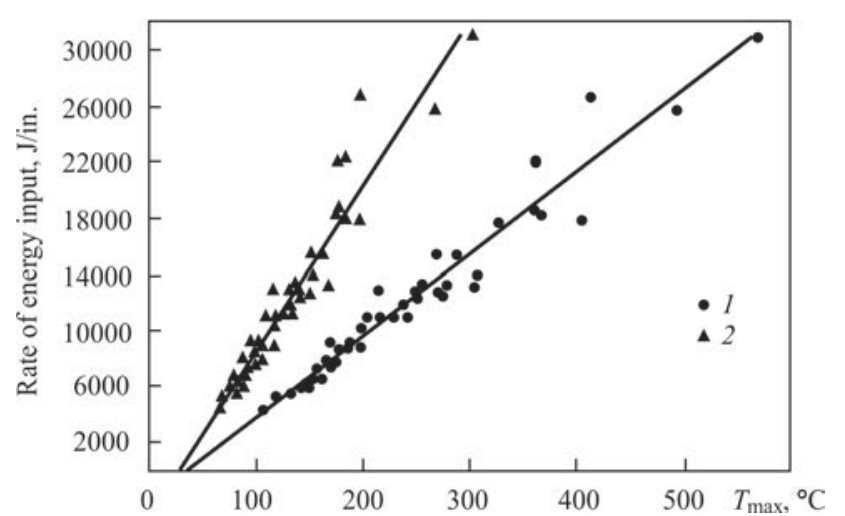

Figure 5. Dependence of maximum temperature values on the rate of energy input in points located at distance $1 / 2 \mathrm{in.}$ from the weld center line (1) and in points located at 1 in. distance (2) [3]

of maximum temperature values in points $1,3,5$ and $2,4,6$, respectively, on the rate of energy input of the process are indicative of linear nature of the above dependencies in the entire studied range of welding mode parameters.

Obtained experimental data were the base for plotting the regression equations for calculation of penetration depth $h$ and its ratio to weld width $h / b$, as functions of the considered parameters of the welding mode. Regression equation proposed by the authors for determination of the penetration depth, shows that the main role here is played by welding speed $S$, followed by modulation amplitude $I_{L} / I_{H}$ and maximum current value $I_{H}$, then fill factor $\delta$, and finally, frequency $f$. Lines of constant penetration depth $h$ in $S-I_{H}$ variables plotted using this equation, are shown in Figure 6. The same Figure shows the lines of constant values of the rate of energy input $X$, calculated as indicated above. As regards the regression equation for calculation of the ratio of penetration depth to weld width, the main role here is played by maximum current value $I_{H}$, followed by welding speed $S$, then modulation amplitude $I_{L} / I_{H}$, frequency $f$ and fill factor $\delta$.

Calculated data given in Figure 6, allow, for instance, determination of optimum combinations of $I_{H}$ and $S$, corresponding to minimum rate of energy input, required for achieving any specified penetration depth. In particular, the best combination of the above parameters of the welding mode to achieve the penetration depth $h=0.09$ in. $(2.29 \mathrm{~mm})$ is $I_{H}=115 \mathrm{~A}, S=$ $=6 \mathrm{in} . / \mathrm{min}$, minimum required value $X$ being equal to about $10 \mathrm{~kJ} / \mathrm{in}$.

This approach was used to analyze 27 combinations of welding mode parameters. Obtained data for DC TIG welding, as well as at three combinations of values of fill factor $\delta$ and modulation amplitude $I_{L} / I_{H}$ are shown in Figure 7.

Finishing consideration of work [3], we should note an important conclusion, reached by the authors, namely at any combinations of mode parameters of

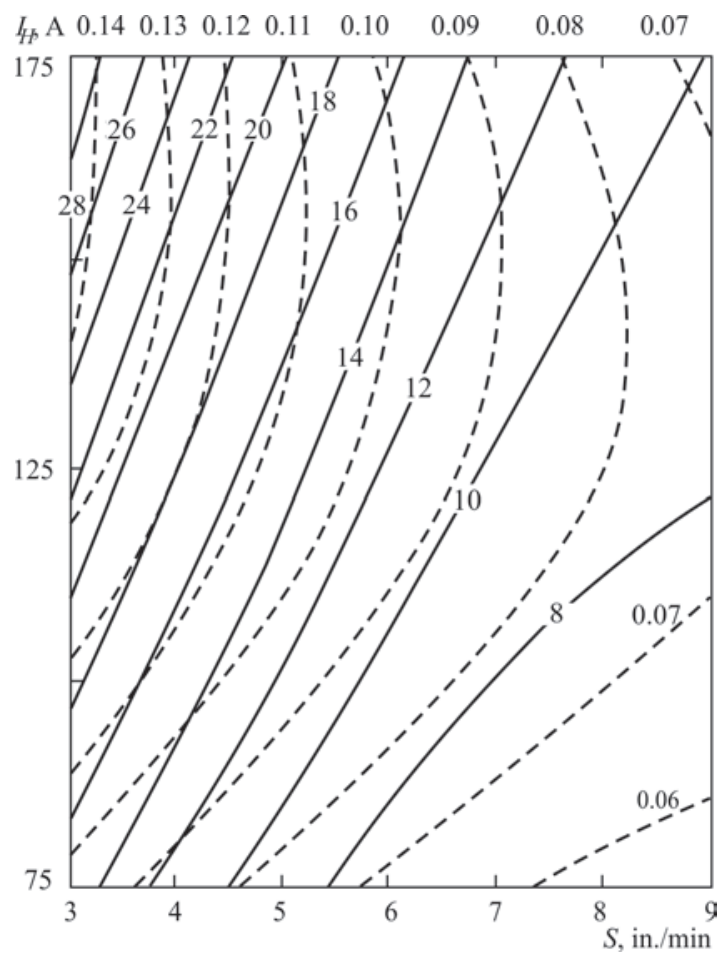

Figure 6. Lines of constant values of penetration depth (dash curves, numbers indicate $h$ values in inches) and rate of energy input (solid curves, numbers indicate $X$ values, $\mathrm{kJ} / \mathrm{in}$.) at $\delta=75 \%$; $I_{L} / I_{H}=20 \% ; f=1 \mathrm{~Hz}$ [3]

TIG welding with LFP modulation of current the penetration depth and its ratio to weld width turn out to be greater than in the case of DC welding, at the same rate of energy input.

Work [4] is devoted to experimental studies of the processes of TIG welding and plasma welding using low-frequency (1-40 Hz) and high-frequency $(2-20 \mathrm{kHz})$ pulse modulation of welding current, as well as combined modulation $(10 \mathrm{~Hz}+2 \mathrm{kHz})$. All the experiments on TIG welding were performed using a torch with tungsten $(\mathrm{W}+2 \% \mathrm{Th})$ cathode of $3 / 32$ in. (2.36 mm) diameter, with 60 deg sharpening

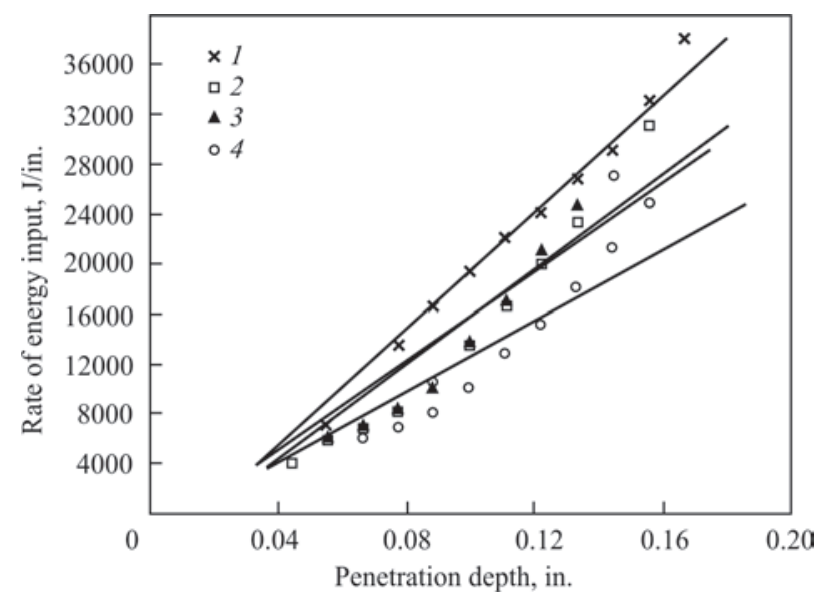

Figure 7. Minimum possible values of the rate of energy input of the process of TIG welding of stainless steel, depending on achieved penetration depth for welding at direct current (1) and three modes with pulse modulation of arc current: $\delta=50 \%, I_{L} / I_{H}=80 \%$ (2); $25 \%$ and $80 \%$ (3); $75 \%$ and $20 \%$ (4) [3] 


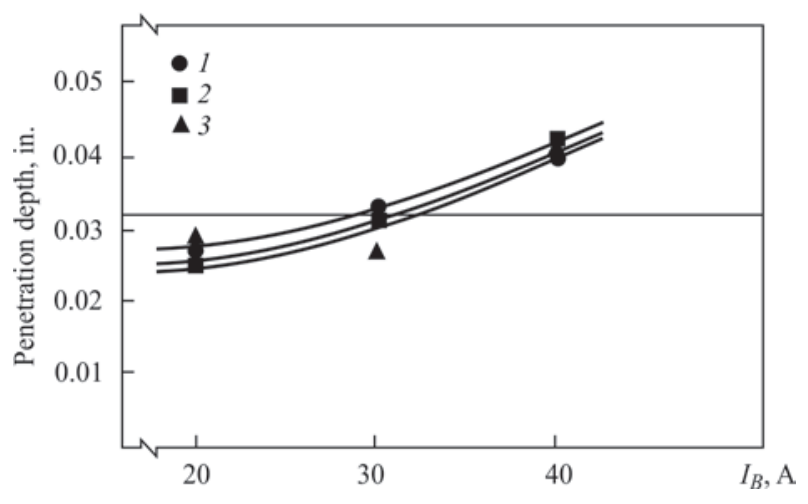

Figure 8. Dependence of penetration depth on pause current at current modulation by rectangular pulses in the form of a meander with repetition rate $f=2$ (1); 10 (2) and 20 (3) $\mathrm{kHz}$ and average current value $I_{a v}=60 \mathrm{~A}$; horizontal line shows the penetration depth in TIG welding at direct current $I=60$ A [4]

angle of the electrode working end, arc length was set equal to $3 / 32$ in. (2.36 mm), and argon was used as shielding gas. Welding of samples from Inconel 600 alloy of $0.109 \mathrm{in}$. (2.77 $\mathrm{mm}$ ) thickness was performed, welding speed was set constant, equal to 4 inches per minute $(1.69 \mathrm{~mm} / \mathrm{s})$. The arc was powered from two sources, one of which was designed for low-frequency modulation of current, and the second, transistor source was used for high-frequency modulation.

As the results of studying the impact of low-frequency pulse modulation of welding current on the depth and shape of metal penetration are described above (see work [13]), we will consider the data of [4], concerning TIG welding with high-frequency pulse modulation of arc current. For correct comparison of penetration depth $h$ at direct current with its value in the case of HFP modulation of arc current by rectangular pulses, the respective experiments were conducted at the same value of average current $I_{\mathrm{av}}=\frac{I_{B} t_{B}+I_{P} t_{P}}{t_{B}+t_{P}}$, where $I_{B}, I_{p}$ are the values of current in the pause and in the pulse; $t_{B}, t_{P}$ are the durations of the pause and pulse, respectively. Figure 8 gives the dependencies of value $h$ on current

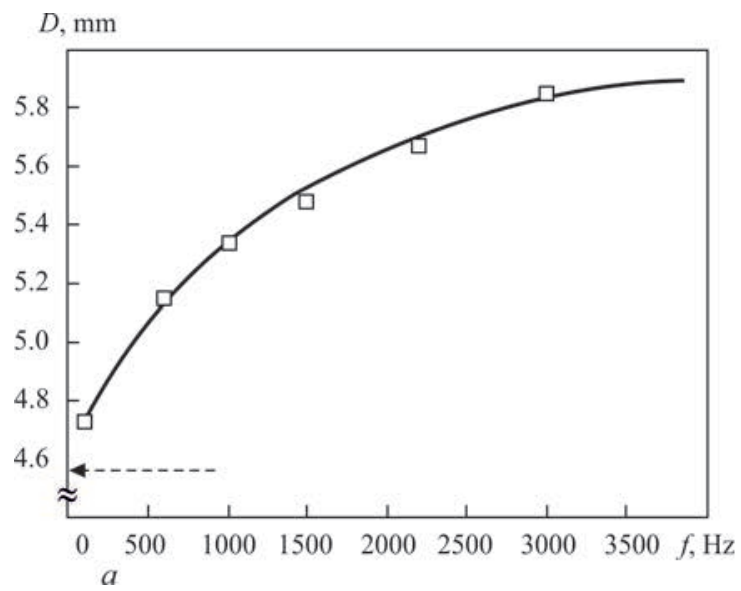

in the pause in TIG welding with current modulation in the form of a meander $\left(\frac{t_{P}}{t_{B}}=1\right)$ at modulation frequencies $f=\frac{1}{t_{B}+t_{P}}$, equal to 2,10 and $20 \mathrm{kHz}$ and average current $I_{\mathrm{av}}=60 \mathrm{~A}$. Horizontal line shows the depth of metal penetration in welding at direct current equal to $I_{\mathrm{av}}$. As follows from experimental data given in this Figure, the penetration depth in TIG welding with HFP modulation of arc current depends weakly on modulation frequency, rises noticeably with $I_{B}$ increase, and at $I_{B}>30$ A exceeds the respective value for DC welding.

In work [4] metallographic investigations of the metal of weld and HAZ were performed, in order to study the influence of current modulation parameters on weld microstructure. In particular, it was established that with increase of modulation frequency $f$ of welding current, the size of metal penetration zone decreases, whereas the size of the HAZ becomes greater. This is indicative of lowering of the efficiency of melting of the metal being welded (thermal efficiency of the process) at $f$ increase. As regards weld metal microstructure, application of HFP modulation of current does not lead to its marked improvement compared to DC TIG welding.

In work [5] studies of the impact of current modulation on penetration depth $D$ and width $W$ of the weld face in welding samples from stainless steel 304 were performed. In the case of sinusoidal modulation of current of $4 \mathrm{~mm}$ arc in the range of 30-270 A (average current $\langle\mathrm{I}\rangle=150 \mathrm{~A}$ ) dependencies of penetration depth and weld width on modulation frequency, shown in Figure 9, were obtained.

As follows from experimental data given in these Figures, the penetration depth in the case of welding by modulated current in the entire studied range of modulation frequencies turns out to be much higher,

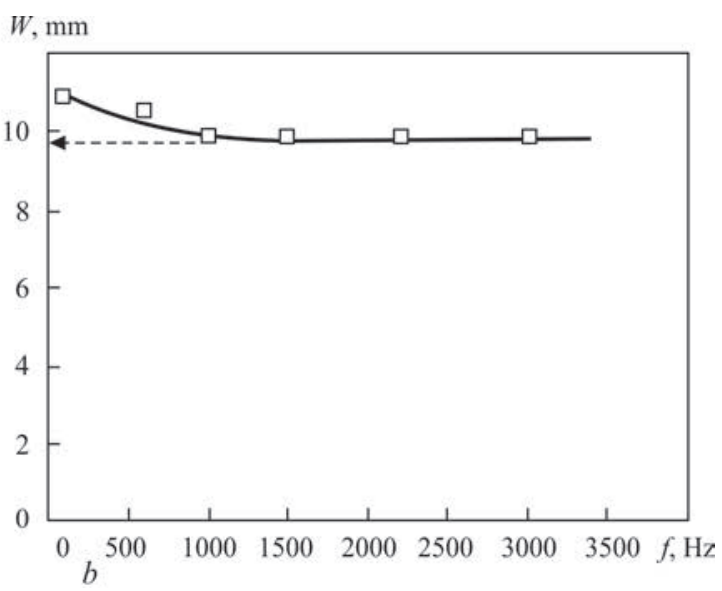

Figure 9. Dependencies of penetration depth $(a)$ and width of weld face side $(b)$ on frequency of sinusoidal modulation of current; dash lines show the respective values for welding at direct current $I=150$ A [5] 
than in the case of welding at direct current equal to average value of modulated current. Here value $D$ rises monotonically with modulation frequency increase, reaching a plateau at frequencies of the order of $4 \mathrm{kHz}$. As regards weld width, in the case of welding with low-frequency current modulation ( $f=$ $=100 \mathrm{~Hz}$ ), it turns out to be somewhat higher than the respective value for DC welding, decreasing with increase of modulation frequency and reaching a constant value, corresponding to $W$ value at DC welding, at frequency of the order of $1.5 \mathrm{kHz}$.

Work [6] also gives the data which are indicative of greater penetration depth at application of high-frequency modulation of arc current. In particular, Figure 10 shows the dependence of penetration depth $T_{N}$ on pulse current $I_{p}$ (curve 1) at modulation frequency of $10 \mathrm{kHz}$, pause current $I_{B}=5 \mathrm{~A}$, and constant average arc current equal to $50 \mathrm{~A}$ (current modulation was performed by rectangular pulses, fill factor was selected from the condition of constant value of average current). The same Figure gives the dependencies of $T_{N}$ on arc length at TIG welding at modulated current with modulation frequency of $10 \mathrm{kHz}$ and average current $\langle I\rangle=50 \mathrm{~A}$ (curve 2), as well as in welding at direct current (curve 3 ) equal to average value of modulated current.

As follows from Figure 10, the penetration depth increases with increase of current modulation amplitude (see curve 1) and decreases markedly at increase of arc length (see curves 2,3), while remaining considerably higher than in the case of current modulation with $10 \mathrm{kHz}$ frequency compared to DC welding.

In addition, work [6] gives the images of cross-sections of welds, made by TIG welding (95\% $\mathrm{Ar}+$ $+5 \% \mathrm{H}$ was shielding gas, without filler wire) of stainless steel 1.4301 (AISI 304) $2 \mathrm{~mm}$ thick at direct current and with HFP modulation of arc current. As follows from comparison of photographs of butt weld cross-sections presented in Figure 11, application of HFP modulation of arc current allows achieving the

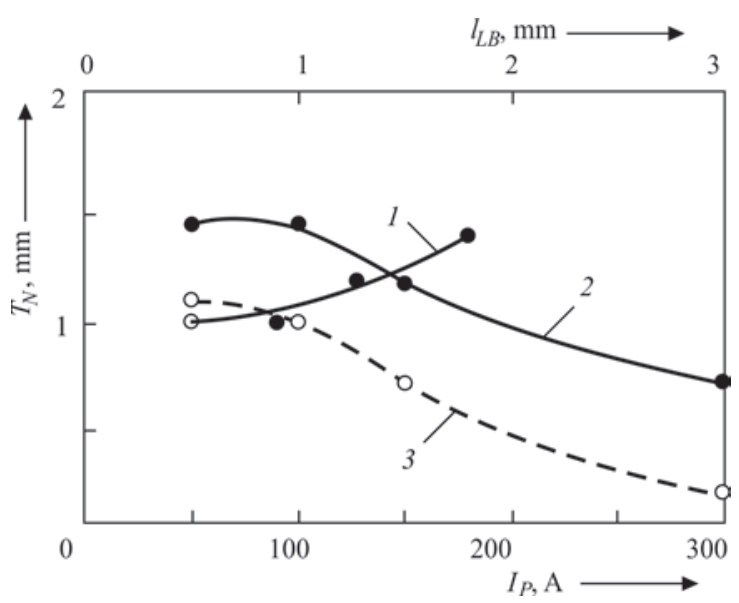

Figure 10. Dependencies of penetration depth $T_{N}$ on pulse current $I_{P}(I)$ and on arc length $I_{L B}(2-10 \mathrm{kHz}, 3-0 \mathrm{~Hz})[6]$

same result, as in the case of welding at direct current equal to average value of modulated current, at significantly higher welding speed. This is indicative of not only higher penetrability of modulated current arc, but also its higher spatial stability.

In [7], alongside the results of experimental studies of the characteristics of an arc with a refractory cathode and copper water-cooled anode at HFP modulation (up to $20 \mathrm{kHz}$ ) with high peak values of current (up to $500 \mathrm{~A}$ ), data are given on the impact of such a modulation on penetration depth and width of overlay welds, made by TIG welding on samples of stainless steel $16 \mathrm{~mm}$ thick, also with application of filler wire of $0.6 \mathrm{~mm}$ diameter (chemical composition of the used materials is given in Table 2).

Figure 12 presents the dependencies of penetration depth $D$ and weld width $W$ on arc length $L$ at TIG welding with HFP modulation of current (average and peak values of current of 150 and 500 A, respectively) and in welding at direct current, equal to average value of modulated current. As follows from experimental data given in this Figure, the width of welds at a short $\operatorname{arc}(L=0.5 \mathrm{~mm})$ is practically independent on modulation frequency. With increase of arc length at modulation frequency of $5 \mathrm{kHz}, W$ value first
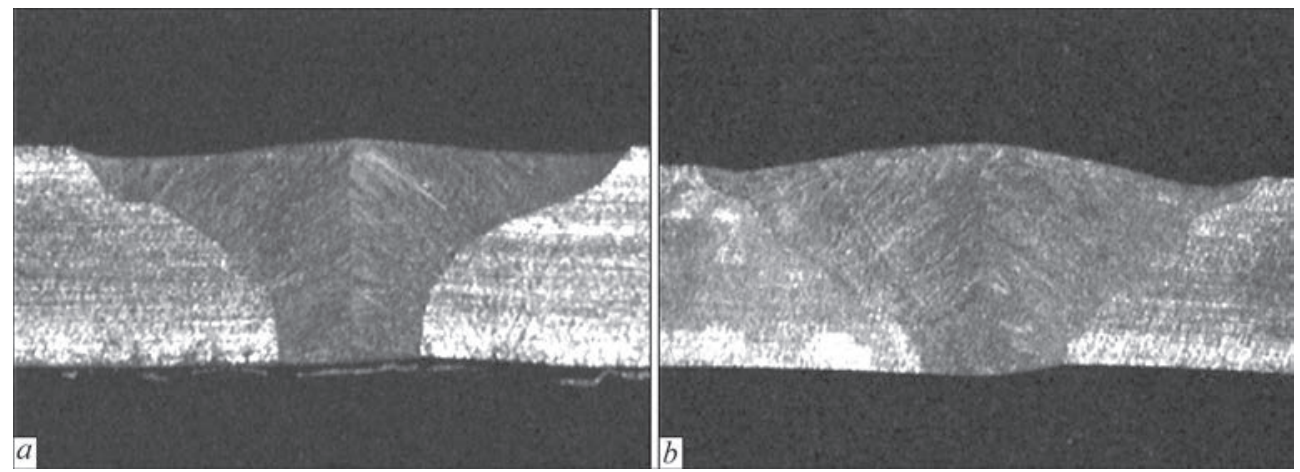

Figure 11. Transverse macrosections of butt welds made on steel $1.43012 \mathrm{~mm}$ thick by TIG welding with HFP modulation of current $(a)$ and at direct current $(b)$ at the following mode parameters: $a-6 \mathrm{kHz}$ modulation frequency, 375 A pulse current, $292 \mathrm{~A}$ average current, $2.4 \mathrm{~m} / \mathrm{min}$ welding speed; $b$ — $292 \mathrm{~A}$ arc current; $1.6 \mathrm{~m} / \mathrm{min}$ welding speed [6] 
Table 2. Composition of metal being welded and filler wire [7]

\begin{tabular}{|c|c|c|c|c|c|c|c|c|}
\hline \multirow{2}{*}{ Material } & \multicolumn{9}{|c|}{ Composition, wt.\% } \\
\cline { 2 - 10 } & $\mathrm{C}$ & $\mathrm{Si}$ & $\mathrm{Mn}$ & $\mathrm{P}$ & $\mathrm{S}$ & $\mathrm{Ni}$ & $\mathrm{Cr}$ & $\mathrm{Fe}$ \\
\hline Metal & 0.04 & 0.6 & 1.01 & 0.032 & 0.005 & 8.26 & 18.34 & Bal. \\
\hline Wire & 0.013 & 0.35 & 1.88 & 0.024 & 0.003 & 12.65 & 19.63 & Bal. \\
\hline
\end{tabular}

rises, then somewhat decreases and then rises again, reaching the maximum value of the order of $10 \mathrm{~mm}$ at $L=3 \mathrm{~mm}$ (see Figure 12, $a$ ). At frequencies of 10 and $16 \mathrm{kHz}, W$ value rises nonmonotonically with increase of arc length. Note that in the case of modulated current welding the welds turn out to be noticeably wider, than in the case of DC welding at the same length of the arc.

As regards the penetration depth at TIG welding with HFP modulation of current at frequencies from 5 up to $16 \mathrm{kHz}$, value $D$ decreases at increase of arc length faster in the range of $L=0.5-1.0 \mathrm{~mm}$ and more smoothly at $L>1 \mathrm{~mm}$, while remaining markedly higher than the respective values for the case of DC welding (see Figure 12, a). In welding with application of filler wire, the above regularities of variation of values $D$ and $W$ are preserved with increase of arc length (see Figure 12).

Figure 13 shows the shapes of the cross-section of overlay welds made by TIG welding of stainless steel (see Table 2) with HFP modulation of current (average and peak current values of 150 and $500 \mathrm{~A}$, respectively), as well as at direct current equal to average value of modulated current. Unfortunately, work [7] does not give any data on welding speed or

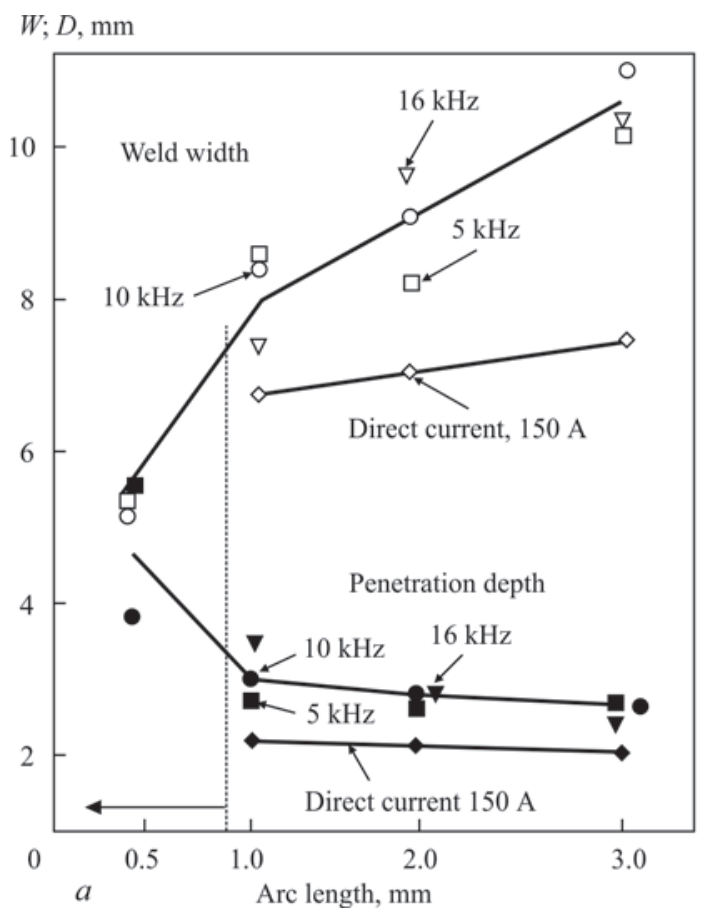

wire feed rate in the experiments, the results of which are presented in Figures 12, 13, and does not specify the length of the arc, at which the penetration shapes shown in Figure 13 were obtained, either.

Work [8] by Indian scientists is a study of the impact of low-frequency $(f=6 \mathrm{~Hz})$ modulation of arc current at TIG welding of an aluminium alloy on temperature distribution in the welded metal and its penetration shape, strength properties and microstructural features of the metal of weld and HAZ, distribution of hardness and residual stresses in the welded samples. All the experiments were performed using an arc with a refractory cathode $(\mathrm{W}+2 \% \mathrm{Th})$ of $3.2 \mathrm{~mm}$ diameter, arc length was kept constant, equal to $2 \mathrm{~mm}$, and chemically pure argon (99.99 \%) was used as shielding gas. Overlay welds were made on $4 \mathrm{~mm}$ thick samples from aluminium alloy AA6351-T6, the composition and mechanical properties of which are given in Tables 3, 4. Temperature was measured by thermocouples located at distances of 5, 15 and $30 \mathrm{~mm}$ from the weld center line.

Parameters of the modes in the experiments on welding at direct current and with low-frequency pulse modulation of arc current are given in Tables 5 and 6 , respectively. Speed $s$ of modulated current

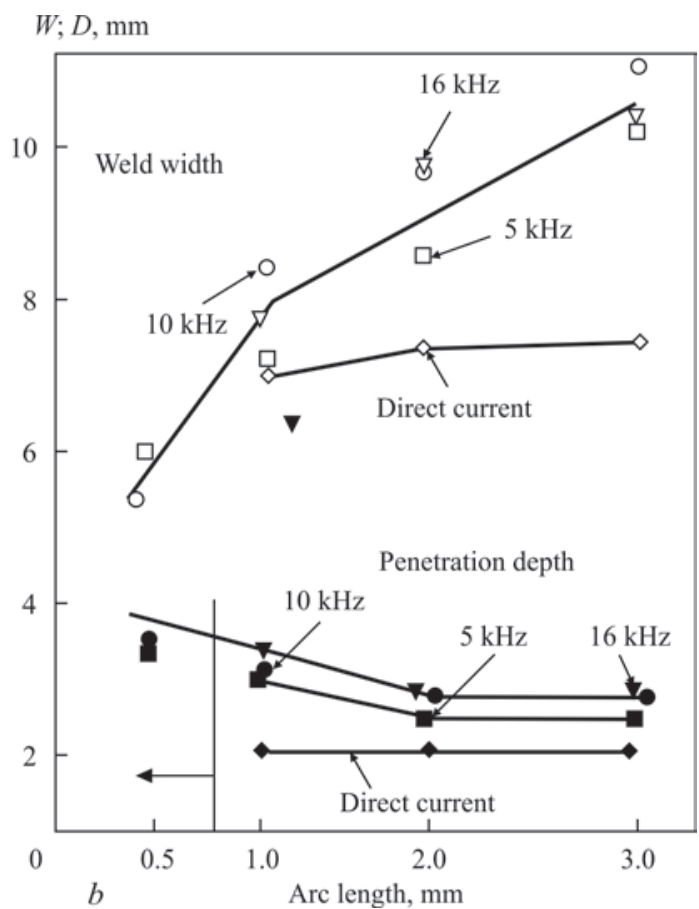

Figure 12. Dependencies of penetration depth and weld width on arc length in TIG welding with current modulation at frequencies of 5, 10 and $16 \mathrm{kHz}$ (500 A peak current, $150 \mathrm{~A}$ average current) and in welding at direct current of $150 \mathrm{~A}: a$ - welding without filler; $b$ - welding with filler wire; horizontal arrow shows the area in which DC welding cannot be performed [7] 


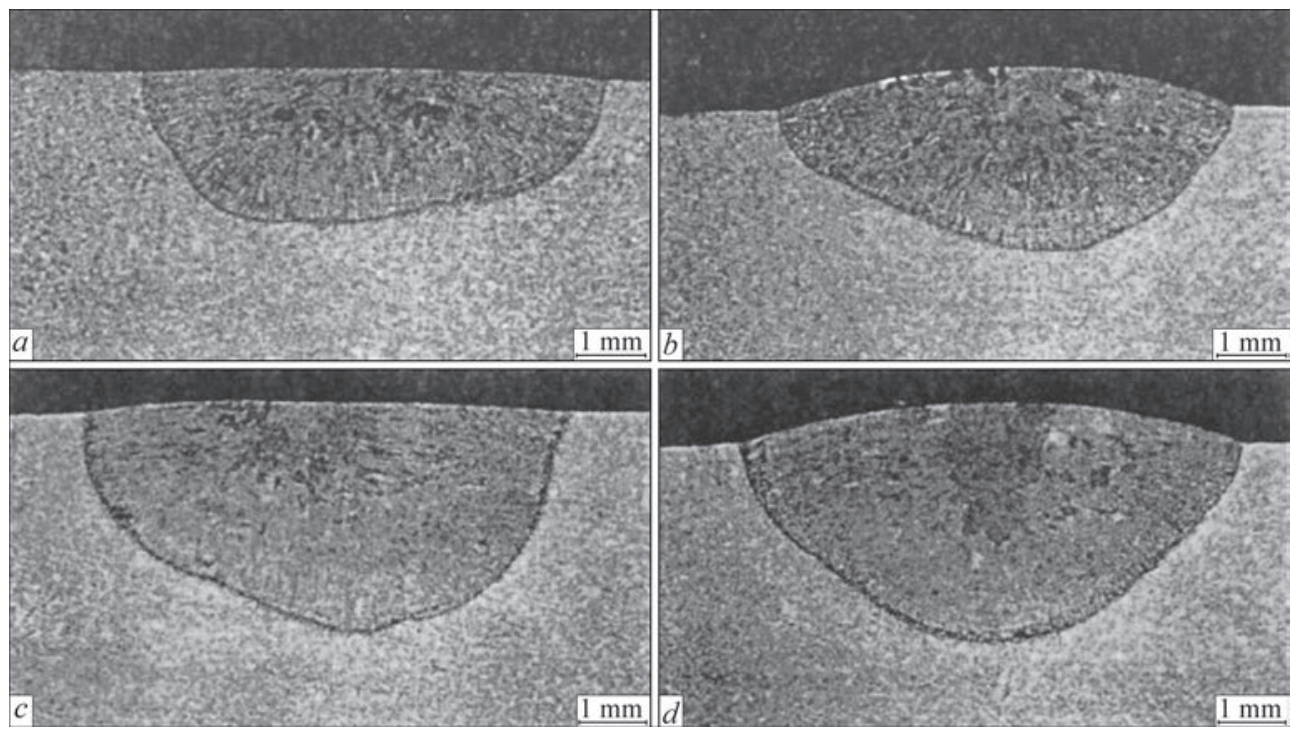

Figure 13. Transverse macrosections of overlay welds in TIG welding at direct current of $150 \mathrm{~A}$, made without filler (a) and with filler wire (c), as well as at HFP modulation of welding current at $16 \mathrm{kHz}$ frequency (500 A peak current, 150 A average current) without application (b) and with application (d) of filler wire [7]

welding was selected the same as at DC welding $(4.167 \mathrm{~mm} / \mathrm{s})$, process efficiency $\eta$ was assumed to be constant, equal to $70 \%$, and independent on the welding mode. The respective rate of energy input was calculated by formula $Q=(\eta I V) / s$, where $I, V$ are the welding current and arc voltage. In the case of modulated current, its value, included into the given formula, was determined as mean $I_{m}=\left(I_{p} t_{p}+I_{b} t_{b}\right) / t_{T}$, where $I_{p}, I_{b}$ are the current values in the pulse and in the pause; $t_{p}, t_{b}$ are the pulse and pause durations; $t_{T}$ is the duration of modulation period; fill factor was calculated as $\delta=t_{p} / t_{T}$.

The shape and geometrical dimensions of the cross-sections of overlay welds, obtained in the experiments on nonconsumable electrode welding at direct current (DC), and in welding by modulated current (MC) are given in Table 7. Here it should be noted that experiment No.5 on DC welding (rate of energy input of $312 \mathrm{~J} / \mathrm{mm}$ ) resulted in cracking, so that the respective data in work [8] are omitted.

Maximum values of temperature and values of cooling rate in the range of $400-200{ }^{\circ} \mathrm{C}$, in points located at the distance of 5 and $15 \mathrm{~mm}$ from the weld center line, are given in Table 8.

Just two samples were used for comparison of the properties of strength, microhardness, microstructure
Table 3. Composition of metal being welded (wt.\%) [8]

\begin{tabular}{|c|c|c|c|c|c|c|c|}
\hline $\mathrm{Mg}$ & $\mathrm{Si}$ & $\mathrm{Fe}$ & $\mathrm{Cu}$ & $\mathrm{Mn}$ & $\mathrm{Zn}$ & $\mathrm{Zr}$ & $\mathrm{Al}$ \\
\hline 0.7 & 1.2 & 0.5 & 0.1 & 0.6 & 0.2 & 0.05 & Bal. \\
\hline
\end{tabular}

Table 4. Mechanical properties of base metal [8]

\begin{tabular}{|c|c|c|c|}
\hline $\begin{array}{c}\text { Yield point, } \\
\text { MPa }\end{array}$ & $\begin{array}{c}\text { Ultimate } \\
\text { strength, MPa }\end{array}$ & $\begin{array}{c}\text { Elongation } \\
\text { per } 50 \mathrm{~mm} \text { of } \\
\text { length, \% }\end{array}$ & $\begin{array}{c}\text { Microhardness } \\
H V \text { at } 0.49 \mathrm{~N}\end{array}$ \\
\hline 150 & 250 & 20 & 95 \\
\hline
\end{tabular}

and residual stresses. On one of them the overlay weld was made by DC arc of $120 \mathrm{~A}$ (experiment No.2), and on the other the weld was made with welding current modulation at pulse current of 140 A (experiment No.4). Penetration depth was approximately the same in both the samples: 1.45 and $1.52 \mathrm{~mm}$ (see Table 7), that allowed comparing the strength properties of overlay welds by removing the unmelted metal down to sample thickness of $1.5 \mathrm{~mm}$. Table 9 gives the results of the respective mechanical testing.

Microhardness distribution of the studied samples is given in Table 10, and Table 11 shows the distribution of residual stresses.

As follows from experimental data, given in Tables 9-11, application of LFP modulation of current ( $f=6 \mathrm{~Hz}$ ) leads to improvement of strength proper-

Table 5. Parameters of DC welding modes [8]

\begin{tabular}{|c|c|c|c|c|c|}
\hline $\begin{array}{c}\text { Experiment } \\
\text { number }\end{array}$ & Welding current, A & Arc voltage, V & Welding speed, mm/s & Process efficiency, \% \\
\hline 1 & 110 & 12.5 & 4.167 & 70 \\
\hline 2 & 120 & 12.7 & 4.167 & 70 \\
\hline 3 & 130 & 12.2 & 4.167 & 70 \\
\hline 4 & 140 & 12.5 & 4.167 & 236 \\
\hline 5 & 150 & 12.4 & 4.167 & 70 \\
\hline
\end{tabular}


Table 6. Parameters of the modes of welding with pulse modulation of arc current $(f=6 \mathrm{~Hz})$ [8]

\begin{tabular}{|c|c|c|c|c|c|}
\hline $\begin{array}{c}\text { Experiment } \\
\text { number }\end{array}$ & Pulse current, A & Pause current, A & Arc voltage, V & Fill factor, \% & Rate of energy input, J/mm \\
\hline 1 & 110 & 55 & 11 & 50 & 161 \\
\hline 2 & 120 & 60 & 12 & 50 & 191 \\
\hline 3 & 130 & 65 & 13 & 50 & 224 \\
\hline 4 & 140 & 70 & 12.5 & 50 & 232 \\
\hline 5 & 150 & 75 & 13.5 & 50 & 269 \\
\hline
\end{tabular}

ties, increase of microhardness and lowering of the level of residual stresses in the samples, compared to those welded at direct current. This is caused by refinement of the structure of the metal of weld and HAZ at welding current modulation, found in [8].
Work [9] gives the experimental data on penetration depth and shape in TIG welding of stainless steel 0Cr18Ni9Ti $6 \mathrm{~mm}$ thick in argon (welding speed of $120 \mathrm{~mm} / \mathrm{min}$ ) with high-frequency $(f=20-80 \mathrm{kHz})$ modulation of current by rectangular pulses in the

Table 7. Cross-sectional shapes and geometry of welds made by TIG welding at direct current and low-frequency modulation of current [8]

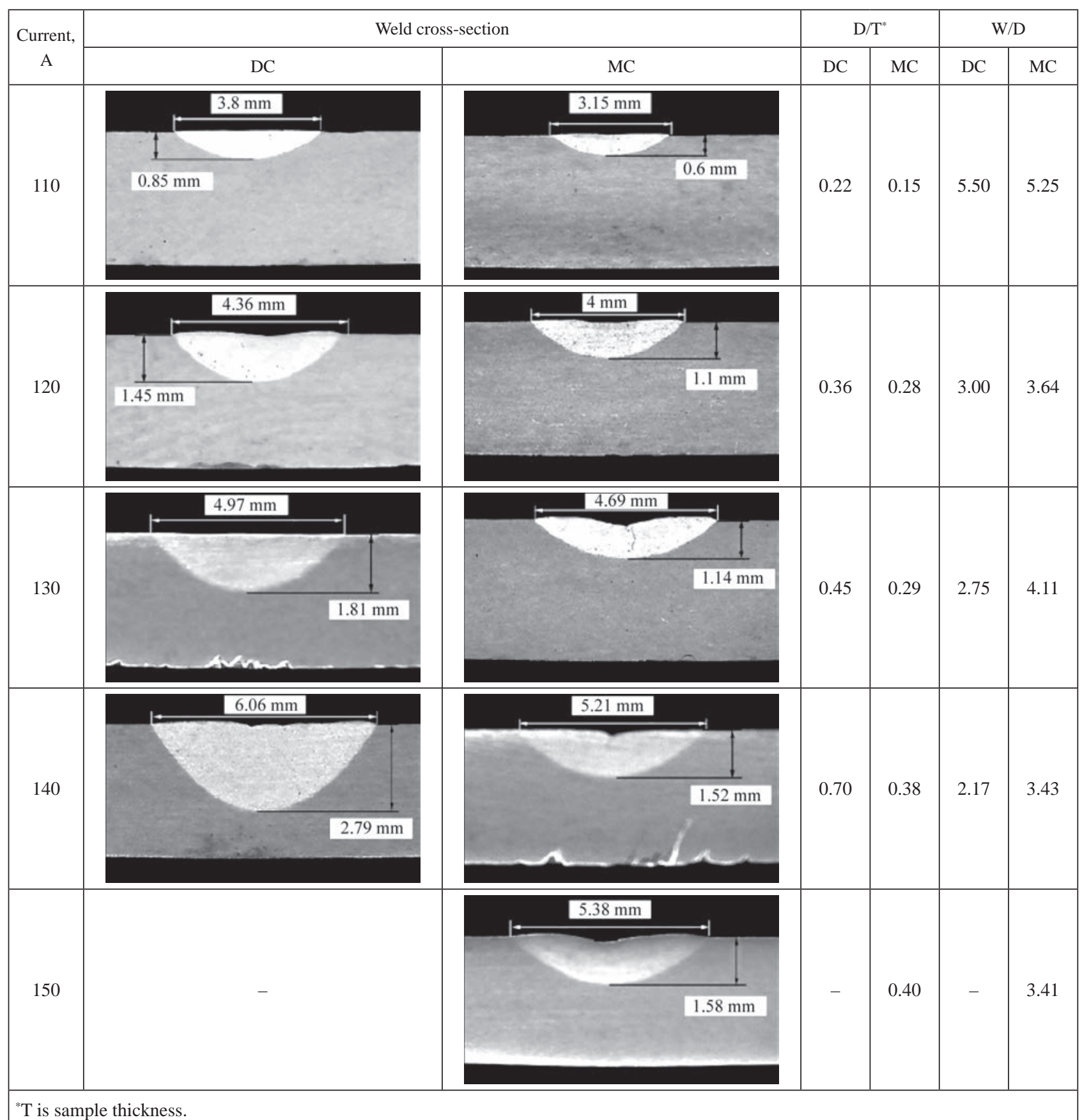


Table 8. Maximum values of temperature and cooling rate in TIG welding at direct current, as well as with pulse modulation of arc current [8]

\begin{tabular}{|c|c|c|c|c|c|c|c|c|c|}
\hline \multirow{2}{*}{$\begin{array}{c}\text { Experiment } \\
\text { number }\end{array}$} & \multirow{2}{*}{ Current, A } & \multicolumn{2}{|c|}{$\begin{array}{c}\text { Rate of energy } \\
\text { input, J/mm }\end{array}$} & \multicolumn{2}{c|}{$\begin{array}{c}\text { Maximum temperature } \\
(5 \mathrm{~mm}), \mathrm{K}\end{array}$} & \multicolumn{2}{c|}{ Cooling rate, ${ }^{\circ} \mathrm{C} / \mathrm{s}$} & \multicolumn{2}{c|}{$\begin{array}{c}\text { Maximum temperature } \\
(15 \mathrm{~mm}), \mathrm{K}\end{array}$} \\
\cline { 3 - 11 } & & DC & MC & DC & MC & DC & MC & DC & MC \\
\hline 1 & 110 & 231 & 161 & 586 & 589 & 16.1 & 19.2 & 475 & 460 \\
\hline 2 & 120 & 256 & 191 & 648 & 609 & 14.4 & 13.5 & 210 & 447 \\
\hline 3 & 130 & 266 & 224 & 666 & 626 & 12.7 & 13.0 & 519 & 484 \\
\hline 4 & 140 & 294 & 232 & 710 & 704 & 11.8 & 12.9 & 544 & 505 \\
\hline 5 & 150 & 312 & 268 & - & 707 & - & 11.9 & - & 516 \\
\hline
\end{tabular}

Table 9. Strength characteristics of welds made at direct current and with pulse modulation of current [8]

\begin{tabular}{|c|c|c|c|c|}
\hline Process & Yield limit, MPa & Ultimate strength, MPa & Elongation, \% & $\begin{array}{c}\text { Strength relative to base } \\
\text { metal, \% }\end{array}$ \\
\hline DC & 185 & 200 & 8 & 80 \\
\hline MC & 205 & 225 & 10 & 90 \\
\hline
\end{tabular}

Table 10. Microhardness distribution in samples welded at direct current and with pulse modulation of current [8]

\begin{tabular}{|c|c|c|c|c|}
\hline \multirow{2}{*}{ Process } & \multicolumn{4}{|c|}{ Microhardness $H V$} \\
\cline { 2 - 5 } & Weld center & $5 \mathrm{~mm}$ from weld center & $15 \mathrm{~mm}$ from weld center & Base metal \\
\hline DC & 72 & 84 & 92 & 95 \\
\hline MC & 81 & 88 & 93 & 95 \\
\hline
\end{tabular}

Table 11. Distribution of residual stresses in samples welded at direct current and with pulse modulation of current [8]

\begin{tabular}{|c|c|c|c|c|}
\hline \multirow{2}{*}{ Process } & \multicolumn{5}{|c|}{ Residual stresses, MPa } \\
\cline { 2 - 5 } & Weld center & $5 \mathrm{~mm}$ from weld center & $15 \mathrm{~mm}$ from weld center & Base metal \\
\hline DC & 134 & 92 & -60.5 & -38.4 \\
\hline MC & 112 & 74 & -55.6 & -36.3 \\
\hline
\end{tabular}

form of a meander (pulse current of $130 \mathrm{~A}$, pause current of $50 \mathrm{~A}$ ). Given for comparison are the respective data for welding at direct current, the value of which is equal to effective value of modulated current $(I=$ $=I_{\text {eff }} \approx 100 \mathrm{~A}$ ). Macrosections of the respective overlay welds are shown in Table 12, and Figure 14 gives the dependencies of penetration depth $H$ and weld width $B$ on modulation frequency. As follows from the given data, the penetration depth rises nonmono-

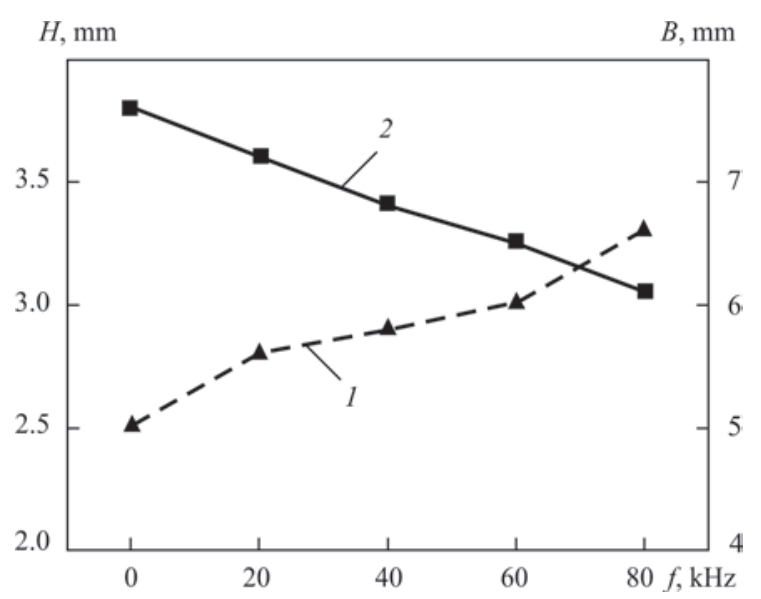

Figure 14. Dependencies of penetration depth (1) and weld width (2) on frequency of arc current modulation [9] tonically with frequency rise, and weld width decreases practically linearly.

The authors of [9] also performed numerical modeling of geometrical parameters of overlay welds, made in the experiments. Calculations were performed taking into account the deflection of weld pool surface, caused by the values of arc pressure on this surface, rising with frequency. Table 13 gives the re-

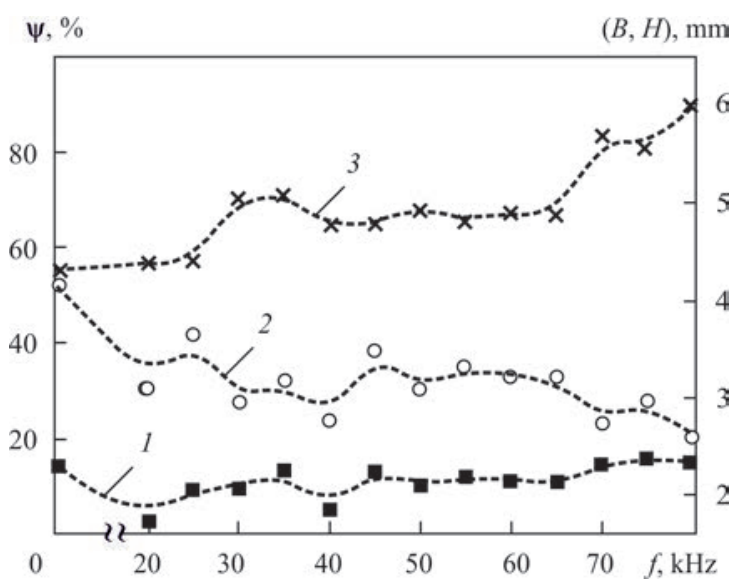

Figure 15. Dependencies of penetration depth $H$, mm (1), weld width $B, \mathrm{~mm}(2)$ and weld form factor $\psi, \%$ (3) on frequency of welding current modulation [10] 
Table 12. Cross-sectional shapes of overlay welds, made at direct current and with HFP modulation of current [9]
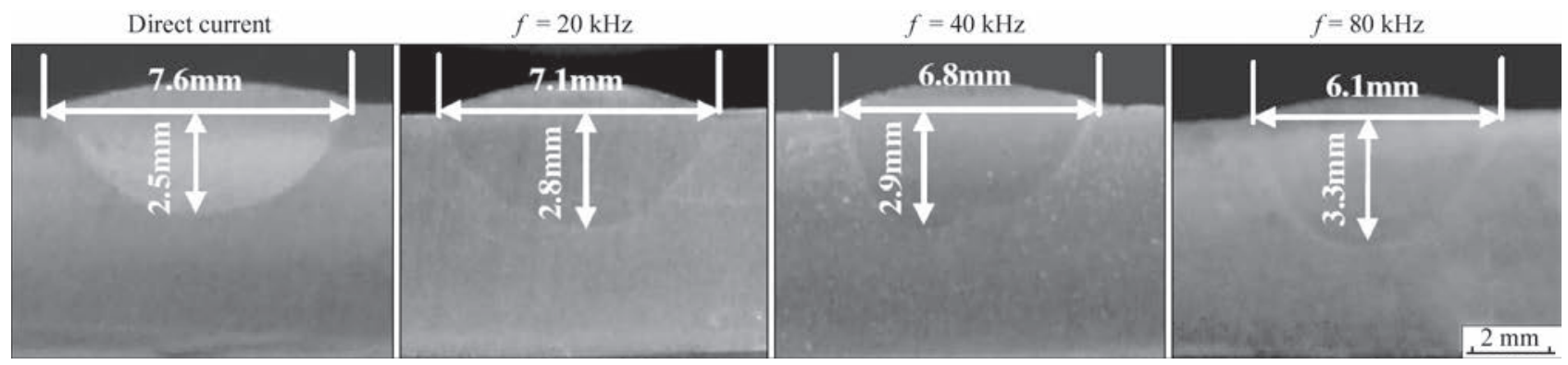

Table 13. Comparison of calculated and experimental data by penetration depth and weld width [9]

\begin{tabular}{|c|c|c|c|c|}
\hline \multirow{2}{*}{ Modulation frequency, $\mathrm{kHz}$} & \multicolumn{2}{|c|}{ Penetration depth, mm } & \multicolumn{2}{c|}{ Weld width, mm } \\
\cline { 2 - 5 } & Experiment & Calculation & Experiment & Calculation \\
\hline 0 & 2.47 & 2.45 & 7.61 & 7.6 \\
\hline 20 & 2.81 & 2.78 & 7.13 & 6.14 \\
\hline 40 & 2.90 & 2.91 & 6.80 & 6.6 \\
\hline 60 & 3.0 & 3.0 & 6.5 & 6.16 \\
\hline 80 & 3.33 & 3.32 & 6.11 & \\
\hline
\end{tabular}

Table 14. Composition of material being welded (wt.\%) [10]

\begin{tabular}{|c|c|c|c|c|c|c|c|}
\hline $\mathrm{Al}$ & $\mathrm{V}$ & $\mathrm{N}$ & $\mathrm{C}$ & $\mathrm{H}$ & $\mathrm{O}$ & $\mathrm{Fe}$ & $\mathrm{Ti}$ \\
\hline 5.82 & 3.99 & 0.023 & 1.83 & 0.0007 & 0.063 & $<0.05$ & Bal. \\
\hline
\end{tabular}

sults of modeling together with the respective experimental data. Comparison of calculated and experimental data is indicative of their amazing coincidence (with the accuracy of the order of $1 \%$ ).

Work [10] of Chinese scientists is devoted to experimental study of the impact of frequency of pulse modulation of arc current on metal penetration in TIG welding. Experiments were performed using $3 \mathrm{~mm}$ arc with refractory (W $+2 \% \mathrm{Ce}$ ) cathode of $2.4 \mathrm{~mm}$ diameter, shielding gas Ar (99.99 \%) and welding speed of $150 \mathrm{~mm} / \mathrm{min}$. Samples $2.5 \mathrm{~mm}$ thick from titanium alloy TS4 were welded. Its composition is given in Table 14. Current modulation parameters were as follows: rectangular pulses in the form of a meander, repeated with the frequency in the range of

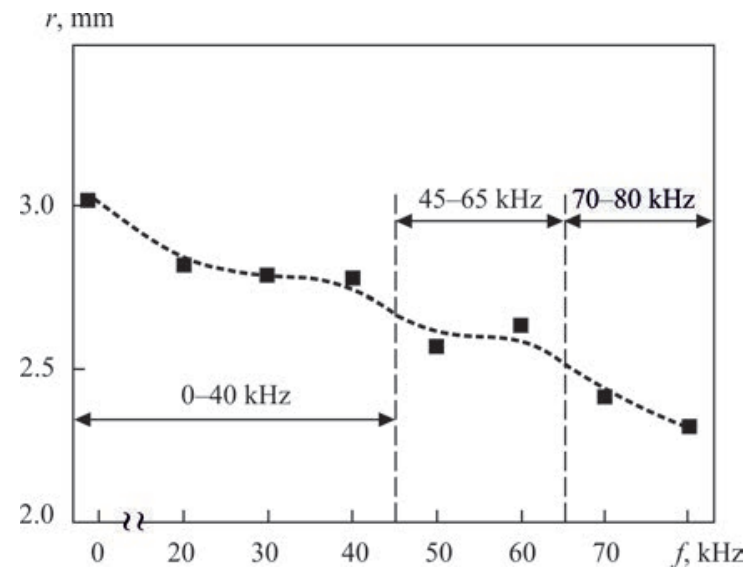

Figure 16. Dependence of arc root radius $r$ on current modulation frequency $f[10]$
20-80 kHz, at base value of current $I_{b}=40$ A, peak value $I_{p}=100 \mathrm{~A}$ (mean current of $70 \mathrm{~A}$ ). Experiments on welding at direct current $I=80$ A were conducted for comparison.

Dependencies of penetration depth $H$, weld width from sample face side $B$ and weld form factor $\psi=$ $=H / B$ on modulation frequency $f$ are given in Figure 15. As follows from experimental data presented in this Figure, weld width decreases markedly with increase of modulation frequency at a certain increase of penetration depth. The authors of [10] explain this tendency by reduction of the radius of anode binding of («root») $r$ of the arc with increase of modulation frequency that is illustrated by experimental data given in Figure 16.

Work [11] is an experimental study of the impact of current parameters of LFP modulation in TIG welding of SAE 1020 steel $6.5 \mathrm{~mm}$ thick in argon atmosphere. Refractory cathode EWTh2 of $2.4 \mathrm{~mm}$ diameter with $60^{\circ}$ sharpening angle of the working end was used. Arc length was $2 \mathrm{~mm}$ in all the experiments, welding speed was $10 \mathrm{~cm} / \mathrm{min}$. Arc current was modulated by rectangular pulses in the form of a meander repeated with the frequency of $50 \mathrm{~Hz}$. Modulation current parameters are given in Table 15.

Figure 17 presents the experimental data on penetration depth, weld width and its cross-sectional area for the first seven experiments, which were performed while maintaining a constant mean value of arc current $I_{m}=150$. 
Table 15. Current parameters of modulation, used during experiment performance [11]

\begin{tabular}{|c|c|c|c|c|c|c|c|}
\hline \multirow{2}{*}{$\begin{array}{c}\text { Experiment } \\
\text { number }\end{array}$} & \multirow{2}{*}{$\begin{array}{c}\text { Base current } \\
\text { value, A }\end{array}$} & \multirow{2}{*}{$\begin{array}{c}\text { Peak current } \\
\text { value, A }\end{array}$} & \multirow{2}{*}{$\begin{array}{c}\text { Modulation ampli- } \\
\text { tude, A }\end{array}$} & \multicolumn{2}{|c|}{ Mean current value, A } & \multicolumn{2}{|c|}{ Effective current value, A } \\
\cline { 5 - 8 } & & & & Calculation & Experiment & Calculation & Experiment \\
\hline 1 & 150 & 150 & 0 & 150 & 150 & 150 & 150 \\
\hline 2 & 95 & 205 & 110 & 150 & 151 & 160 & 160 \\
\hline 3 & 70 & 230 & 160 & 150 & 151 & 170 & 169 \\
\hline 4 & 50 & 250 & 200 & 150 & 150 & 180 & 179 \\
\hline 5 & 35 & 265 & 230 & 150 & 151 & 189 & 188 \\
\hline 6 & 20 & 280 & 260 & 150 & 146 & 198 & 192 \\
\hline 7 & 10 & 290 & 280 & 150 & 146 & 205 & 198 \\
\hline 8 & 128 & 168 & 40 & 148 & 148 & 150 & 150 \\
\hline 9 & 78 & 198 & 120 & 138 & 139 & 150 & 151 \\
\hline 10 & 10 & 212 & 200 & 111 & 114 & 150 & 150 \\
\hline
\end{tabular}

As follows from the diagrams given in this Figure, weld width increases with increase of modulation amplitude, and, therefore, of the effective (rms) value of current $I_{r m s}$ (see Table 15), while the penetration depth practically does not change, remaining below the respective value for DC welding. The cross-sectional area of the welds is also becoming larger with increase of effective value of current and begins exceeding the penetration depth in the case of DC welding at $I_{r m s}>198 \mathrm{~A}$.

Figure 18 gives similar data for experiments 1 , 8-10, performed under the condition of constant $I_{r m s}$ and respective lowering of $I_{m}$.

The experimental data given in Figure 18 are indicative of noticeable reduction (compared to the respective DC welding characteristics) of penetration depth and cross-sectional area of the weld at decrease of mean value of arc current, whereas weld width does not change significantly. This led the authors of [11] to the conclusion that the penetration depth in TIG welding with low-frequency modulation of current depends mainly on mean value of modulated current, whereas weld width depends on its effective value.

Work [12] is also devoted to analysis of the impact of such characteristics of welding current modulation as its mean $I_{m}$ and effective (rms) value $I_{r m s}$ on penetration depth, width and cross-sectional area of the weld, as well as on the rate of energy input in TIG welding of carbon steel $6.3 \mathrm{~mm}$ thick in argon atmosphere. Experiments were performed using a refractory cathode $(\mathrm{W}+2 \% \mathrm{Th})$ of $4 \mathrm{~mm}$ diameter with $60^{\circ}$ angle of sharpening of the working end, arc length was constant, and equal to $3.5 \mathrm{~mm}$, welding speed was $12 \mathrm{~cm} / \mathrm{min}$. Arc current was modulated by rectangular pulses in the form of a meander $\left(t_{p}=t_{b}=\right.$ $=0.25 \mathrm{~s}, 2 \mathrm{~Hz}$ frequency), modulation current parameters are given in Table 16.

Experimental data given in Figure 19 confirm the conclusion of work [11] that the geometrical characteristics of welds in TIG welding of carbon steel with
LFP modulation of current are determined by both the mean and effective value of modulated current.

Analysis of the results of experimental work on investigation of the processes of metal penetration, geometrical characteristics, quality and mechanical characteristics of welds in TIG welding with welding current modulation leads to the following conclusions:

1. In TIG welding of aluminium alloys application of low-frequency pulse modulation of arc current with
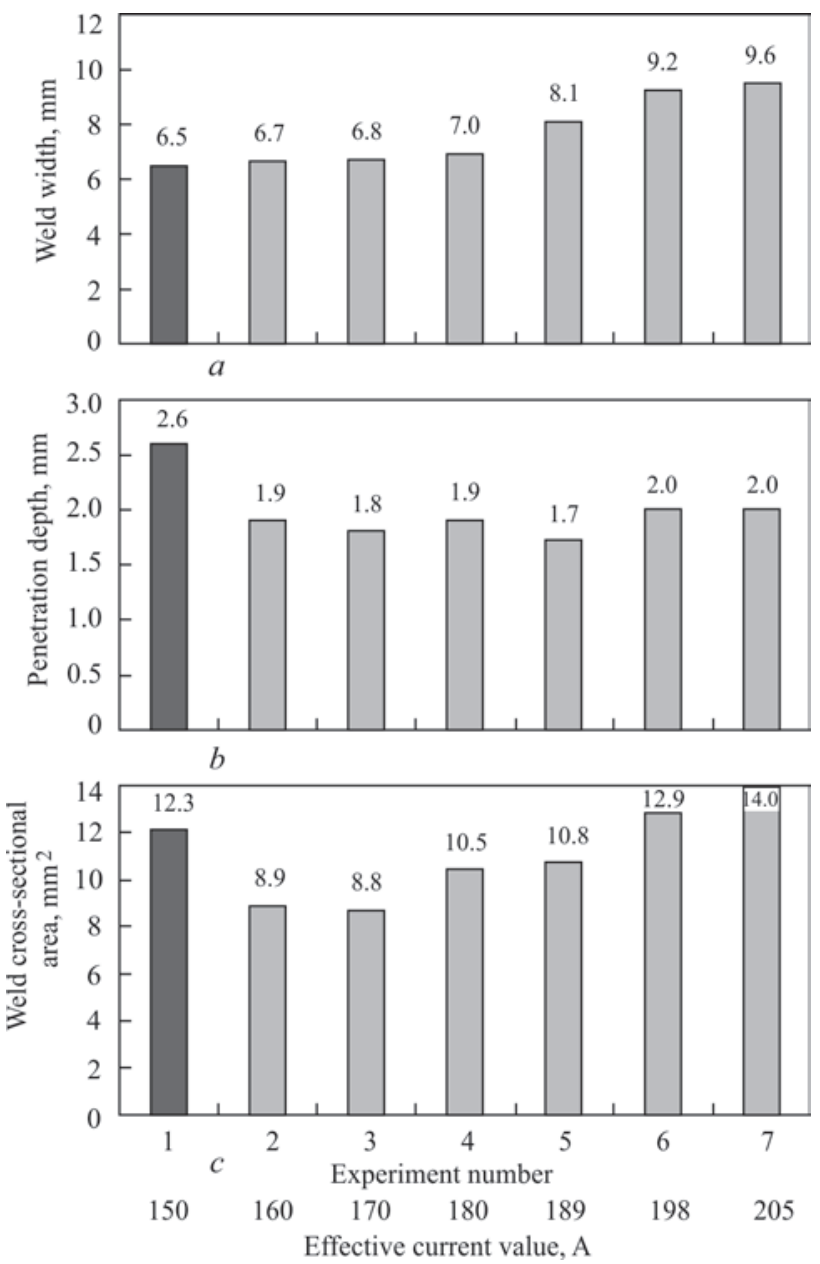

Figure 17. Dependencies of weld width $(a)$, penetration depth $(b)$ and weld cross-sectional area $(c)$ on effective value of current at constant $I_{\mathrm{m}}=150$ A [11] 
Table 16. Current modulation parameters used during the experiments [12]

\begin{tabular}{|c|c|c|c|c|c|c|c|}
\hline \multirow{2}{*}{ Mode } & \multicolumn{3}{|c|}{ Set parameters } & \multicolumn{4}{c|}{ Measured parameters } \\
\cline { 2 - 8 } & $I_{\mathrm{m}}, \mathrm{A}$ & $I_{\mathrm{p}}, \mathrm{A}$ & $I_{\mathrm{b}}, \mathrm{A}$ & $I_{\mathrm{m}}, \mathrm{A}$ & $I_{\mathrm{rms}}, \mathrm{A}$ & $U_{\mathrm{m}}, \mathrm{V}$ & $U_{\mathrm{rms}}, \mathrm{V}$ \\
\hline$\Delta I 300$ & 200 & 350 & 50 & 199 & 249 & 12.5 & 12.8 \\
\hline$\Delta I 200$ & 200 & 300 & 100 & 202 & 225 & 12.9 & 13.0 \\
\hline$\Delta I 100$ & 200 & 250 & 150 & 200 & 206 & 12.7 & 12.9 \\
\hline$\Delta I 50$ & 200 & 225 & 175 & 200 & 201 & 12.8 & 13.0 \\
\hline$\Delta I 20$ & 200 & 210 & 190 & 200 & 200 & 12.6 & 12.8 \\
\hline$\Delta I 10$ & 200 & 205 & 195 & 198 & 200 & 12.5 & 12.7 \\
\hline$\Delta I 0$ & 200 & - & - & 199 & 200 & 12.8 & 12.8 \\
\hline$\Delta I 0$ & 206 & - & - & 206 & 206 & 12.9 & 12.9 \\
\hline$\Delta I 0$ & 224 & - & - & 225 & 225 & 12.6 & 12.6 \\
\hline$\Delta I 0$ & 249 & - & - & 251 & 251 & 12.9 & 12.9 \\
\hline
\end{tabular}

$6 \mathrm{~Hz}$ frequency results in a noticeable improvement of strength properties (by 10-13\%), and increase of microhardness (up to $12 \%$ ) of weld metal, as well as lowering of residual stresses (up to $20 \%$ ), compared to samples, welded at direct current. This is caused by refinement of the structure of weld and HAZ metal at LFP modulation of welding current. Application of HFP modulation of current with the frequency of up to $25 \mathrm{kHz}$ essentially reduces the number of pores and
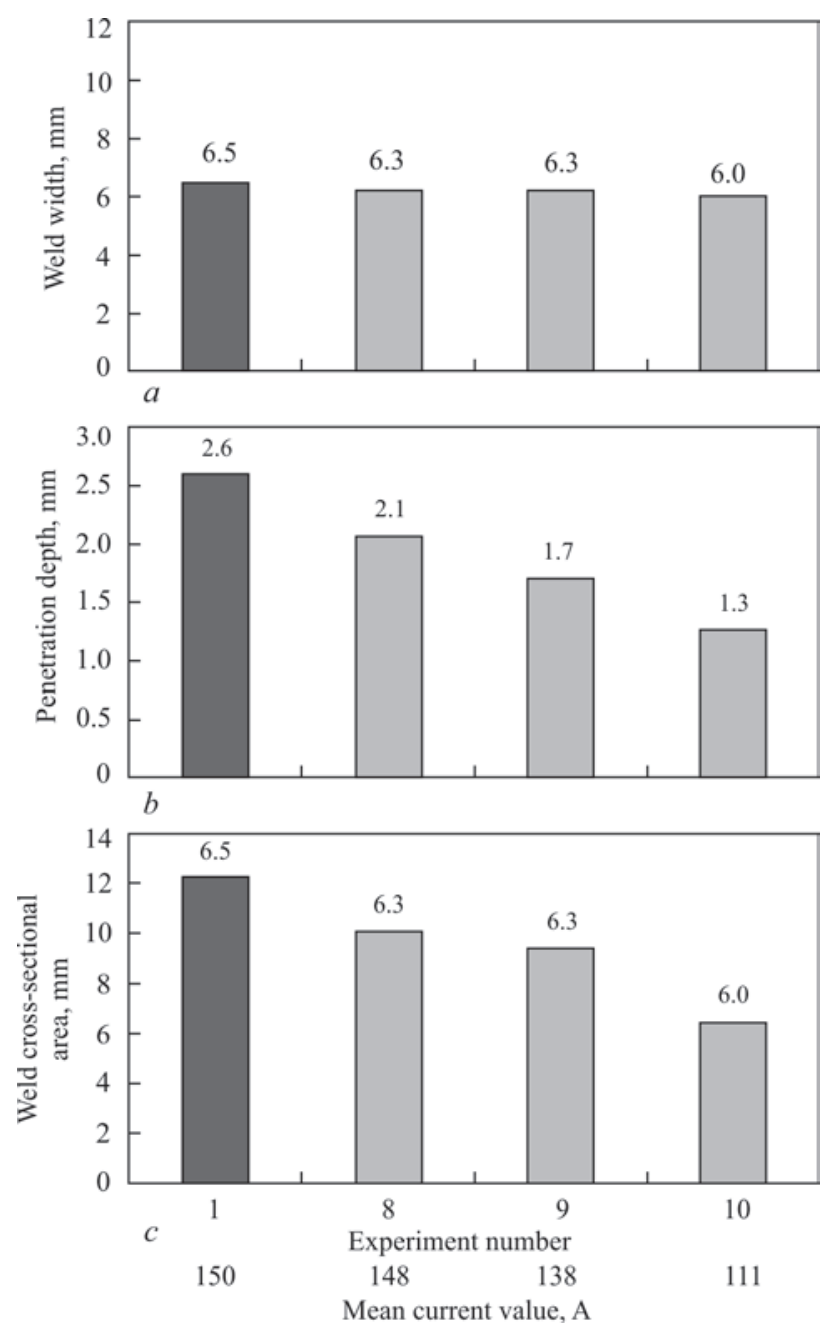

Figure 18. Dependencies of weld width $(a)$, penetration depth $(b)$ and weld cross-sectional area $(c)$ on mean value of current at constant $I_{\text {rms }}=150$ A [11] nonmetallic inclusions per a unit of weld length (up to $80 \%)$. In addition, such a modulation can be effectively used for breaking up the heterogeneous cast structure of weld metal, observed in the welds made at direct current. As a result, the microstructure of weld metal in TIG welding of aluminium alloys with HFP modulation of arc current is more homogeneous, so that such welds have fracture toughness values by 10-15\% higher than in DC welding.

2. In the case of TIG welding of stainless steel with low-frequency modulation of current by rectangular pulses repeated at the frequency of $1-5 \mathrm{~Hz}$, the penetration depth and its ratio to weld width, turn out to be larger than in the case of DC welding with the same rate of energy input. At medium frequency sinusoidal
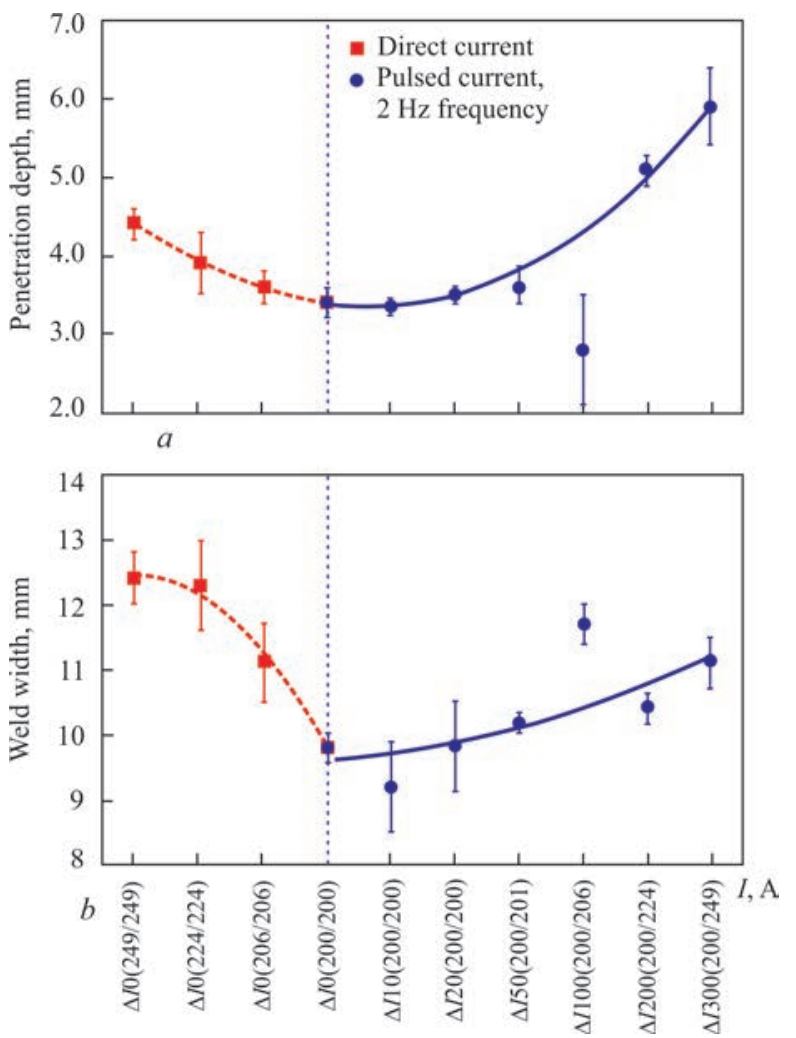

Figure 19. Impact of mean $I_{\mathrm{m}}$ and effective $I_{\mathrm{rms}}$ current values on penetration depth $(a)$ and weld width $(b)$, where $\Delta l$ is the modulation amplitude; in parenthesis $-I_{\mathrm{m}} / I_{\mathrm{rms}}[12]$ 
modulation of current in the range of up to $4 \mathrm{kHz}$ and high-frequency modulation of current by rectangular pulses at frequencies in the range of $10-80 \mathrm{kHz}$, the penetration depth of stainless steel also exceeds the respective value at DC TIG welding, equal to mean value of modulated current. As regards the weld width, it turns out to be somewhat larger than the respective value for welds made by DC TIG welding.

3 . With increase of frequency of pulse modulation of welding current in the case of TIG welding of nickel-chromium high-temperature alloys the size of the metal penetration zone decreases, whereas the size of HAZ increases. This is indicative of lowering of the efficiency of melting of the metal being welded (thermal efficiency) at increase of arc current modulation frequency. As regards the weld metal microstructure, application of HFP modulation of current does not lead to its noticeable improvement, compared to DC TIG welding.

4. At TIG welding of carbon steel with low-frequency modulation of current by rectangular pulses, the metal penetration depth mainly depends on mean value of modulated current, whereas the weld width depends on its effective value.

1. Boyi, U., Krivtsun, I.V. (2019) Processes of nonconsumable electrode welding with welding current modulation (Review). Pt 1: Peculiarities of burning of nonstationary arcs with refractory cathode. The Paton Welding J., 11, 23-32.

2. Roden, W.A. (1972) High-frequency, pulsed-current GTA welding. In: Proc. of National Aerospace Engineering and
Manufacturing Meeting (2-5 Oct. 1972, San Diego, California, USA). Paper 720874, 1-8.

3. Leitner, R.E., McElhinney, G.H., Pruitt, E.L. (1973) An investigation of pulsed GTA welding variables. Welding J., Res. Suppl., 9, 405-410.

4. Omar, A.A., Lundin, C.D. (1979) Pulsed plasma — pulsed GTA arcs: A study of the process variables. Ibid., 4, 97-105.

5. Saedi, H.R., Unkel, W. (1988) Arc and weld pool behavior for pulsed current GTAW. Ibid., 11, 247-255.

6. Dzelnitzki, D. (2000) Muendersbach TIG - direct-current welding with high-frequency pulses, an interesting process variant. EWM Hightec Welding GmbH. WM008801. DOC: 08.00 .

7. Onuki, J., Anazawa, Y., Nihei, M. et al. (2002) Development of a new high-frequency, high-peak current power source for high constricted arc formation. Japan. J. Appl. Phys., 41, 5821-5826.

8. Karunakaran, N., Balasubramanian,V. (2011) Effect of pulsed current on temperature distribution, weld bead profiles and characteristics of gas tungsten arc welded aluminum alloy joints. Transact. Nonferrous Met. Soc. China, 21, 278-286.

9. Qi, B., Yang, M., Cong, B. et al. (2013) The effect of arc behavior on weld geometry by high-frequency pulse GTAW process with 0Cr18Ni9Ti stainless steel. Int. J. Adv. Manuf. Technol., 66, 1545-1553.

10. Yang, Z., Qi, B., Cong, B. et al. (2013) Effect of pulse frequency on weld appearance behavior by TC4 titanium alloys. Transact. China Welding Institute, 34(12), 37-40.

11. Cunha, T.V.D., Louise-Voigt, A., Bohorquez, C.E.N. (2016) Analysis of mean and RMS current welding in the pulsed TIG welding process. J. of Materials Processing Technology, 231, 449-455.

12. Silva, D.C.C., Scotti, A. (2016) Using either mean or RMS values to represent current in modeling of arc welding bead geometries. Ibid., 240, 382-387.

\section{The Tenth International Conferensce}

Technologies in Welding and Related Mathematical Modeling and Information

Processes

Dedicated to the 150 th anniversary of the acad. E.O. Paton - founder of the world's first welding institute

\section{Ukraine, Odessa, Hotel "Arkadia»}

September $14-18,2020$

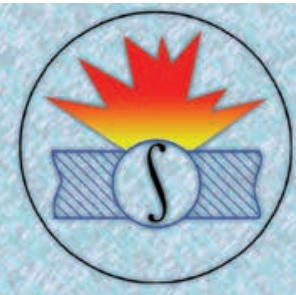

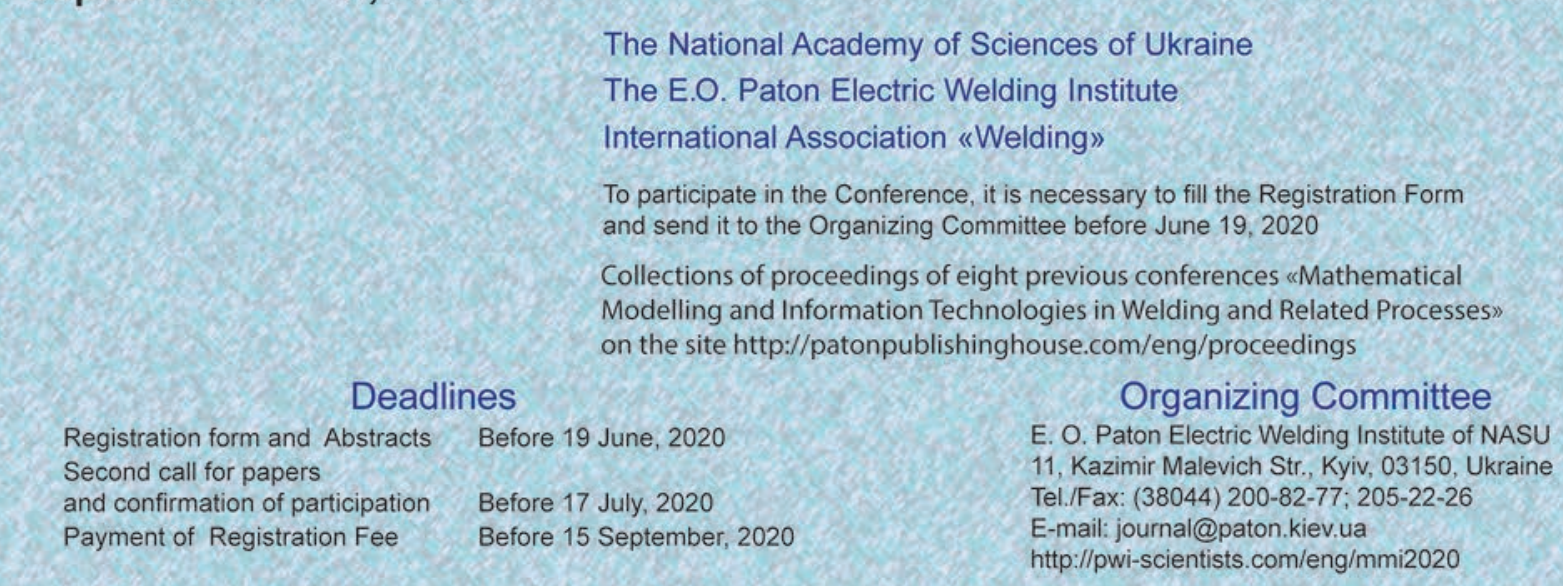




\title{
FEATURES OF ARC WITH PULSED SELF-REGULATION OF ELECTRODE MELTING PROCESS IN MANUAL ARC WELDING
}

\author{
S.Yu. MAKSYMOV, V.S. SYDORUK and D.M. KRAZHANOVSKYI
}

E.O. Paton Electric Welding Institute of the NAS of Ukraine

11 Kazymyr Malevych Str., 03150, Kyiv, Ukraine. E-mail: office@paton.kiev.ua

\begin{abstract}
The article deals with the problem of providing stability of the electrode arc melting process with respect to welding or surfacing technology. It was proposed to use a current source assembled from serially manufactured components. The peculiarity of the proposed source is that it is a source of pulsating DC voltage, powered from 220V single-phase mains. It was shown that the process was equally stable both in case of mechanised welding in carbon gas, as well as during manual welding using electrodes for direct current under the conditions, which are substantially lower than those recommended by the developers of electrode materials. The proposed circuit diagram of the power source provides the ability to vary the value of the current over a wide range, which will extend the technological capabilities of welding, including larger gaps between the edges and in different spatial positions. 15 Ref., 1 Table, 5 Figures.
\end{abstract}

Keywords : self-regulation, electrode melting process, electric parameters, oscillatory character of the arc, drop overflow, complex current source, volt-ampere characteristic, oscillogram, histogram, breaking arc length

The basis of arc fusion welding as well as related processes (surfacing, brazing, remelting) is the melting of a metal electrode under the action of the arc. Arc melting of an electrode is a nonstationary process: formation, detachment from the end of the electrode and transfer of a molten metal drop through the interelectrode (arc) gap; instability of arc length, etc. There is a problem of controlling this process to maintain its stability. The typical phenomena which mean the loss of stability are an excessive increase in the length of the arc until its natural break and a decrease in the length of the arc until a short circuit of the electrode on the workpiece.

Two possibilities of maintaining stability are known: active control and self-regulation of the electrode melting process.

Active control is known in two variants: manual and automatic.

Automatic control, as a rule, reproduces the algorithms of manual control by means of automation. In this case, in welding complex, in addition to welding unit and power source, there is a third component: process control unit. Priority in this method of welding belongs to the General Electric Company, P. Nobel (1920) [1].

Back at the time, automatic control was applied in welding with a long arc, mainly under flux, in which a short circuit of the electrode was taken as disaster it ended in a termination of the arc process. In recent years, a considerable number of processes with au- tomatic control have been developed concerning arc welding in shielding gases, in which the arc is periodically alternated with controlled short circuits of electrode through a molten metal drop [1].

Let us recall the most famous among them.

1. STT - Surface Tension Transfer [2]. The process was patented by the Lincoln Electric Company in 1988 and has been implemented in industry since 1994.

2. Adaptive pulsed processes of welding and surfacing by Yu.M. Saraev [3].

3. CMT - Cold Metal Transfer [4].

4. Automatic welding and surfacing using a digitally controlled power source, which is characterized by the ability to create an external (volt-ampere) characteristic in the form of a multisection broken line [5]. The authors call it a self-adaptive closed-loop automatic arc welding control system.

Automatic welding arc control provides the highest quality of welding and is irreplaceable in the manufacture of particularly critical structures, mainly of thin-sheet metal and dissimilar metals.

In mass production, as well as in case of individual production, in particular, at small enterprises, welding with automatic control is not yet competitive as compared to welding with self-regulation.

Self-regulation differs from active control in the fact, that welding complex does not contain a control unit. The stability of the process is maintained due to the fact, that power source is designed in such a way, 
that it spontaneously reacts to the situation in the arc, and it is unambiguous: to every change in the length of the arc, and accordingly, to its voltage, it reacts by changing the current directed in the opposite direction. As the arc length decreases (at a constant electrode feed rate), the source increases the current, due to which the electrode melting rate grows and the arc length is increased to a preset value. In the case of an increase in the value of the arc length against a preset one, the response of the source is the opposite: the current is decreased, and accordingly, the melting rate of the electrode is reduced.

The principle of self-regulation of the arc was proposed by V.I. Dyatlov at the E.O. Paton Electric Welding Institute in 1942 [6].

However, the «classic» method of self-regulation has a serious drawback: it works, as was shown by B.E. Paton [7], only at a sufficiently large current density on the electrode. On the basis of production experience, we found that the minimum possible current density (in automatic submerged-arc welding with the use of a low-carbon wire of $5 \mathrm{~mm}$ diameter) is equal to $30 \mathrm{~A} / \mathrm{mm}^{2}$. During welding in shielding gases, it may exceed $100 \mathrm{~A} / \mathrm{mm}^{2}$.

It became necessary to develop such an algorithm for self-regulation of electrode melting, in which the stability of welding process would be high with a decrease in the current density at the electrode, at least as that in manual arc welding $\left(12 \mathrm{~A} / \mathrm{mm}^{2}\right)$. It means that in welding using a wire of a «large» diameter at low speed of its feeding, the arc should neither break during an accidental increase in its length, nor extinguish in a short circuit during a decrease in its length.

We followed the path of combining the properties of manual arc welding in a one process (the VAC should be steeply drooping, where $U_{\text {o-c }}$ is several times higher than a preset $U_{a}$ ) with the property of mechanized welding, where the $\mathrm{VAC}_{\mathrm{s}}$ should be flat drooping, and $U_{\text {o-c }}$ does not much exceed the set value of $U_{\mathrm{a}}$. It is rather difficult to prevent the oscillations of arc parameters. But if we «damp» them, we turn them into a tool of technology. How did we managed to do that? We powered arc simultaneously from two sources: with steeply drooping $\mathrm{VAC}_{\mathrm{s}}$ both for manual arc welding as well as with a flat drooping - as in mechanized one.

Since the change of electrical parameters - voltage and current in the welding process is pulsed, the proposed type of self-regulation was called pulsed [8].

One of the characteristic features of such an arc is its oscillatory character: the length of the arc decreases periodically - sometimes (if necessary) - to a short circuit, then it increases again (which is related to the detachment of an electrode metal drop formed at the end of melting electrode and its transfer to a metal pool). During the period of arc shortening (as a rule, it coincides with the period of formation of a molten metal drop at the end of the electrode) the welding current increases, and if a drop was not able to detach from the electrode, it touches a metal pool, «freezing» of the electrode does not occur due to the already jump-like increase in current at the moment as compared to a «normal» amplitude.

That period is essential during the cycle of arc length oscillation. Unlike the process of melting the electrode at a long arc, when a drop detaches from the end of the electrode and is transferred to the welding pool through the electrode gap, here, a drop «flows» from the end of the electrode directly into the metal pool. This occurs in welding on a short arc with periodic short circuits, and the melting of the electrode at such moments does not stop, otherwise, the electrode would «frozen» to a welded product. In contrast to a pure arc melting, here in the periods of short circuits another process occurs - contact melting [8]. The periods of arc and contact melting alternate with the frequency of short circuits of the electrode.

The process of contact melting can be controlled. For this purpose in the electrical circuit diagram of the power source it is necessary to provide a third component, so to speak, a third source. Its main characteristics are the following: low open-circuit voltage (not more than the sum of cathode and anode voltage drops), rigid volt-ampere characteristic, high short-circuit current.

Such an algorithm is extremely effective for mechanized arc welding at a constant electrode feed rate, where the minimum allowable current density at the electrode can be reduced by several times, and sometimes by an order of a value, as compared to traditional mechanized welding.

However, the same algorithm turned to be a quite useful and required for manual arc welding/surfacing by coated electrodes.

The affinity of algorithms of power source response on situation in the arc for mechanized arc welding/ surfacing on the one hand and for manual one on the other, opens a good perspective for building universal power sources suitable for both mechanized as well as manual arc welding with appropriate choice of parameters for power source response.

Moreover, it turns to be possible to create a power source for DC welding/surfacing (more precisely with a current of straight polarity) which is connected to a single-phase $220 \mathrm{~V}$ mains (in fact, «household» mains), which can attract the interest of a wide range of users and not only industrial enterprises. 


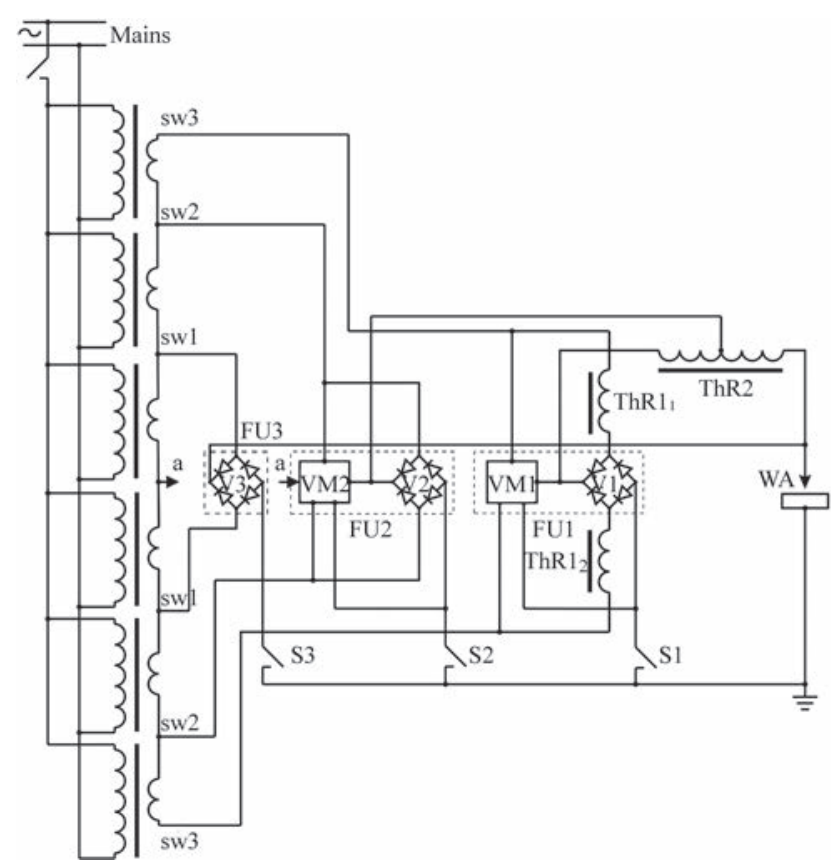

Figure 1. Scheme of the proposed «composed» power source

This paper presents the results of experiments using a source of straight polarity which is connected to the 220 $\mathrm{V}$ «household» mains based on, attention!, three transformers of serial production with a rigid volt-ampere characteristic and low open-circuit voltage of $14 \mathrm{~V}$ : two OSM1 - $1.0 \mathrm{kVA}$ and one OSM1 - $1.6 \mathrm{kVA}$.

Below, one of the variants of the scheme of the proposed «composed» power source in the variant with three low-voltage transformers on a secondary voltage of $14 \mathrm{~V}$ is given, which served as the basis for the three functional units FU of the «combined» source (Figure 1). Those units differ in the shapes of volt-ampere characteristics: the first has a steeply drooping shape with an elevated open-circuit voltage $U_{\text {o-c }}$ of the arc, which provides a constant arc burning at a low current at its increased voltage, the second flat drooping shape with a medium voltage $U_{\text {o-c }}$ which provides a steady burning of the arc at a set «working» current and the third one is with a rigid volt-ampere characteristic, which provides a «hot start» and contact electrode melting. Transformers are parallel-connected to the electric mains by primary windings and their secondary windings are series-connected, due to which their secondary voltage (open-circuit) is multiplied by the total number of secondary windings. Since each transformer has two secondary windings with a voltage of $14 \mathrm{~V}$ and there are 3 such transformers, the total open-circuit voltage of all the secondary windings is $84 \mathrm{~V}$. Together with the rectifying unit R1 and the voltage multiplier VM1, those windings form the functional unit FU1. The multiplier VM1 is used when it is necessary to additionally raise the $U_{\text {o-c }}$ of the source. A «steep drooping» of the VAC is created by the throttle $\mathrm{ThR}_{1}$ and additionally by the $\mathrm{ThR}_{2}$.
The second functional unit $\mathrm{FU}_{2}$ with a flat drooping VACh contains 4 series-connected secondary windings of transformers, rectifying unit R2, and a part of windings of the throttle $\mathrm{ThR}_{2}$.

The third functional unit FU3 with a rigid VAC contains 2 series-connected secondary windings of transformers and rectifying unit R3.

Again it should be noted that the mentioned voltage multipliers are used when in order to increase the process stability, it is necessary to raise the open-circuit voltage on the corresponding functional unit of the power source.

Since the experimental composed assembled power source has a single-phase connection and that in the periods of changing the polarity the current drops to zero, it can be assumed that the stability of the electrode melting process should be low, which makes the power source unsuitable for welding. However, the experiments have shown that this «non-standard» source provided a steady process both for manual welding as well as for mechanized one in carbon gas.

The coated electrodes were used, which are suitable both for DC welding (UONI-13/55, OZL-8) as well as for AC welding (ANO-24).

Simultaneously, for comparison, the experiments with the power from the serial rectifier VDU-306 were carried out.

The procedure of experiments consisted in the fact that in the process of arc burning with the help of the information-measuring system IBC, oscillograms of the arc current and voltage were recorded at a frequency of $10 \mathrm{kHz}$ (Figures 2, 3). The system processed those parameters by using the special software and on request it provided a graphical display of their specific values in the coordinates $U-I$, recorded at different moments (the latter was called the volt-ampere characteristic of the electrode melting process) (Figure 4). In addition, the system generated histograms of those parameters (a number of their fixed values depending on the amplitude) - Figure 5.

The interpretation of such patterns is given below.

Figure 2 presents the current and voltage oscillograms for the electrodes of the grade ANO-24 of 3 $\mathrm{mm}$ diameter with the power from the experimental source, and Figure 3 shows oscillograms for the electrodes OZL-8 of $3 \mathrm{~mm}$ diameter with a power both from the experimental source (Figure 3, $a$ ) and from the serial VDU-306 (Figure 3, b).

In the Figures one can see the «wave-form» nature of the oscillograms, especially, of the current ones.

As can be seen from Figure 2, the arc oscillations are not strictly periodic, their frequency ranges from $9 \mathrm{~Hz}$ (see the moment of $9.5 \mathrm{~s}$ ) to $23 \mathrm{~Hz}$ (the moment of $9.75 \mathrm{~s}$ ). Short circuits through electrode metal 

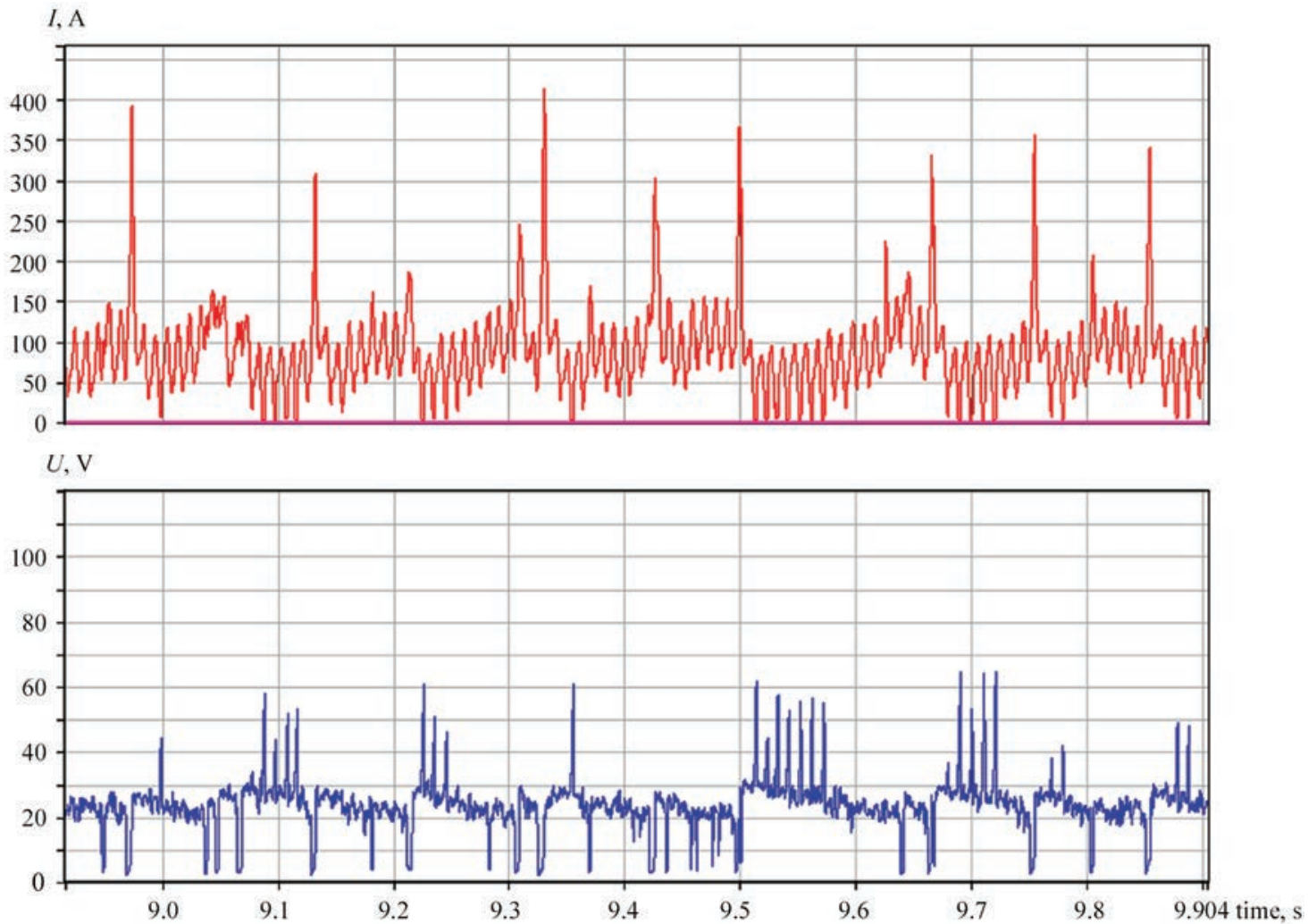

Figure 2. Current and voltage oscillograms of the process of welding using the electrodes of the grade ANO-24 of $3 \mathrm{~mm}$ diameter

drops occurred at $8.97 ; 9.136 ; 9.33$ s etc. At the time when the «ordinary» amplitude of the arc current was $150 \mathrm{~A}$, the value of the current pulses at the moment of closing a drop on a metal pool, as a rule, exceeded $250 \mathrm{~A}$ and reached $450 \mathrm{~A}$ (for example, the moment of $9.33 \mathrm{~s})$, despite the fact that an average current value was about $80 \mathrm{~A}$, i.e. the current pulses at the moments of short circuits exceeded the average current value by 3.0-5.6 times. Naturally, with such current pulses, «freezing» is out of the question.

A sawtooth pulsed nature of the oscillograms with a frequency of $100 \mathrm{~Hz}$ corresponds to the industrial frequency of current of $50 \mathrm{~Hz}$.

The welding voltage during the process of arc oscillation was within the range of $20-30 \mathrm{~V}$, except of some «moments»: to the values of about $4 \mathrm{~V}$ at short circuits.

The remarkable stability of the arc with such a «torn» shape of current and voltage oscillograms, which can be seen in Figure 2, contradicts with existing canonical notions about the arc stability: the continuity of current and voltage oscillograms at slight deviations from the mean value, especially with respect to arc voltage, and raises the problem of formulation of stability conditions for the electrode melting process during arc welding with a pulsed self-regulation of this process.

The oscillation process of electrode melting described above has a technological and industrial profit from several points of view.
First, the oxidation of electrode metal drop by the arc atmosphere is decreased by reducing the length of its «free run» through the arc gap. Secondly, the alternation during the cycle of oscillation of the arc of elevated current - at shortening, and elevated voltage - at elongation of the arc provides, on the one hand, reliable penetration of the base metal and on the other hand - acceptable formation of a weld bead. Thirdly, the shift of the mode to the region of lower voltages creates the prerequisites for reducing the electric power consumption (energy saving).

The latter is illustrated by the results of experiments with the use of electrodes OZL-8 of $3 \mathrm{~mm}$ diameter. Welding was performed from two sources alternatively (for comparison): from the experimental and serial VDU-306. In Figure 3, $a$ the oscillograms of current and voltage obtained during welding from the experimental source are shown, in Figure 3, $b$ - the same from the serial VDU-306 are shown. It is seen that as compared to the experimental source, the arc from VDU-306 is characterized by oscillations in current and voltage with negligible amplitudes, which indicates the welding mode on a long arc. The exceptions are episodes in the time intervals close to 8.59657 and $8.62 \mathrm{~s}$, and also between 8.84 and $8.86 \mathrm{~s}$ - short circuits through the electrode metal drops (frequency of short circuits is about $4 \mathrm{~Hz}$ ).

The comparison of volt-ampere characteristics of the processes (Figure 4, $a, b$ ) allows establishing sig- 

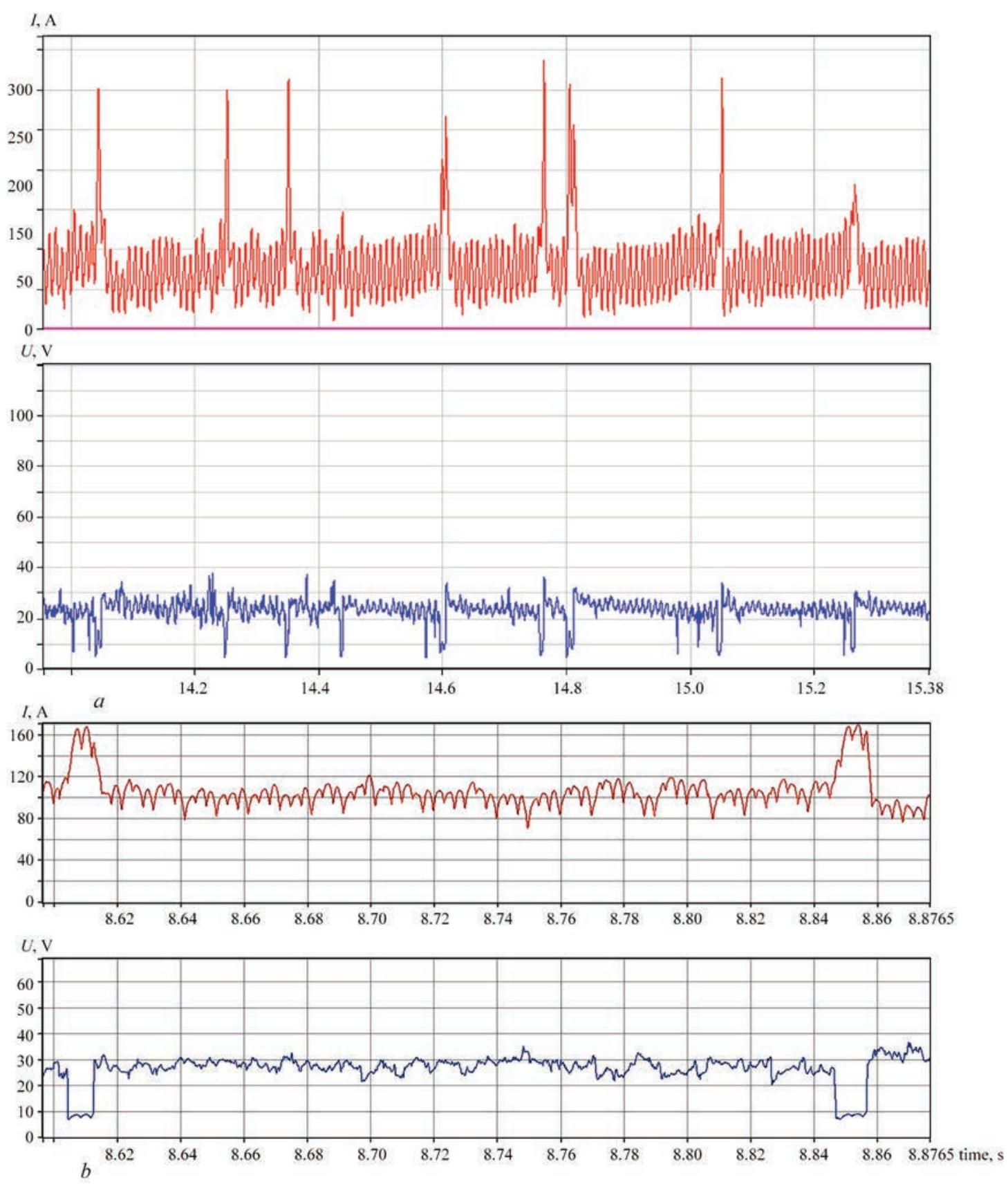

Figure 3. Current and voltage oscillograms obtained during welding from the experimental power source $(a)$ and the power source VDU-306 (b) using the electrodes OZL-8 with a diameter of $3 \mathrm{~mm}$

nificant differences between them. If during welding from VDU-306, the region of existing modes is located in the voltage interval of $18-38 \mathrm{~V}$ in the range of welding currents from 70 to $125 \mathrm{~A}$ at an average current value of about $97 \mathrm{~A}$ (Figure $4, b$ ), then the similar indicators for the experimental source are $13-30 \mathrm{~V}$, and the current is 30-160 A at a mean value of current of about $88 \mathrm{~A}$. It is seen that the region of modes from the experimental source is located much lower, than from VDU-306. Thus, at a current of $75 \mathrm{~A}$, the arc voltage was at different moments on the experimental source in the region from 13 to $30 \mathrm{~V}$ (on average $21.5 \mathrm{~V}$ ) (Figure 4, a), and from VDU-306 - respectively from 28 to $36 \mathrm{~V}$, on average $-32 \mathrm{~V}$, (Figure 4, b), i.e. almost 1.5 times higher. Accordingly, the energy consumption on the arc at the same current during welding from VDU-306 is 1.5 times higher than from the experimental source.

Another feature of the compared modes: during the use of the experimental source, the fraction of energy spent on melting the electrode at the moment of short circuits (which is called contact melting, that region of the melting mode is located separately in the lower part of the volt-ampere characteristic in the form of an ascending dark band) is much larger than from VDU306: here it covers the range of short circuit currents from 75 to 325 A, while from VDU-306 - it ranges from 115 to $170 \mathrm{~A}$. As far as the voltage drop at short 

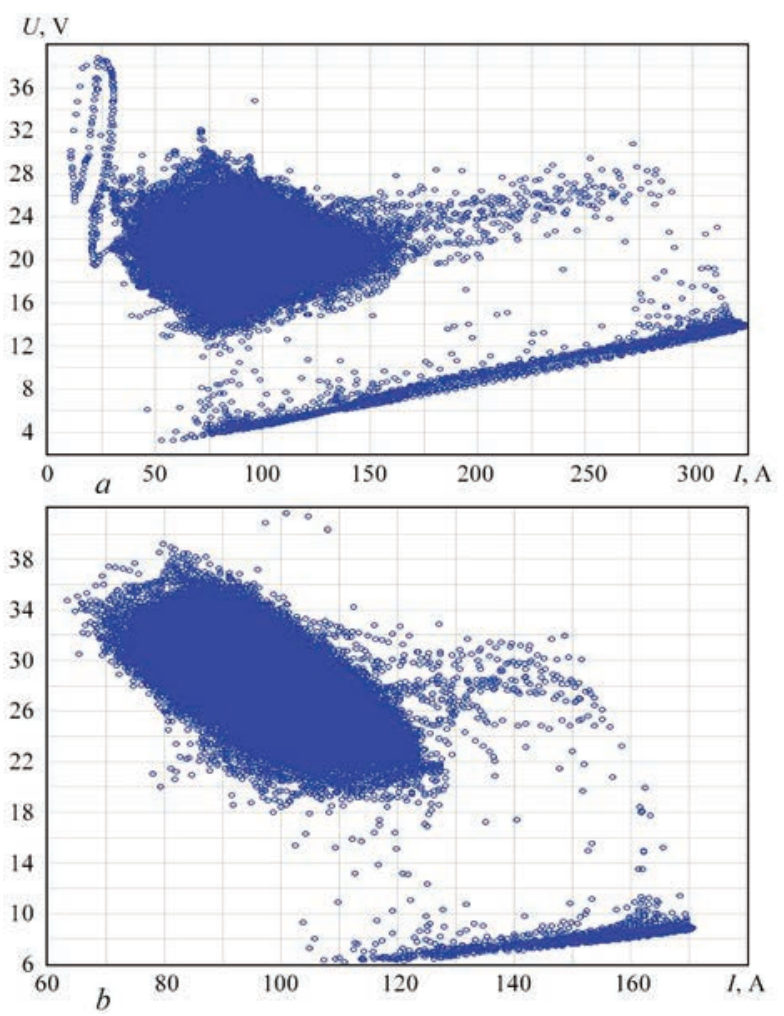

Figure 4. Volt-ampere characteristic of welding process from the experimental power source $(a)$ and the power source VDU-306 (b) using the electrodes OZL-8 with a diameter of $3 \mathrm{~mm}$

circuits is in 2.6-5.0 times less than that of the arcs at the same current values, the consumption on contact melting is lower than that on the arc. And this is an additional channel for saving electric power.

Below a table of characteristic arc parameters for experimental welding at the minimum «set» values of welding current for electrodes of different grades of $3 \mathrm{~mm}$ diameter with a forced arc break is given.

From the Table it follows that the «set» value of the low-ampere arc current during welding from the experimental source is significantly lower than the limit of its rated value for the three mentioned grades of electrodes given the fact, that the arc length at the moments of forced breaking is significantly larger than the standard value of $2-4 \mathrm{~mm}$.

It should be noted that in all cases of welding listed in the Table, the arc ignition was reliable (despite
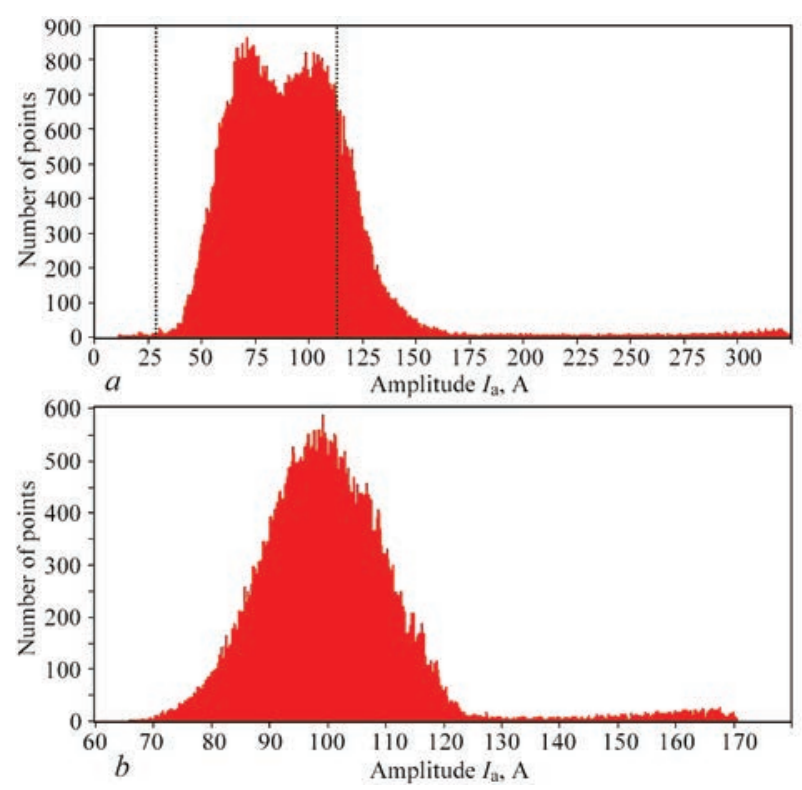

Figure 5. Histogram of current of welding process using the electrodes OZL-8 powered by the experimental power source $(a)$ and the power source VDU-306 of serial production $(b)$

a low «set» current value) and the arc burning was stable.

Here is just one variant of the technology being developed: manual arc welding. Some results of experiments using experimental («self-made») single-phase («household») DC source and the one assembled from products of serial production are shown: step-down transformers with a rigid volt-ampere characteristic, with a low open-circuit voltage of $14 \mathrm{~V}$, which is not inherent for welding technology (commonly used in control systems), diodes (possible thyristors), throttle, etc.

Today some other variants of the developed technology have been worked out: mechanized arc welding with a constant electrode wire feed rate, with twinned electrodes, with a combination of plate and wire electrode, etc.

Some encouraging results have been obtained: the burning of alloying elements and the consumption of electric power are reduced, the microstructure of weld metal and near-weld zone is refined, etc.

A part of the proposed technical solutions is protected by patents ([9], [15]).

Characteristic parameters of the arc during experimental welding

\begin{tabular}{|c|c|c|c|c|c|}
\hline \multirow{3}{*}{ Electrode grade } & \multicolumn{5}{|c|}{ Arc parameters } \\
\hline & \multicolumn{2}{|c|}{ «Set» values } & \multicolumn{3}{|c|}{ Values at the moment of arc break } \\
\hline & Arc current $I_{\mathrm{a}}$, A & Arc voltage $U_{\mathrm{a}}, \mathrm{V}$ & $\begin{array}{l}\text { «Breaking» length of } \\
\text { the } \operatorname{arc} L_{\mathrm{a}}, \mathrm{mm}\end{array}$ & $\begin{array}{c}\text { «Breaking» voltage } \\
U_{\text {b.a }}, \mathrm{V}\end{array}$ & $\begin{array}{c}\text { «Breaking» current } \\
I_{\mathrm{b} . \mathrm{a}} \mathrm{A}\end{array}$ \\
\hline ANO-24 & 63 & 23 & 18 & 38 & 36 \\
\hline UONI-13/55 & 68 & 23 & 16 & 40 & 40 \\
\hline OZL-8 & 68 & 23 & 14 & 40 & 40 \\
\hline
\end{tabular}


It can be noted that similar phenomenon is observed also in electroslag welding.

\section{Conclusions}

1. Experiments on welding using coated electrodes of different grades, powered by an experimental source, built in accordance with the principle of pulsed self-regulation of the arc, showed a good excitation of the arc, even under the condition of a small set rated current, which is provided by a higher value of short circuit current - up to $450 \mathrm{~A}$, as well as good arc stability, which is confirmed by its large length at the moment of forced breaking - up to $14-18 \mathrm{~mm}$ as compared to the normative value of the arc length of 2-4 mm, despite the fact that the arc current was below its rated value.

2. As far as the experiments were successful with the use of DC source (more precisely, current of direct polarity) powered by a single-phase 220V («household») mains, small enterprises and physical entities can be users of such a source and of the proposed technological solutions.

3. The technology assumes the ability to perform welding on currents substantially lower of their rated value, maintaining an excellent excitation and a good arc stability, which in some cases provides elimination of the use of scarce electrodes of small diameter.

4. The ability to vary the value of current over a wide range allows extending the technological capabilities of welding, including larger gaps between the edges, in different spatial positions, welding of dissimilar metals, surfacing, etc.

5. As the parameters of the arc at equal currents from the experimental source are displaced in comparison with VDU-306 in the region of lower voltages, the developed technology provides a real opportunity to save electric power.
1. Pogrebisky, D.M. (2016) Welding of metals: Classification, brief history, development. INSTY PRINTS, Jerusalem.

2. Bruce, D., DeRuntz (2003) Assessing the benefits of surface tension transfer ${ }^{\circledR}$ welding to industry. $J$. of Industrial Technology, 19 (4), 2-7.

3. Saraev, Yu.N. (1995) Development of adaptive pulsed technological processes of welding and surfacing: Syn. of Thesis for Dr. of Techn. Sci. Deg. Moscow, TsNIITMASh [in Russian].

4. Hacke, H., Himmelbauer, K. (2005) The CMT-process - a revolution in welding technology. IIW Doc. XII-1875-05.

5. Zhimihng, Ou, Yong, W., Masao, U., Manabu, T. (1999) New concept for the characteristic of an arc welding power source (Report II). Transact. JWRI, 28(1), 26-38.

6. Paton, E.O. (1956) Memoirs. Derzh. Vyd-vo Khud. Lit-ry, Kyiv [in Russian].

7. Paton, B.E. (1952) Self-regulation of arc welding using consumable electrode. Avtomatich. Svarka, 1, 38-45 [in Russian].

8. Paton, B., Sidoruk, V., Maksimov, S. (2016) Pulsed self regulation melting of electrode process. LAP LAMBERT Academic Publishing, Saarbruecken, Germany.

9. Paton, B.E., Krivtsun, I.V., Sydoruk, V.S. et al. (2014) Method of arc welding, surfacing and soldering using consumable electrode and current supply for its realization. Pat. Ukraine 104214 [in Ukrainian].

10. Paton, B.E., Sydoruk, V.S., Maksymov, S.Yu, Klochko, R.I. et al. (2014) Method of electric arc welding, soldering or remelting using consumable electrode by modulation of mode parameters. Pat. Ukraine 106293 [in Ukrainian].

11. Paton, B.E, Sydoruk, V.S., Maksymov, S. Yu. et al. (2015) Method of manual arc welding or surfacing with coated electrodes by modulation of arc parameters. Pat. Ukraine 110397 [in Ukrainian].

12. Maksymov, S. Yu., Sydoruk, V.S., Korotynskyi, O.A. et al. (2016) Method of manual arc welding or surfacing by modulated current with control of arc parameters. Pat. Ukraine 110556 [in Ukrainian].

13. Paton, B.E, Maksymov, S.Yu., Sydoruk, V.S. (2017) Method of electric arc mechanized welding in vertical and/or inclined positions with pulsed self regulation of electrode melting process. Pat. Ukraine 113883 [in Ukrainian].

14. Paton, B.E, Kolesnik, G.F., Maksymov, S.Yu. et al. (2017) Current supply for arc welding, surfacing or soldering using consumable electrode. Pat. Ukraine 114908 [in Russian].

15. Paton, B.E., Sydoruk, V.S., Maksymov, S.Yu. (2017) Current supply for arc welding, surfacing or soldering of remote structures. Pat. Ukraine 114938 [in Ukrainian].

Received 04.12.2019

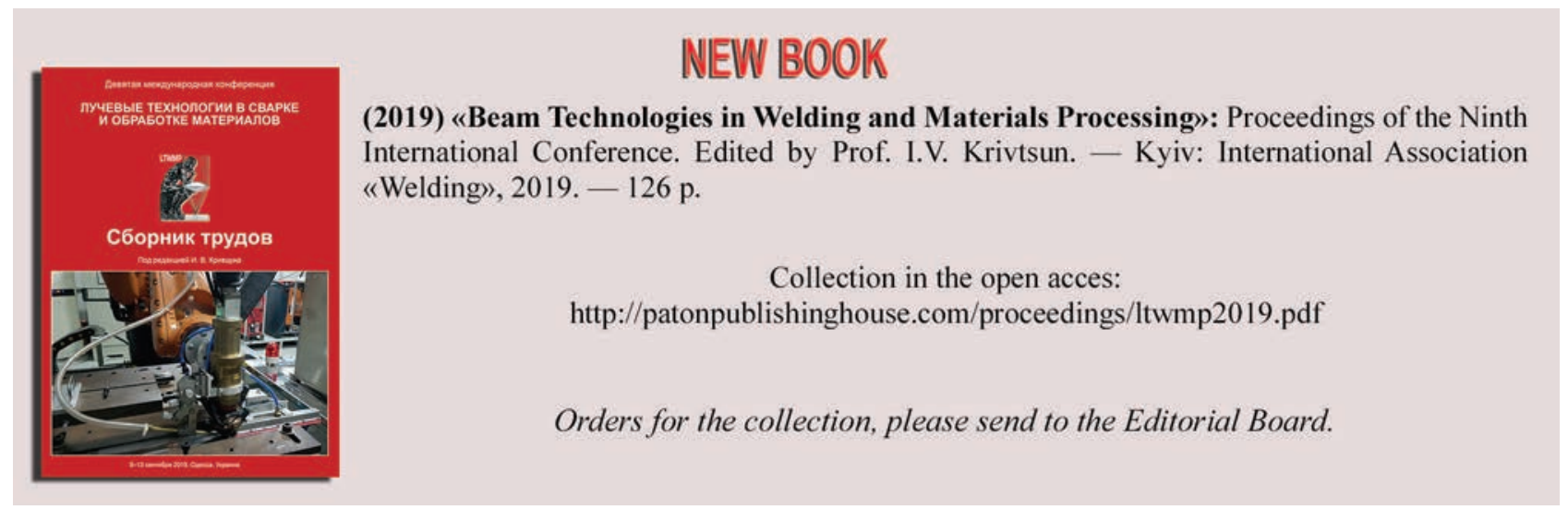




\title{
HYBRID LASER-MICROPLASMA WELDING OF STAINLESS STEELS*
}

\author{
I.V. KRIVTSUN ${ }^{1}$, V.N. KORZHIK ${ }^{1,2}$, V.Yu. KHASKIN ${ }^{1,2}$, Z. LO ${ }^{2}$ and E.V. ILLYASHENKO ${ }^{1}$ \\ ${ }^{1}$ E.O. Paton Electric Welding Institute of the NAS of Ukraine \\ 11 Kazymyr Malevych Str., 03150, Kyiv, Ukraine. E-mail: office@paton.kiev.ua \\ ${ }^{2}$ Guangdong Welding Institute (China-Ukraine E.O. Paton Institute of Welding) \\ 363 Changxing Str., Tianhe, 510650, Guangzhou. E-mail: wuby@gwi.gd.cn
}

\begin{abstract}
Hybrid laser-microplasma welding is one of the modern innovative processes of welding sheet stainless steels, allowing minimization of residual deformations, producing high-quality and durable joints. In this study, basic techniques of hybrid laser-microplasma welding were optimized, mode parameters were précised, and mechanical properties and corrosion resistance of the produced joints of SUS304 steel were assessed. The good prospects for application of laser-microplasma welding for joining thin stainless steels were confirmed experimentally. 6 Ref., 2 Tables, 10 Figures.
\end{abstract}

Ke y words : laser-microplasma welding, SUS304 stainless steel, filler wire, rate of energy input, strength, elongation, corrosion resistance, hybrid effect

Welded items from sheet stainless steels are manufactured by modern industry with the purpose of their application in the areas of engineering, associated with the need for operation of sufficiently strong structures, exposed to corrosion and certain mechanical impacts. Examples of such tasks are as follows: manufacturing household structures for conditions of marine climate or higher humidity, elements of hull structures of transport equipment (for instance, railway car bodies), expansion bellows for nuclear engineering, chemical and food industry equipment (for instance, tanks, filters), etc. Here, it is often necessary to perform butt welding of stainless steels up to $3.0 \mathrm{~mm}$ thick. As a rule, flash-butt [1] or argon-arc [2], more seldom plasma welding [3], are used to solve such tasks.

However, these welding processes by far not always allow achieving mechanical characteristics of the produced joints maximum close to those of the base metal, and also often do not meet the requirements of minimizing the residual welding deformations of sheet steels. Laser welding is one of the best welding methods today in terms of minimizing residual deformations, producing high-quality and durable welds [4]. However, because of comparatively high cost of laser equipment, this process has not become widely accepted now. One of the ways to lower the cost of laser equipment is reduction of radiation power due to its partial replacement by plasma-arc component in the welding process. Such a process is called hybrid laser-plasma welding [5]. If in this case the welded joint quality close to laser welding quality is preserved, we can get a new promising welding technology. Therefore, this work is devoted to investigation of the capabilities of hybrid laser-microplasma welding of sheet stainless steels in the case of SUS304 steel of thickness $\delta=0.3-3.0 \mathrm{~mm}$.

The objective of this work is optimizing the basic techniques of hybrid laser-microplasma welding of sheet stainless steels in the case of welding SUS304 steel, selection of mode parameters for such techniques, as well as checking the mechanical and corrosion properties of the produced joints.

Technological studies of the process of hybrid laser-microplasma welding of stainless steel SUS304 (08Kh18N10 analog) were conducted according to the scheme given in Figure 1. Experiments were performed with application of a disc laser with radiation wave length $\lambda=1.03 \mu \mathrm{m}$, the power of which was varied within $0.3-1.2 \mathrm{~kW}$. The focal spot diameter was of the order of $0.4 \mathrm{~mm}$. In the integrated coaxial direct action plasmatron of original design applied for studies, the laser radiation was combined with constricted low-amperage arc of up to $2.3 \mathrm{~kW}$ power [6]. In it the focused laser radiation and constricted arc were guided jointly through a common nozzle of $2.5 \mathrm{~mm}$ diameter to the sample being welded, located at the distance of the order of $3 \mathrm{~mm}$ from the nozzle edge. The focal plane of laser radiation was located at the depth of the order of $0.5 \mathrm{~mm}$ relative to the sample surface. There was a capability of filler wire feeding at the rate

*By materials of a report, presented at the International Conference «Beam Technologies in Welding and Materials Processing», September 9-13, 2019, Odessa. 


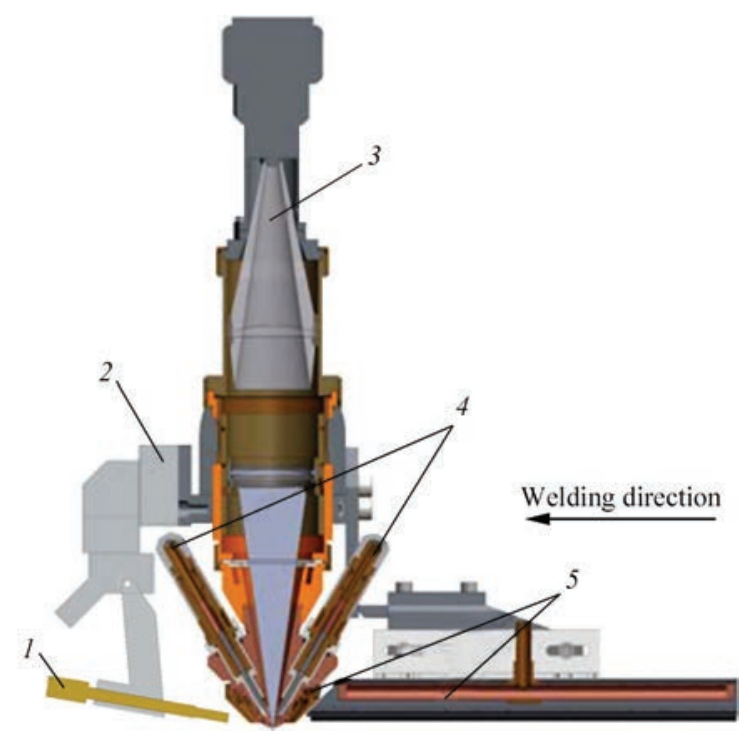

Figure 1. Scheme of integrated plasmatron and conducting the experiments: 1 - filler wire feed; 2 - attachment to the robot arm; 3 - feeding laser radiation of $0.3-1.2 \mathrm{~kW} ; 4$ - cathode assemblies; 5 - gas shielding

of $60-600 \mathrm{~m} / \mathrm{h}$. A continuous straight polarity electric arc was used in the experiments. Arc current of integrated microplasmatron was smoothly adjustable up to $80 \mathrm{~A}$ at arc voltage of up to $28 \mathrm{~V}$. SUS304 steel sheets of $(200-300) \times 100 \times \delta \mathrm{mm}$ size where $\delta=0.3 ; 0.5 ; 1.0$; $1.5 ; 3.0 \mathrm{~mm}$, were used as samples for butt welding and making penetration beads. ESAB OK Autrod 308L wire $(0.8 \mathrm{~mm}$ diameter) was applied as filler, which was fed at the rate of $60 \mathrm{~m} / \mathrm{h}$. Integrated plasmatron was moved relative to the sample being welded, using anthropomorphous robot KUKA KR30HA (Figure 2).

Conducted experiments showed the high stability of the process of laser-microplasma welding. In the case of hybrid butt welding of SUS304 steel sheets $(\delta=$ $3.0 \mathrm{~mm}$ ) with filler wire, positive results were obtained both with the gap of $0.5 \mathrm{~mm}$ between the edges being welded, and without the gap. Positive results by the cri-

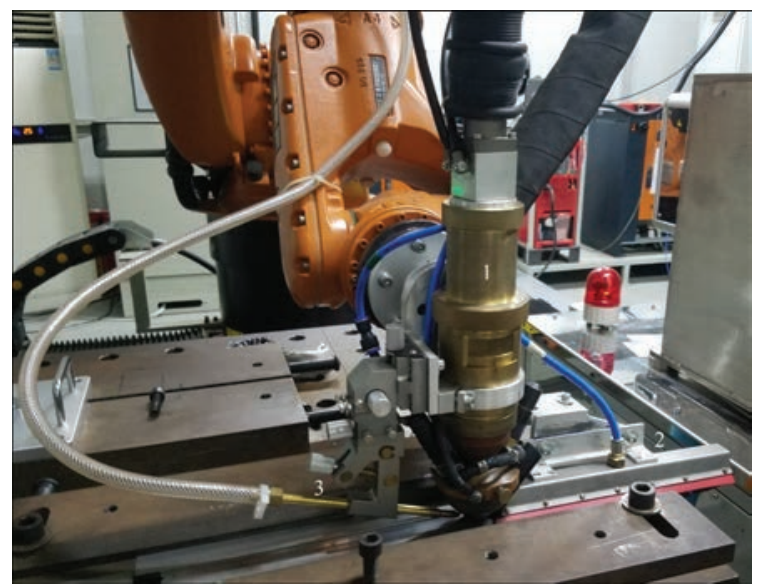

Figure 2. Appearance of the head for laser-microplasma welding in the arm of KUKA KR30HA robot: 1 - integrated plasmatron; 2 - system of formed weld shielding; 3 - nozzle for filler wire feeding
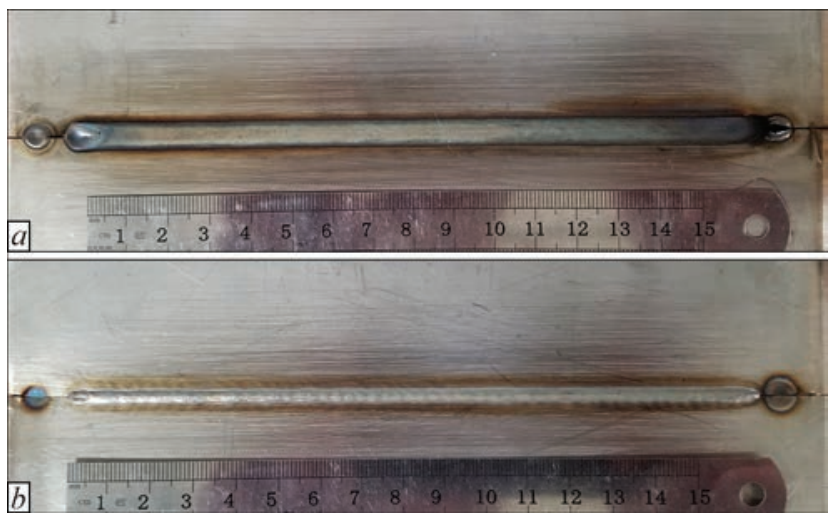

Figure 3. Appearance of SUS304 steel plates $(\delta=3.0 \mathrm{~mm})$, butt welded with a gap of $0.5 \mathrm{~mm}$ between the edges by laser-microplasma process (radiation power $P=1.2 \mathrm{~kW}$; welding current $I=$ $=80 \mathrm{~A}$; voltage $U=28 \mathrm{~V}$; welding speed $v=30 \mathrm{~m} / \mathrm{h}$ ): face $(a)$ and reverse $(b)$ sides

terion of formation of the top and reverse beads of the weld were obtained in a broad range of welding speeds from 30 up to $50 \mathrm{~m} / \mathrm{h}$. Here, acceptable results of welding without the gap between the edges were observed in the range of speeds of 30-40 m/h, and in welding with the gap - in the range of 40-50 $\mathrm{m} / \mathrm{h}$ (Figures 3, 4).

Performance of a number of experiments enables determination of the modes of hybrid butt welding of SUS304 steel sheets, both without application of filler wire (Table 1), and with its application (Table 2). These parameters were used for welding joints, from which samples of XIII (XIIIa) type (GOST 6996-66) for performance of mechanical testing and samples of an arbitrary shape for studying the corrosion resistance by weighting procedure were prepared. More over, when studying the process of laser-microplasma welding of SUS304 steel without filler wire application such parameters of the mode were established, which allow performance of sound welded joints without undercuts or weld sagging in the entire range of the considered thicknesses. One of the examples is the result of welding SUS304 steel of thickness $\delta=1.5 \mathrm{~mm}$, which is given in below and on Figures 5, 6.

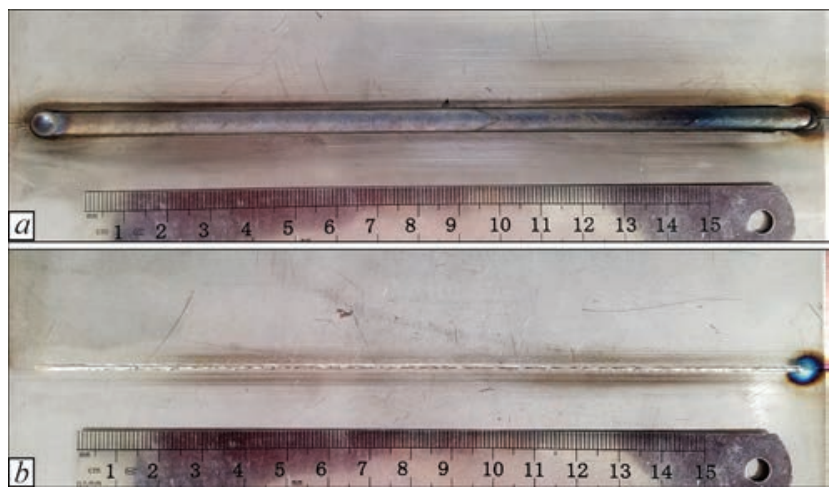

Figure 4. Appearance of SUS304 steel plates $(\delta=3.0 \mathrm{~mm})$, butt welded without a gap between the edges by laser-microplasma process (radiation power $P=1.2 \mathrm{~kW}$; welding current $I=80 \mathrm{~A}$; voltage $U=28 \mathrm{~V}$; welding speed $v=40 \mathrm{~m} / \mathrm{h}$ ): face ( $a$ ) and reverse sides $(b)$ 

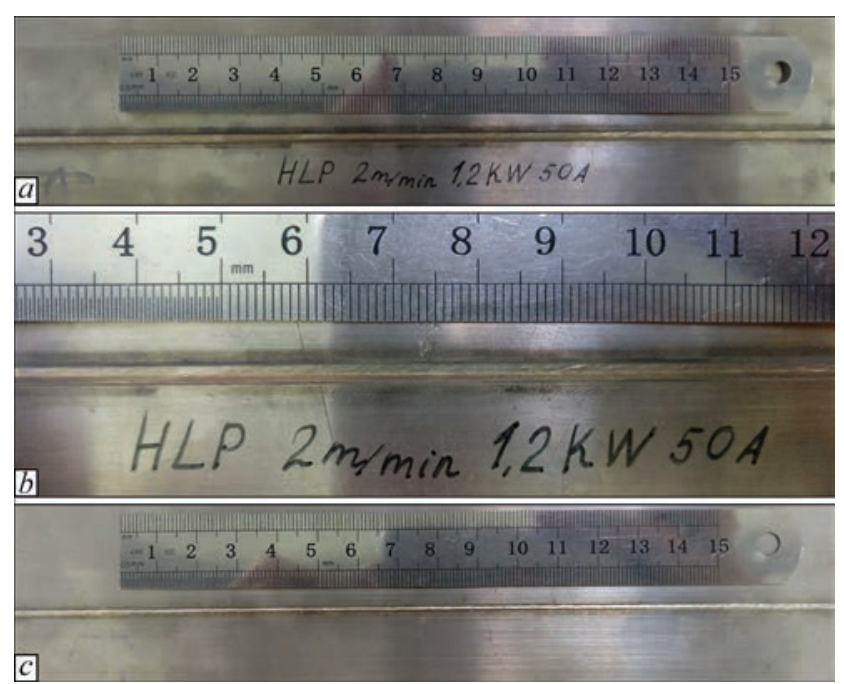

Figure 5. Welded sample of SUS304 $(\delta=1.5 \mathrm{~mm})$ : face $(a, b)$ and reverse $(c)$ sides

Mode and result of hybrid laser-microplasma welding of a defectfree joint of SUS304 steel $(\delta=1.5 \mathrm{~mm})$ without filler application

Laser power $P$, W . . . . . . . . . . . . . . . . . . . . 1200

Arc current $I$, A . . . . . . . . . . . . . . . . . . . . 50

Plasma gas flow rate $Q_{\mathrm{pl}}, 1 / \mathrm{min} \ldots \ldots \ldots \ldots \ldots \ldots \ldots$

Shielding gas flow rate $Q_{\text {sh }}, 1 /$ min $\ldots \ldots \ldots \ldots \ldots \ldots 10$

Welding speed $v, \mathrm{~m} / \mathrm{min} \ldots \ldots \ldots \ldots \ldots \ldots \ldots \ldots \ldots \ldots \ldots$

Gap from part to nozzle, $\mathrm{mm} \ldots \ldots \ldots \ldots \ldots \ldots \ldots$

Flow rate of additional shielding gas $Q_{\text {ad.sh }}, 1 / \min \ldots \ldots \ldots 20$

Flow rate of gas for weld root shielding $Q_{\text {rev }}, 1 / \min \ldots \ldots \ldots 20$

Width of weld face (upper) part, mm . . . . . . . . . . 2.1

Face side convexity, $\mathrm{mm} \ldots \ldots \ldots \ldots \ldots \ldots \ldots . \ldots \ldots . \ldots \ldots$

Weld reverse side (root) width, $\mathrm{mm} \ldots \ldots \ldots \ldots \ldots \ldots \ldots$

Weld reverse side (root) convexity, mm . . . . . . . . . 0.25

Two series of three samples each were cut out, in order to obtain the results of comparative mechanical testing of base metal and joint of SUS304 steel $(\delta=$ $=1.5 \mathrm{~mm}$ ), butt welded by laser-microplasma process without filler. One more series of four samples was cut out of welded by hybrid process butt joints of the same steel of thickness $\delta=1$ and $3 \mathrm{~mm}$ (two samples of each type). Tensile testing machine of MTS Criterion 45 type was used to perform static tensile tests of butt welds to determine the ultimate strength $\delta_{t}(\mathrm{MPa})$ and relative elongation $\delta(\%)$. Results measured for each sample series were averaged. Derived averaged values were used to plot the respective diagrams (Figure 7). As a result, it was established that strength of joints at hybrid laser-microplasma welding of SUS304 stainless steel is equal to about $96 \%$ of that of base metal, relative elongation of samples welded by such a process is $100 \%$ of base metal. The given values are satisfactory for the majority of the welding tasks.

Corrosion resistance testing of butt welded joints of SUS304 steel $(\delta=1.0 ; 1.5$ and $3.0 \mathrm{~mm}$ ), produced by laser-microplasma welding without filler wire, was performed by the weighting procedure. According to this procedure, templates (three samples for each case) of width close to that of the welds, were cut out of the

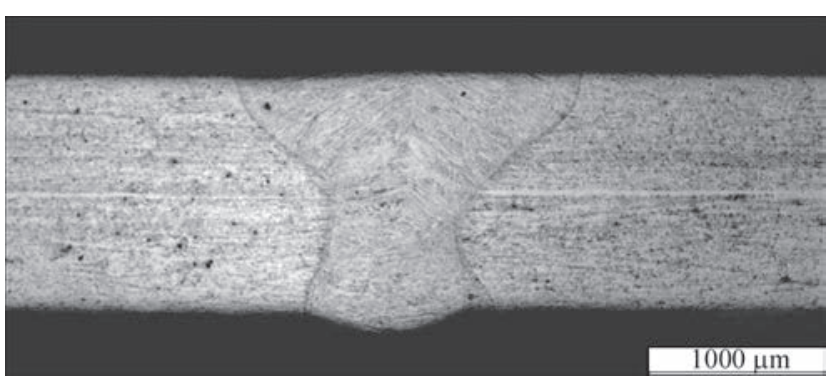

Figure 6. Macrostructure of butt joint of SUS304 steel $(\delta=1.5 \mathrm{~mm})$, made by laser-microplasma welding without filler wire

HAZ. Template size was $(5-10) \times(3-8) \times \delta \mathrm{mm}$. Thus, the template contained a certain part of the weld and $\mathrm{HAZ}$ at minimum proportion of base metal. Templates of close dimensions (reference samples) were cut out from base metal separately. Ready templates were weighed in analytical balance with the accuracy of up to $0.001 \mathrm{~g}$, which was followed by immersion into the so-called aqua regia - a mixture of $1 \mathrm{HNO}_{3}+2 \mathrm{HCl}$ acids. After a certain time (usually, 1-2 h), the samples were taken out, thoroughly rinsed and weighed once more. The extent of weight loss allows judging the rate of corrosion. Comparison of weight loss in reference sample from base metal with weight loss of welded sample allows determination of corrosion resistance of the latter.

Results of corrosion testing of the cutout samples are shown as diagrams in Figure 8. These results lead to the conclusion that all the obtained data are within the experimental error, and deviation of the values of weight loss of welded joints from the base metal is in the range of 3-4\%. Sample weight loss is within $0.7-0.8 \mathrm{~g} / \mathrm{h}$. Corrosion rate here is equal to (6-7) $10^{-3} \mathrm{~g} / \mathrm{min}$. The observed tendency of increase of samples weight loss with increase of their thickness is attributable to grain size growth and increase of the HAZ due to a higher rate of energy input in welding.

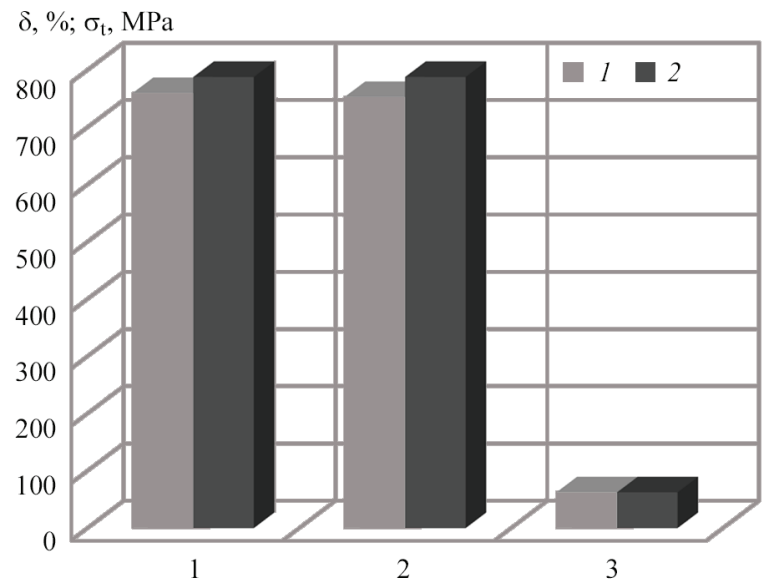

Figure 7. Comparative results of mechanical testing of samples of SUS304 steel (1) and base metal (2) welded by laser-microplasma process at their static tensile testing: 1 - averaged ultimate strength $\sigma_{\mathrm{t}}(\mathrm{MPa})$ for 1 and $3 \mathrm{~mm}$ thick samples; 2 - averaged ultimate strength $\sigma_{\mathrm{t}}(\mathrm{MPa})$ for $1.5 \mathrm{~mm}$ samples; 3 - relative elongation $\delta(\%)$ for all the cases 
Table 1. Modes and results of hybrid laser-microplasma welding of SUS304 sheet steel without filler wire application

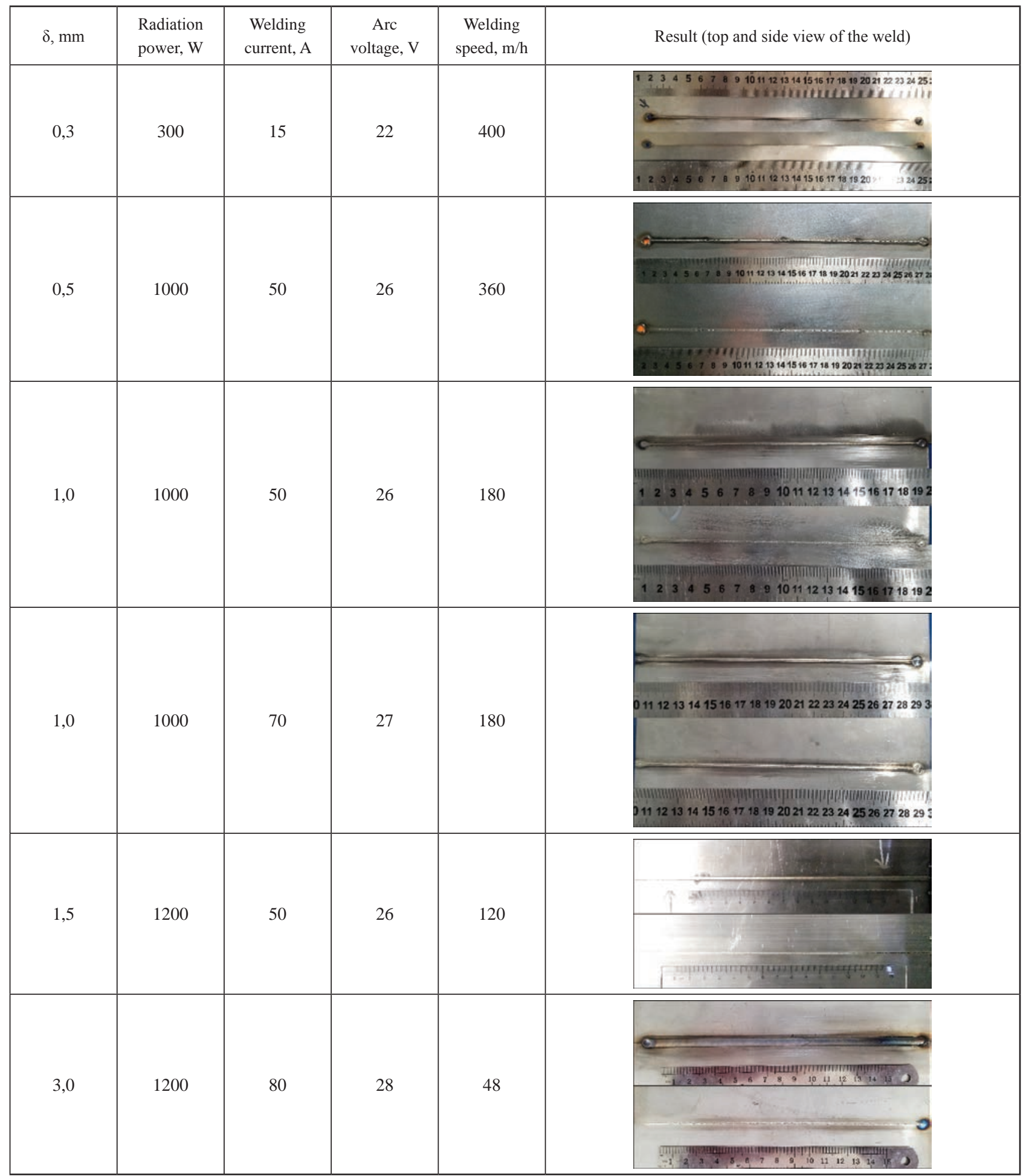

During analysis of the conducted technological studies, the rate of energy input of the process $(E, \mathrm{~J} / \mathrm{mm})$ was determined as a sum of powers of laser $(P, W)$ and microplasma (IU, W) components referred to welding speed $(v, \mathrm{~mm} / \mathrm{s})$. Calculation results were used to plot a dependence of the change of the rate of energy input in the two considered processes of laser-microplasma welding: with filler wire and without it (Figure 9). Comparison of curves 1 and 2, given in Figure 9, showed that the rate of the process energy input should be increased by $20-40 \%$ in the case of welding with closely abutted edges, and by $15-30 \%$ in the case of welding with a gap between the edges, in order to apply the filler wire. It is desirable for the value of such a gap to be of the order of $15-20 \%$ of the abutted edge thickness.

The following experiment was performed for comparison of the results of laser, microplasma and hybrid laser-microplasma welding. Laser-microplasma process without filler application was used to achieve 
Table 2. Modes and results of hybrid laser-microplasma welding of SUS304 sheet steel with filler wire application ( $0.8 \mathrm{~mm}$ diameter), fed at the speed of $60 \mathrm{~m} / \mathrm{h}$

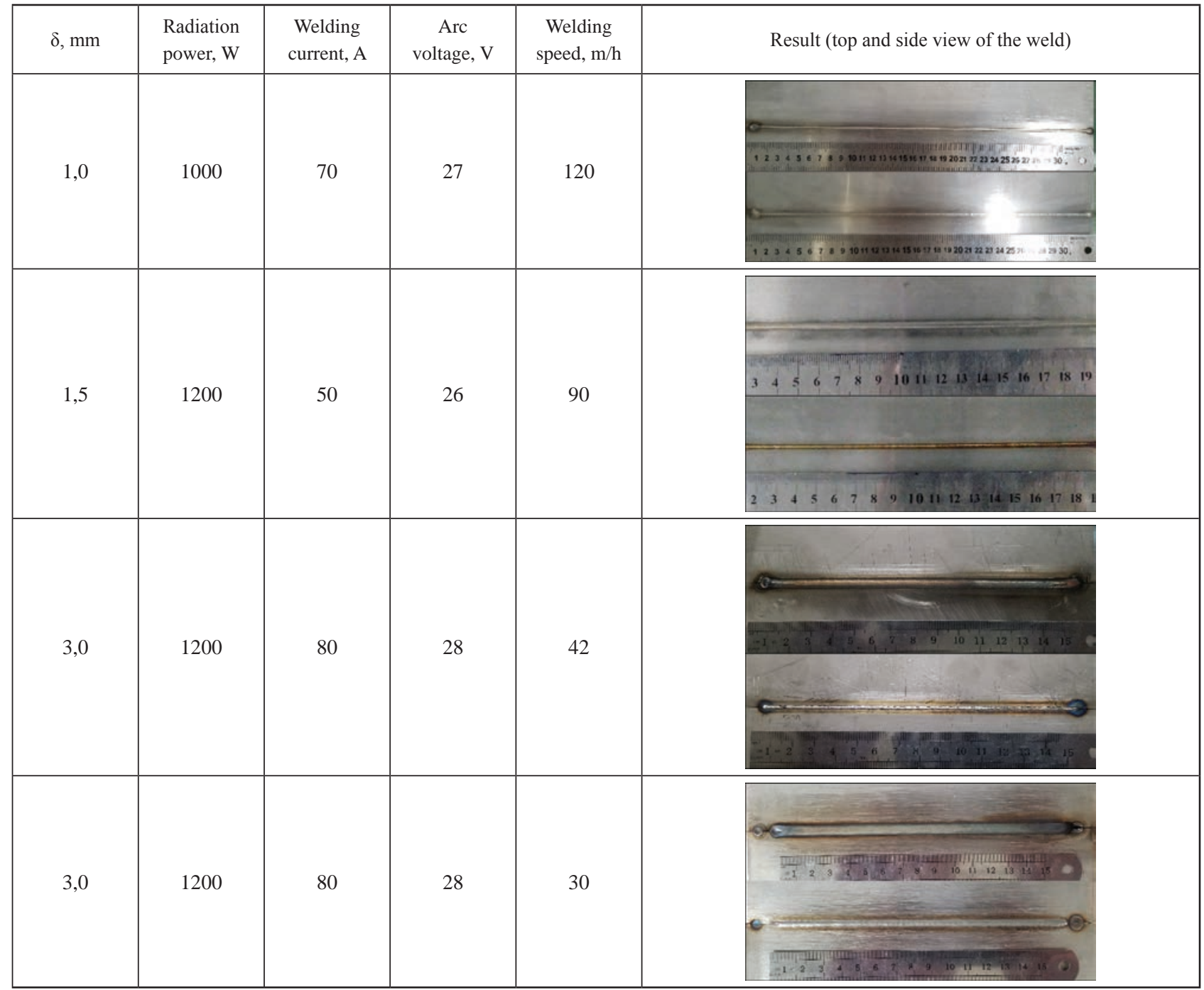

guaranteed penetration in a plate of SUS304 steel $\delta=$ $=3.0 \mathrm{~mm}$ ) in the following mode: $P=1200 \mathrm{~W}, I=$ $=80 \mathrm{~A} ; U=28 \mathrm{~V} ; v=45 \mathrm{~m} / \mathrm{h}$. Then two penetration beads were deposited by laser and microplasma processes (Figure 10) at the same speed and with the same

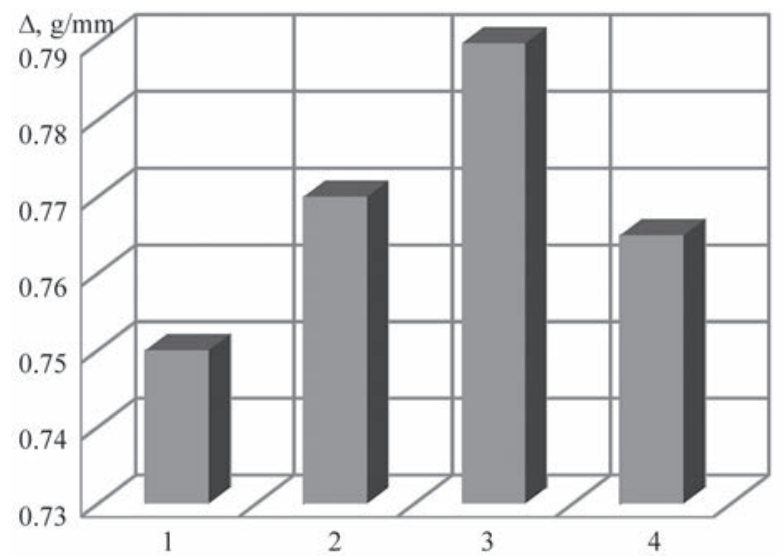

Figure 8. Averaged values of weight loss of samples from SUS304 steel $(\Delta): 1-\delta=1.0 \mathrm{~mm} ; 2-\delta=1.5 \mathrm{~mm} ; 3-\delta=3.0$ mm; 4 - base metal other parameters of the mode. Here the sum of the rates of energy inputs of the component processes corresponded to the rate of energy input in hybrid welding.

Investigation of the cross-sections of these penetration beads showed that the depth of penetration in

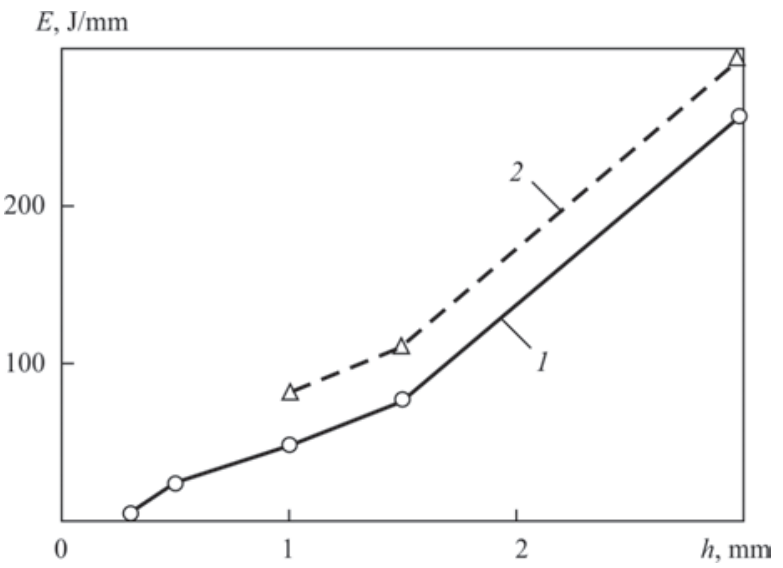

Figure 9. Dependencies of the rate of energy input $E(\mathrm{~J} / \mathrm{mm})$ of laser-microplasma welding without wire (1) and with wire (2) on thickness $h(\mathrm{~mm})$ of welded SUS304 steel 


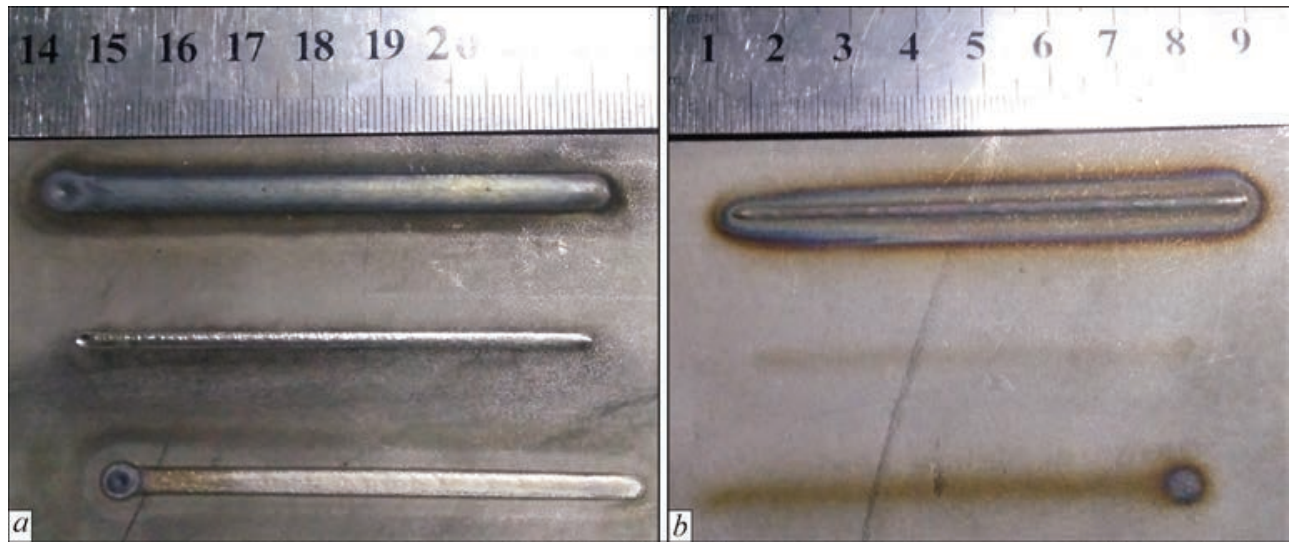

Figure 10. Appearance of face $(a)$ and reverse $(b)$ sides of penetrations in a plate of SUS304 steel of thickness $\delta=3.0 \mathrm{~mm}$ (top to bottom), hybrid, laser, microplasma

the hybrid process exceeds by approximately $25 \%$ the sum of penetration depths of laser and microplasma processes. This led to the conclusion about the presence of a pronounced hybrid effect in the case of laser-microplasma welding by the considered method.

\section{Conclusions}

1. During this work, hybrid laser-microplasma welding of sheet stainless steels was studied in the case of SUS304 steel without filler wire, and with its application. It was determined that application of filler wire is rational, starting from thicknesses not less than $1.0 \mathrm{~mm}$. Here, in order to achieve complete remelting of $0.8 \mathrm{~mm}$ wire in the case of welding with closely abutted edges, the rate of the process energy input should be increased by 20-40 \%, and in the case of welding with a gap between the edges - by $15-30 \%$. The size of the gap should be equal to a value of the order of $15-20 \%$ of the abutted edge thickness.

2. Determination of mechanical properties of the produced by hybrid laser-microplasma welding joints of SUS304 stainless steel showed that their static tensile strength is equal to about $96 \%$ of that of the base metal, and relative elongation is similar to this parameter of the base metal. The given values are acceptable for the majority of welding tasks.

3. Corrosion testing showed that deviation of the values of welded joint weight loss relative to base metal is within 3-4\%. Weight loss of the samples is within $0.7-0.8 \mathrm{~g} / \mathrm{h}$. Corrosion rate here is equal to (6-7) $\cdot 10^{-3} \mathrm{~g} / \mathrm{min}$. The extent of sample weight loss becomes greater with increase of their thickness that can be attributed to increase of grain size and HAZ, caused by increase of the rate of energy input in welding.

4. Comparative studies of beads made on SUS304 steel by laser, microplasma and hybrid processes showed that the penetration depth in hybrid process is by approximately $25 \%$ greater than the sum of penetration depths in laser and microplasma processes. Here, the sum of the rates of energy inputs of the component processes corresponded to the rate of energy input in hybrid welding. This is indicative of the presence of hybrid effect in the case of laser-microplasma welding.

The work was performed within project No.2018GDASCX-0803 «Research and development of laser and plasma technologies for hybrid welding and cutting», Guangzhou, China, as well as within special project No.2017GDASCX-0411 «Capacity Building of Innovation-Driven Development for Special Fund Projects» of the Programs of the Academy of Sciences of Guangdong Province (PRC) «Investigation of physico-chemical processes at interaction of vapour plasma with metals surface and development of scientific fundamentals of the technology of water-air plasma cutting of sheet steels for producing welded joints».

1. Banov, M.D. (2008) Technology and equipment for resistance welding: Manual for students of schools of vocat. educ. $3^{\text {rd }}$ ed. Moscow, Akademiya [in Russian].

2. Petrov, V.N. (1969) Welding and cutting of stainless steels. Leningrad, Sudostroenie [in Russian].

3. Sosnin, N.A., Ermakov, S.A., Topolyansky, P.A. (2008) Plasma technologies. Welding, coating, strengthening. Moscow, Mashinostroenie [in Russian].

4. Grigoryants, A.G., Shiganov, I.N. (1988) Laser engineering and technology. In: 7 Books. Book 5: Laser welding of metals: Manual for higher educ. instit. Ed. by A.G. Grigoryants. Moscow, Vysshaya Shkola [in Russian].

5. Krivtsun, I.V., Shelyagin, V.D., Khaskin, V.Yu. et al. (2007) Hybrid laser-plasma welding of aluminium alloys. The Paton Welding J., 5, 36-40.

6. Krivtsun, I.V., Korzhik, V.N., Khaskin, V.Yu. et al. (2017) Unit of new generation for laser-microplasma welding. In: Proc. of 8th Int. Conf. on Beam Technologies in Welding and Materials Processing. Ed. by I.V. Krivtsun. Kiev, IAW, 95-100. 


\title{
MODERNIZATION OF HEADS OF AUTOMATIC WELDING MACHINES FOR ORBITAL TIG-WELDING OF PIPELINES OF NPP POWER UNITS
}

\author{
L.M. LOBANOV ${ }^{1}$, N.M. MAKHLIN ${ }^{2}$, V.E. VODOLAZSKY ${ }^{2}$, V.E. POPOV ${ }^{2}$ and D.S. OLIYANENKO ${ }^{2}$ \\ ${ }^{1}$ E.O. Paton Electric Welding Institute of the NAS of Ukraine \\ 11 Kazymyr Malevych Str., 03150, Kyiv, Ukraine. E-mail: office@paton.kiev.ua \\ ${ }^{2} \mathrm{SE}$ «Scientific and Engineering Center of welding and control in the field of nuclear energy \\ of Ukraine of E.O. Paton Electric Welding Institute of the NAS of Ukraine» \\ 11, Kazymyr Malevych Str., 03150, Kyiv, Ukraine. E-mail: electro@paton.Kyiv.ua
}

\begin{abstract}
To the accuracy and reliability of actuating mechanisms of modern automatic machines for orbital (GTAW) welding of position joints of pipelines of NPP power units a number of specific requirements is made. In particular, they concern the largest diameters of faceplates of welding heads of such automatic machines, in which, as a rule, all or the most of those mechanisms are located. This paper describes the designs of actuating mechanisms of modern automatic machines for GTAW of position joints of NPP pipelines, designed at the Scientific and Engineering Center of welding and control in the field of nuclear energy. Designed were the mechanisms of clamping (fixation) of welding heads on a pipe being welded, the mechanism for arc length stabilization, the mechanism for rotation (rotator) of faceplate around the axis of pipes to be welded, the mechanism for automatic regulation of arc voltage, the mechanism for oscillation of nonconsumable electrode (across the weld) and the mechanism for filler wire feed. The results of industrial operation of some automatic machines for GTAW, designed at the Scientific and Engineering Center of welding and control in the field of nuclear energy, are presented, in which the described mechanisms are used. The aim of this work is to present the results of works carried out at the Scientific and Engineering Center of welding and control in the field of nuclear energy in the direction of creating components of automatic machines for GTAW of position joints of thin-walled pipelines of steels from austenite, pearlite classes, carbon steels and alloys of nonferrous metals (except aluminum and its alloys). 11 Ref., 2 Tables, 6 Figures.
\end{abstract}

Ke yw ord s : automatic orbital arc welding, nonconsumable electrode, inert gases, welding head, faceplate, actuating mechanisms, faceplate rotator, nonconsumable electrode oscillator, filler wire

One of the basic requirements to welding heads of automatic machines of a hinge type for GTAW is the minimum possible diameter of their rotating parts (faceplates), which is explained by the need in providing GTAW of position pipeline joints under the conditions of actual distances between the pipes existing at NPPs. Therefore, the creation of welding heads capable of operating in a wide range of outer diameters of welded pipelines is not possible, which demands dividing this range into subranges taking into account the diameters of pipelines used in the Ukrainian nuclear power industry.

The earlier investigations carried out at the Research and Design Institute of Installation Technology (NIKIMT) (Moscow) [1, 2] found that for welding of position joints of thin-walled pipelines (widely used during assembly, repair and modernization of NPP power units) applying the GTAW method, the most acceptable methods are autopressing, successive penetration or antipressing, which can significantly simplify the design of the corresponding welding equipment, including welding heads. The experience of NIKIMT and other organizations, which took into account the influence of the maximum permissible deviations of parameters of automatic arc orbital GTAW method of position pipe joints on the quality of welded joints [3, 4], served as the basis for designing domestic orbital automatic machines for GTAW and their mechanisms at the Scientific and Engineering Center of welding and control in the field of nuclear energy. It should be noted that in the direction of designing and manufacturing of orbital automatic

\footnotetext{
${ }^{*}$ Engineers N.S. Fedorenko, V.L. Kobryansky, V.M. Gavva, A.D. Cherednik, A.V. Tkachenko, V.Yu. Buryak and E.V. Kunkina (Scientific and Engineering Center of welding and control in the field of nuclear energy) took an active part in the designing of welding machine heads for GTAW.
} 
Table 1. Some basic parameters and characteristics of welding heads in welding automatic machines for GTAW using the methods of auto-moulding, sequential penetration or anti-moulding

\begin{tabular}{|c|c|c|c|c|c|}
\hline \multirow[b]{2}{*}{ Number } & \multirow[b]{2}{*}{$\begin{array}{l}\text { Description of parameter, } \\
\text { characteristics }\end{array}$} & \multicolumn{4}{|c|}{ Welding head (brand or designation and developer/manufacturer) } \\
\hline & & $\begin{array}{c}\text { ADTs 627.03.00.000 } \\
\text { (for welding in argon), } \\
\text { Ukraine, Scientific } \\
\text { and Engineering Center } \\
\text { of welding and control } \\
\text { in the field of nuclear } \\
\text { energy }\end{array}$ & $\begin{array}{c}\text { ADTs 627.03.00.000-01 } \\
\text { (for welding in helium), } \\
\text { Ukraine, Scientific } \\
\text { and Engineering Center } \\
\text { of welding and control } \\
\text { in the field of nuclear } \\
\text { energy }\end{array}$ & $\begin{array}{c}\text { ADTs 625.03.00.000 } \\
\text { (for welding in argon), } \\
\text { Ukraine, Scientific } \\
\text { and Engineering Center } \\
\text { of welding and control } \\
\text { in the field of nuclear } \\
\text { energy }\end{array}$ & $\begin{array}{c}\text { ADTs } 626.03 .00 .000 \\
\text { (for welding in argon), } \\
\text { Ukraine, Scientific } \\
\text { and Engineering Center } \\
\text { of welding and control } \\
\text { in the field of nuclear } \\
\text { energy }\end{array}$ \\
\hline 1 & $\begin{array}{l}\text { Minimum diameter of welded } \\
\text { pipe, mm }\end{array}$ & 7 & 7 & 18 & 42 \\
\hline 2 & $\begin{array}{l}\text { Maximum diameter of welded } \\
\text { pipe, } \mathrm{mm}\end{array}$ & 24 & 24 & 42 & 76 \\
\hline 3 & Maximum welding current, $\mathrm{A}$ & 140 & 140 & 160 & 200 \\
\hline 4 & $\begin{array}{l}\text { Range of welding speed } \\
\text { control, } \mathrm{m} / \mathrm{h}\end{array}$ & \multicolumn{2}{|c|}{$0.42-48.80$} & $1.9-33.5$ & $4.0-39.6$ \\
\hline 5 & $\begin{array}{l}\text { Diameter of nonconsumable } \\
\text { (tungsten) electrode, mm }\end{array}$ & \multicolumn{2}{|c|}{1.6} & \multicolumn{2}{|c|}{$2.0-3.0$} \\
\hline 6 & $\begin{array}{l}\text { Radius of rotating parts, mm, } \\
\text { not more than }\end{array}$ & \multicolumn{2}{|c|}{50} & 70 & 86 \\
\hline 7 & Electrode cooling & \multicolumn{4}{|c|}{ Gas } \\
\hline 8 & $\begin{array}{l}\text { Arc voltage stabilization } \\
\text { system }\end{array}$ & \multicolumn{2}{|c|}{ Mechanical coppier stabilizer (ALS) } & \multicolumn{2}{|c|}{ Automatic arc voltage regulator (AAVR) } \\
\hline 9 & $\begin{array}{l}\text { Overall dimensions: } \\
\text { length, mm, not more than } \\
\text { width, mm, not more than } \\
\text { height, mm, not more than }\end{array}$ & \multicolumn{2}{|c|}{$\begin{array}{l}110 \\
285 \\
280 \\
\end{array}$} & $\begin{array}{l}142 \\
285 \\
357 \\
\end{array}$ & $\begin{array}{l}178 \\
330 \\
357 \\
\end{array}$ \\
\hline 10 & $\begin{array}{l}\text { Head mass (without communi- } \\
\text { cation cables and hoses), kg, } \\
\text { not more than }\end{array}$ & \multicolumn{2}{|c|}{3.00} & 3.50 & 4.30 \\
\hline
\end{tabular}

Table 1. Cont.

\begin{tabular}{|c|c|c|c|c|c|}
\hline \multirow[b]{2}{*}{ Number } & \multirow[b]{2}{*}{$\begin{array}{l}\text { Description of parameter, } \\
\text { characteristics }\end{array}$} & \multicolumn{4}{|c|}{ Welding head (brand or designation and developer/manufacturer) } \\
\hline & & $\begin{array}{l}\text { ODA-1s (for welding } \\
\text { in argon), Russia, } \\
\text { NIKIMT }\end{array}$ & $\begin{array}{l}\text { ODA-2s (for welding } \\
\text { in argon), Russia, } \\
\text { NIKIMT }\end{array}$ & $\begin{array}{l}\text { ODA-3s (for welding } \\
\text { in argon), Russia, } \\
\text { NIKIMT }\end{array}$ & $\begin{array}{c}\text { MU-IV 8/38 P } \\
\text { (for welding in argon), } \\
\text { France, Polysoude }\end{array}$ \\
\hline 1 & $\begin{array}{l}\text { Minimum diameter of welded } \\
\text { pipe, mm }\end{array}$ & 8 & 20 & 42 & 8 \\
\hline 2 & $\begin{array}{l}\text { Maximum diameter of welded } \\
\text { pipe, mm }\end{array}$ & 26 & 42 & 76 & 38 \\
\hline 3 & Maximum welding current, A & 100 & 160 & 200 & 180 \\
\hline 4 & $\begin{array}{l}\text { Range of welding speed } \\
\text { control, } \mathrm{m} / \mathrm{h}\end{array}$ & $6.0-23.0$ & \multicolumn{2}{|c|}{$6.0-30.0$} & $0.5-40.0$ \\
\hline 5 & $\begin{array}{l}\text { Diameter of nonconsumable } \\
\text { (tungsten) electrode, mm }\end{array}$ & \multicolumn{2}{|c|}{$2.0-3.0$} & \multicolumn{2}{|c|}{$2.0-4.0$} \\
\hline 6 & $\begin{array}{l}\text { Radius of rotating parts, mm, } \\
\text { not more than }\end{array}$ & 40 & 55 & 90 & 63 \\
\hline 7 & Electrode cooling & \multicolumn{4}{|c|}{ Water } \\
\hline 8 & $\begin{array}{l}\text { Arc voltage stabilization } \\
\text { system }\end{array}$ & $\begin{array}{c}\text { Mechanical copying } \\
\text { stabilizer (ALS) }\end{array}$ & \multicolumn{3}{|c|}{ Automatic arc voltage regulator (AAVR) } \\
\hline 9 & $\begin{array}{l}\text { Overall dimensions: } \\
\text { length, mm, not more than } \\
\text { width, mm, not more than } \\
\text { height, mm, not more than }\end{array}$ & $\begin{array}{c}81 \\
146 \\
235 \\
\end{array}$ & $\begin{array}{l}100 \\
180 \\
250\end{array}$ & $\begin{array}{l}155 \\
190 \\
355 \\
\end{array}$ & $\begin{array}{l}112 \\
152 \\
282\end{array}$ \\
\hline 10 & $\begin{array}{l}\text { Head mass (without communi- } \\
\text { cation cables and hoses), kg, } \\
\text { not more than }\end{array}$ & 3.70 & 5.70 & 11.70 & 3.25 \\
\hline
\end{tabular}


machines for GTAW, considerable successes were achieved by such well-known companies as ARC MACHINES, INC and DIMETRICS, INC (USA), POLYSOUDE (France), ESAB (Sweden), SIEMENS and GES. M.B.H» (Germany), RTA (Italy), NIKIMT (Russia) and others.

Table 1 presents some of the basic comparative parameters and characteristics of welding heads designed and manufactured by different companies available at the market, which are widely used in Ukraine and Russia in the machines for GTAW of thin-walled metal pipelines of NPP power units applying autopressing, successive penetration or antipressing.

To the features of welding heads ADTs 627.03.00.000, ADTs 627.03.00. 000-01, ADTs 625.03.00.000 and ADTs 626.03.00.000 designed at the Scientific and Engineering Center for welding and control in the field of nuclear energy, which are applied for GTAW of thin-walled metal pipelines by the methods of auto-moulding, successive penetration or anti-moulding, one can attribute the possibility of using them to perform step-pulse welding and modulated current welding while maintaining a constant rotation speed of their faceplates (welding speed), which significantly extends the technological capabilities of designed domestic automatic machines for GTAW. Another feature of these welding heads is the ability to use the same control system with controllers of mechanism drives, which allows not only providing a preliminary setting and smooth regulation (programming) of the values of parameters of the welding cycles and modes, but also setting a number of fully circumferential arc passes (from 1 to 4 ), as well as reversing the direction of faceplates rotation after a certain number of such passes [5-9].

The welding head ADTs 627.03.00.000-01 is designed for operation in a controlled environment (mainly in helium) with an axis inclined by $15^{\circ}$ (angular degrees) of a nonconsumable electrode relative to the vertical to a product being welded and differs from the welding head ADTs 627.03.00.000 only by an insulator through which the torch ADTs 627.03.02.000 with a nonconsumable electrode is mounted, a type of electric plugs and a gas fitting pipe of current and gas supply, which provides a connection of a head for its operation inside a sealed chamber with a controlled environment.

Figure 1 shows a general view of welding heads ADTs 627.03.00.000, ADTs 625.03.00.000 and ADTs 626.03.00.000. In more detail, the general view of welding heads ADTs 627.03.00.000 and ADTs 627.03.00.000-01 is shown in Figure 2. On the output gear of head reducer rotator 1 , faceplate 5 is mount-

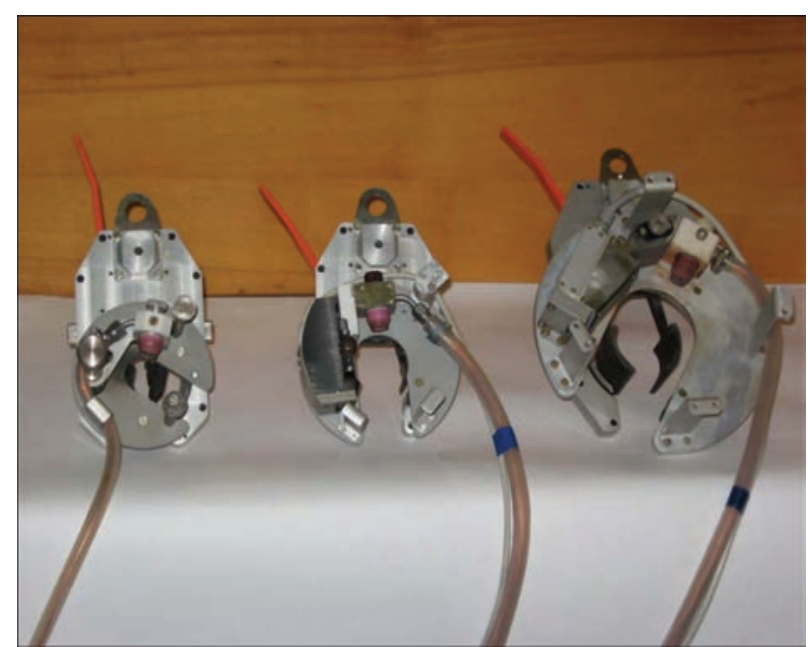

Figure 1. General view of welding heads ADTs 627.03.00.000, ADTs 625.03.00.000 and ADTs 626.03.00.000 on the side of their faceplates

ed. On the faceplate, lever 2 of copying stabilizer, torch with nonconsumable electrode, the spatial position of which is fixed (including the «stickout») by means of flywheel 3 , copying scheme 8 , two supports 6 for laying current gas supply inlet and support 7 for its fixation («predeformation») are mounted. Lever 2 includes copying screw 8 , lever itself 9 , nut with flywheel 10 made of electrical insulation material, casing 11 , and also axis, sleeve and spring attached

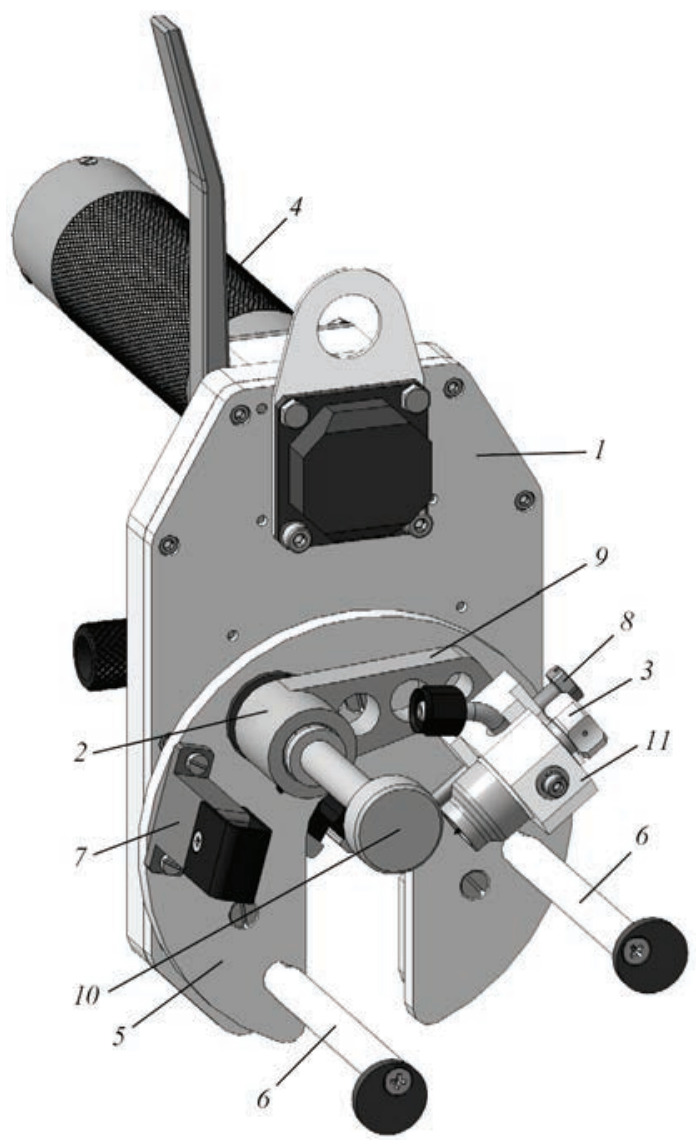

Figure 2. General view of welding head ADTs 627.03.00.000 (ADTs 627.03.00.000-01) on the side of faceplate (4 - handle is hollow, other designations see in the text) 
to faceplate and interacting with nut 10 . Casing 11 provides a fixation of torch with nonconsumable electrode in it and its electrical insulation from the potential of faceplate 5 , and, therefore, from the potential of a pipeline being welded. The axis included in lever 2 provides its rotation at a certain angle in the plane of faceplate 5 , which provides an additional convenience when performing the operations of setting the welding head ADTs 627.03.00.000 (ADTs 627.03.00.000-01) on a pipeline being welded and its removing from the pipeline, as well as during the adjustment and maintenance of torch with nonconsumable electrode. Nut 10 is designed to fix lever 2 in the working position or its release when it is necessary to perform its rotation. Copying screw 8 provides setting the length of an interelectrode gap (length of welding arc) required for welding process and its maintenance (by means of lever spring 2) with an accuracy of not worse than $\pm 0.2 \mathrm{~mm}$ when faceplate 5 is rotated around the pipeline to be welded.

The mechanisms of rotation and clamping (fixing) of all welding heads designed at the Scientific and Engineering Center of welding and control in the field of nuclear energy, as well as AAVR head mechanisms are designed according to single unified schemes and for rotation mechanisms they differ only by the power of gear motor and reduction coefficient for each head

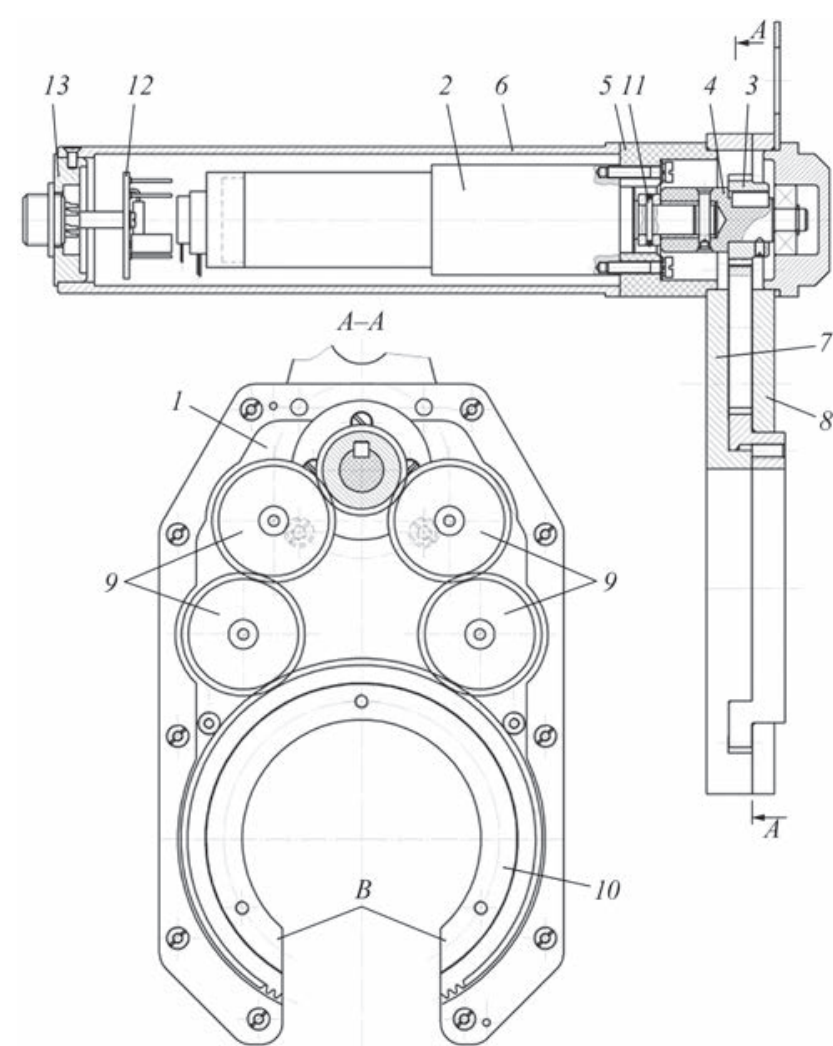

Figure 3. General view of rotator of all models of welding heads designed at the Scientific and Engineering Center of welding and control in the field of nuclear energy (on the side of their clamping mechanism (designations see in the text) model, and for clamping (fixing) mechanisms on the pipe being welded they differ by the geometry and gripping area. The rotation mechanisms of a number of heads are driven with the help of unified adjustable reversive electric drives, produced on gear motors 2657 W 024 CR 30/1 of «Faul Haber» and encoders (speed sensors for shaft rotation of electric motors) of Kübler Company, generating 125 or 128 pulses per one full revolution of a motor shaft. The control of such drives is considered in detail in [8]. Figure 3 shows a general view of rotators of all head models designed at the Scientific and Engineering Center of welding and control in the field of nuclear energy. The transmission of a torque from the output shaft of gear motor of drive 2 to drive gear 3 of reducing gear 1 of welding head is carried out by means of shaft 4 . Protection of drive 2 from the effect of electrical potentials that may occur on the assemblies and parts of reducing gear 1 is provided both by means of shaft 4 , as well as by intermediate piece 5 made of an insulating material, and protection from the action of mechanical environmental factors is performed with the help of cylindrical handle 6 , in which, in addition to drive 2, limiting filter 12 and plug 13 for connecting communication cable to rotator are located. Reducing gear 1 of the welding head includes casing 7 , cover 8 of the casing, set of gears 9 and output gear 10. In order to provide mounting of welding heads on pipes of «infinite» length, casing 7 , cover 8 and output gear 10 and faceplate are made with a slot $B$. Output gear 10 of reducing gear 1 is meshed with two gears of the set of gears 9 , which provides a smooth and continuous rotation of output gear 10 regardless of its angular position relative to its two orthogonal axes (axes of the plane perpendicular to the longitudinal axis of a pipeline being welded). The other two gears of the set of gears 9 are meshed with drive gear 3 , mounted on shaft 4 by means of a key connection. Shaft 4 is manufactured in the form of a cylindrical body of revolution made of an insulating material, which is attached to the output shaft of drive 2 using the inner steel sleeve and pin 11 . Pin 11 protects drive 2 from exceeding the maximum allowable load value - when reaching or exceeding this value, pin 11 is cut off and should be replaced after eliminating the causes of excessive load. On output gear 10, faceplate is installed.

Since during designing automatic machines ADTs 627 U3.1, ADTs 625 U3.1, ADTs 626 U3.1, ADTs 628 UKhL4, ADTs 629 UKhL4 and ADTs 630 UKhL4 for GTAW the most progressive world experience in this direction and technological capabilities of domestic production were taken into account, clamping (fixing) mechanisms designed at the Scientific and Engineer- 


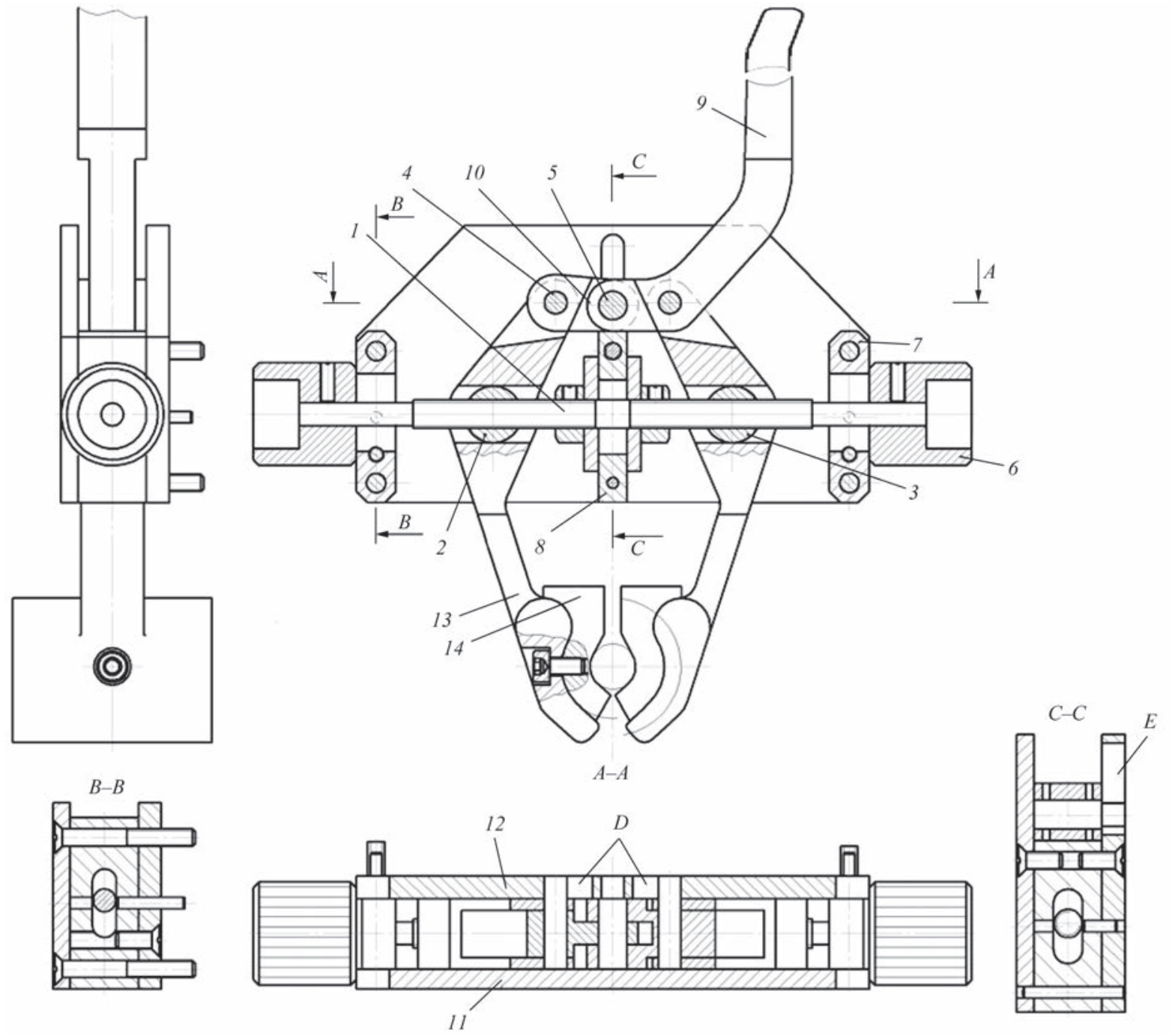

Figure 4. General view of clamping mechanism in all models of welding heads (designations see in the text) designed at the Scientific and Engineering Center of welding and control in the field of nuclear energy

ing Center of welding and control in the field of nuclear energy, welding heads on a pipe to be welded are in many respects resemble to the mechanisms of a similar purpose produced by Polysoude (France). The basis of this technical solution was the properties of a «breaking» lever. A general view of the mechanisms for clamping welding heads designed at the Scientific and Engineering Center of welding and control in the field of nuclear energy is shown in Figure 4. The clamping mechanism consists of screw 7 , nuts 2 and 3 , axes 4 and 5 , flywheels 6 , supports 7 and 8 , lever 9 , connecting rod 10 , cheeks 11 and 12 , grips 13 and inserts 14 . Screw 1 is made in the form of a pin, having a right-hand thread on a one end and a left-hand thread on the other. Nut 2 installed in one of the grips 13 also has a right-hand thread, and nut 3 installed in the other grip 13 has a left-hand thread. When screw 1 is rotated (using flywheels 6), the grips 13 converge or diverge, depending on the direction of rotation of flywheels 6 . In addition, with the help of axes 4 , grips 13 are connected with lever 9 , which, in turn, is con- nected to connecting rod 10 with the help of axis 5 . Since two slots $D$ and one slot $E$ are provided in cheek 12 , when lever 9 is rotated, axes 4 acquire the ability to move in the slots $D$, and axis 5 - in the slot $E$. At the same time grips 13 are rotated around the nuts 2 and 3. In one of the possible extreme positions of lever 9 , axes 4 will be shifted down (in the vertical direction) by $0.5 \mathrm{~mm}$ relative to axis 5 , as a result of which the clamping mechanism will come to a state, in which it turns out to be kinematically closed. Taking into account the design and kinematic diagram of the clamping mechanism for fixing the welding head on a pipeline to be welded, the head should be mounted on a pipeline to be welded, lever 9 of the clamping mechanism should be moved to the extreme left position and flywheels 6 should be half-way rotated in the direction providing bringing grips 13 into a contact with the outer surface of a pipeline to be welded, after which lever 9 is set to the extreme right position and flywheels 6 are turned in a half-turn in the direction that provides convergence of grips 13, and lever 9 is 


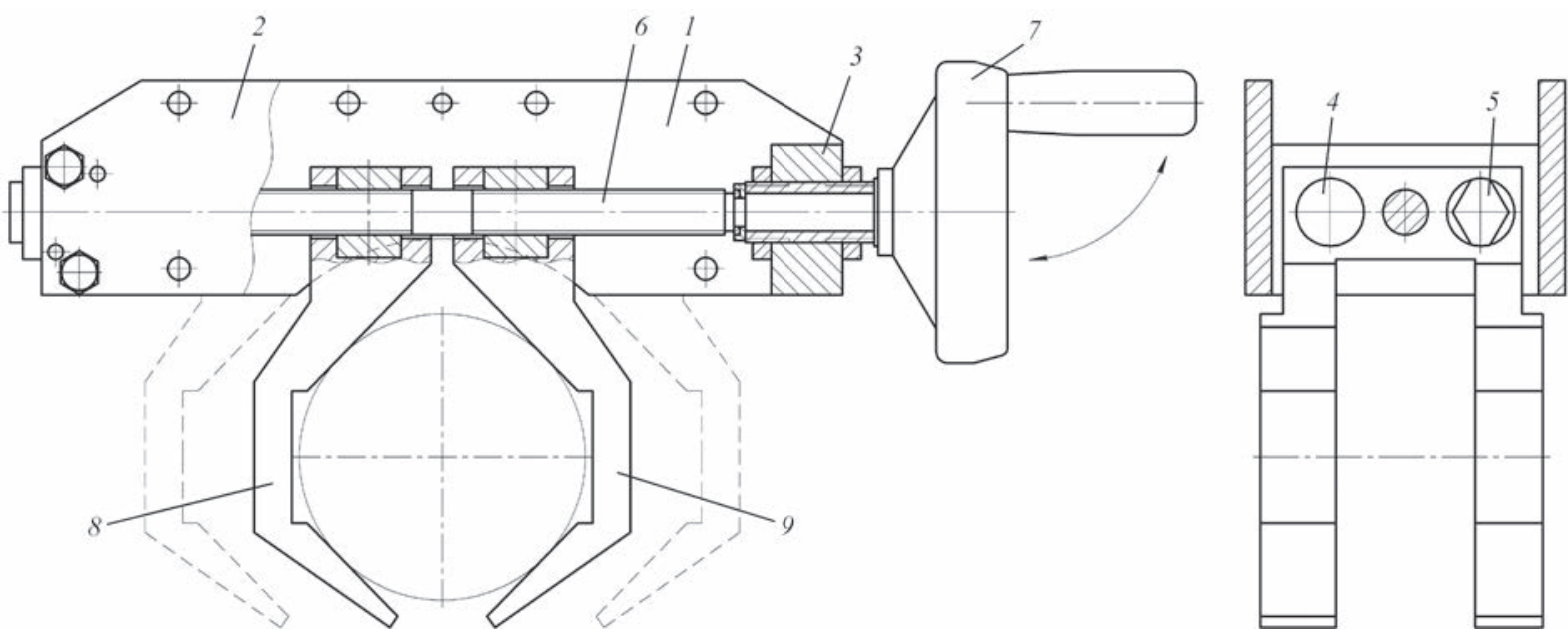

Figure 5. General view of alternative clamping mechanisms for all models of welding heads (designations see in the text) designed at the Scientific and Engineering Center of welding and control in the field of nuclear energy

moved (with a click) to the extreme left position. Then it is necessary to check the reliability of fixing of the welding head on a pipeline being welded and in case of insufficient clamping of the head, repeat all the operations of its fixing in the abovementioned sequence.

However, in the process of introduction and pilot operation of automatic machines ADTs 627 U3.1, ADTs 625 U3.1 and ADTs 626 U3.1 for GTAW, the disadvantages in the clamping mechanisms of welding heads were revealed, a general view of which is shown in Figure 4. The most significant drawbacks of such clamping mechanisms include the need for their preliminary adjustment on specimens, whose outer diameter is the same or very close to the outer diameter of a pipeline to be welded, high requirements to the absence of ovality of its outer surface, impossibility of achieving accuracy of alignment of the welding head on a pipeline being welded, which predetermine the necessity of using AAVR, the need in providing the smallest possible distance between the pipes to orient a certain spatial position of the welding head due to the presence of lever 9 in its clamping mechanism. The alternative clamping mechanisms, designed in 2017-2019 at the Scientific and Engineering Center of welding and control in the field of nuclear energy, the general view of which (typical) is shown in Figure 5, taking into account the experience of NIKIMT and other organizations, to a large extent are deprived of the noted drawbacks. As is seen from the Figure, the proposed clamping mechanism consists of two base plates 1 and 2, separated by supports 3 . Along the guides 4 and 5 , one of which is made tetrahedral, by means of screw 6 having a right and left-hand thread on its own opposite ends and rotating by flywheel 7 with a throwing up handle, clamps (prisms) 8 and 9 can move in two opposite directions. One of the advantages of this technical solution is the preservation of the radii of rotating parts of welding heads, the val- ues of which are given in Tables 1 and 2. To other advantages the fact should be attributed, that due to the exact performance of working surfaces of the clamps and their synchronous movement, converging and diverging, as well as the possibility of adjusting the position of the axis of the clamping mechanism relative to the axis of rotation of the welding head with a subsequent fixation of that position during its assembly, the proposed clamping mechanism provides an accurate alignment of the welding head on a pipe being welded. Moreover, there is no need in maintaining the set arc length in the welding process (for example, using the ALS or AAVR device).

At the same time, for regulating, presetting (programming) and automatic maintaining the arc voltage stable during welding in accordance with the set value and the selected algorithm of welding cycle in welding heads ADTs 625.03.00.000 and ADTs 626.03.00.000, the unified device AAVR is provided. The mechanism of this device represents a fixed casing, in which parallel to the plane of faceplates of the mentioned welding heads a low-power reversible direct current gear motor (for example, 1524 T 024 SR IE2 - 128 $16 / 7$ of «Faul Haber») is located. By means of a gear, output shaft of gear motor is connected with actuating screw installed in the fixed casing of the AAVR mechanism, which provides the conversion of the rotational motion of the shaft of the gear motor (in either of two possible directions) into the reciprocating motion of actuating screw, causing a corresponding linear movement of slider along the two fixed cylindrical guides. In its turn, through the metal bracket and insulator (made of electrical insulating material), slider is rigidly connected to the welding torch body, which makes it possible to move this torch along the axis that coincides with the axis of nonconsumable electrode installed in the torch in one of two possible directions. The choice of this direction during practicing of a pre- 
determined welding cycle occurs automatically and depends on the sign of the error signal, determined by the mismatch of the actual and set (programmed) values of the arc voltage $[4,9]$. To prevent damage of reducing gear of the AAVR mechanism when its slider is located in one of the extreme positions, actuating screw of this mechanism is equipped with a protective coupling. A detailed description of operation of the controller performing control of the operation of the AAVR device of welding heads ADTs 625.03.00.000 and ADTs 626.03.00.000 is given in [8].

The automatic machines ADTs 627 U3.1, ADTs 625 U3.1 and ADTs 626 U3.1 for GTAW of position joints of metal pipelines, containing the drives described above, not only successfully passed the complex technological and operational tests at the E.O. Paton Electric Welding Institute of the NAS of Ukraine and at the Scientific and Engineering Center of welding and control in the field of nuclear energy, but also passed the pilot tests at the Atomenergomash, the Design Bureau Atomprylad of the SE NNEC Energoatom and also at the TISER LLC. Moreover, the pilot models of automatic machines ADTs 627 U3.1 with welding heads ADTs 627. 03. 00. 000 and ADTs 627. 03. 00. 000-01 are in operation from 2010 to the present day. The results of pilot testing are positive. At present time, at the Scientific and Engineering Center of welding and control in the field of nuclear energy, the complex technological and operational tests of automatic machines ADTs 628 UKhL4, ADTs 629 UKhL4 and ADTs 630 UKhL4 for GTAW of position joints of metal pipelines with oscillations of nonconsumable electrode and mechanized filler wire feed are being completed.

The mechanisms of rotation and clamping of welding heads ADTs 628.03.00.000, ADTs 629.03.00.000 and ADTs 630.03.00.000 for GTAW are manufactured similarly to the same mechanisms of welding heads ADTs 627. 03. 00. 000, ADTs 627.03.00. 000-01, ADTs 625.03.00.000 and ADTs 626.03. 00. 000 , while the rotation mechanisms of welding heads ADTs 628.03.00.000, ADTs 629.03.00.000 and ADTs 630.03.00.000 use the same limiting filters and the principles of design of reducing gears as in welding heads ADTs 627. 03. 00. 000, ADTs 627. 03. 00.00001, ADTs 625. 03. 00. 000 and ADTs 626. 03. 00.000, and clamping mechanisms differ from the latter only by grips. A general view of a typical design of welding heads ADTs 628.03.00.000, ADTs 629.03.00.000 and ADTs 630.03.00.000 is shown in Figure 6. Table 2 shows some of the basic comparative parameters and characteristics of the heads, proposed by the market, which are used in machines for GTAW of metal pipe-

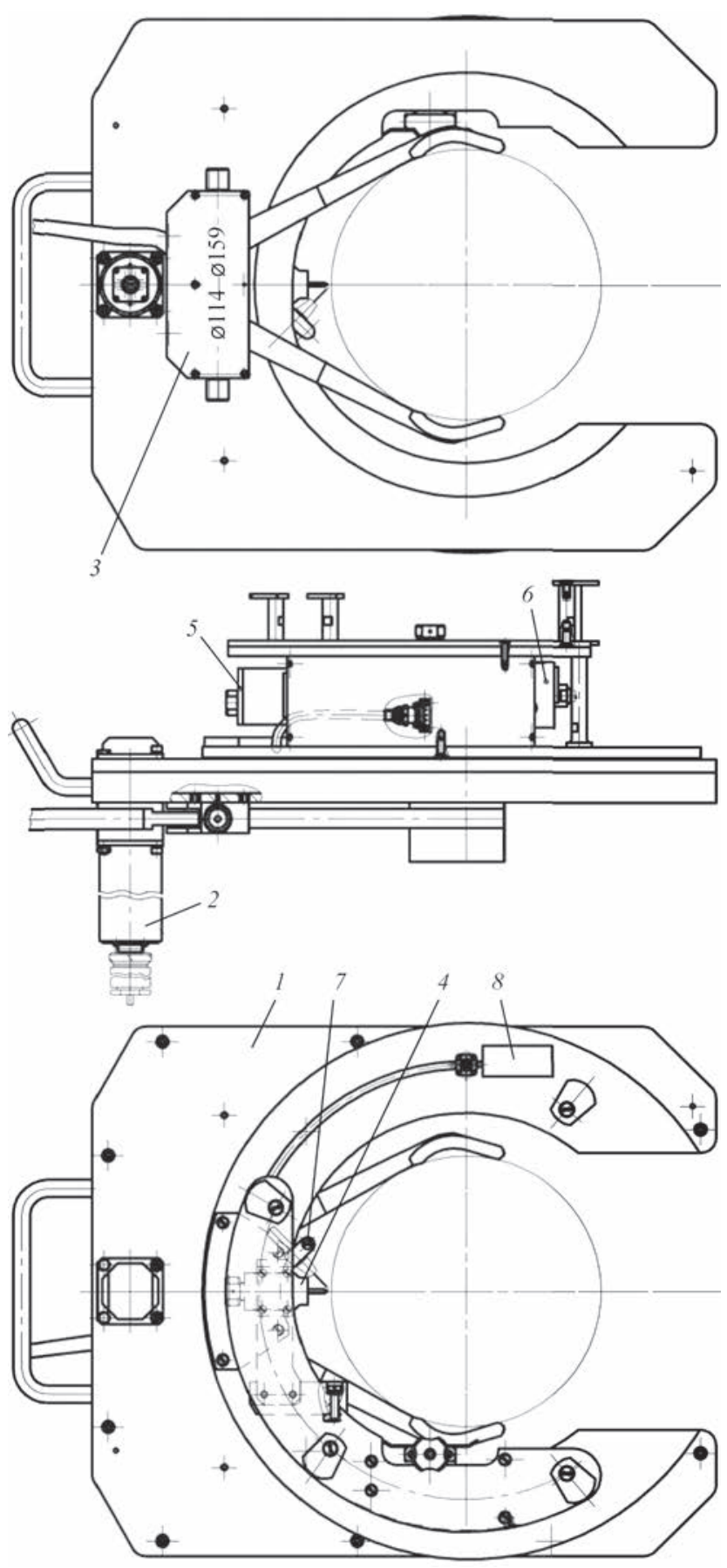

Figure 6. Typical general view of welding heads ADTs 628.03.00.000, ADTs 629.03.00.000 and ADTs 630.03.00.000: 1 - casing; 2 - rotation mechanism (rotator); 3 - mechanism for clamping (fixing) welding head on a pipe being welded; 4 torch; 5 - AAVR mechanism; 6 - mechanism of transverse movement of nonconsumable electrode (oscillator); 7 - liner; 8 - sensor of spatial (angular) position of nonconsumable electrode

lines with oscillations of nonconsumable electrode and filler wire feed designed and manufactured by different companies [6, 10, 11].

The feature of welding heads ADTs 627.03.0.000, ADTs 629.03.00.000 and ADTs 626.03.0.000 is that in addition to the actuating mechanisms mounted in the fixed casings of these heads and on their faceplates (torch, 
Table 2. Some basic parameters and characteristics of welding heads in welding automatic machines for GTAW with the oscillations of nonconsumable electrode and filler wire feed

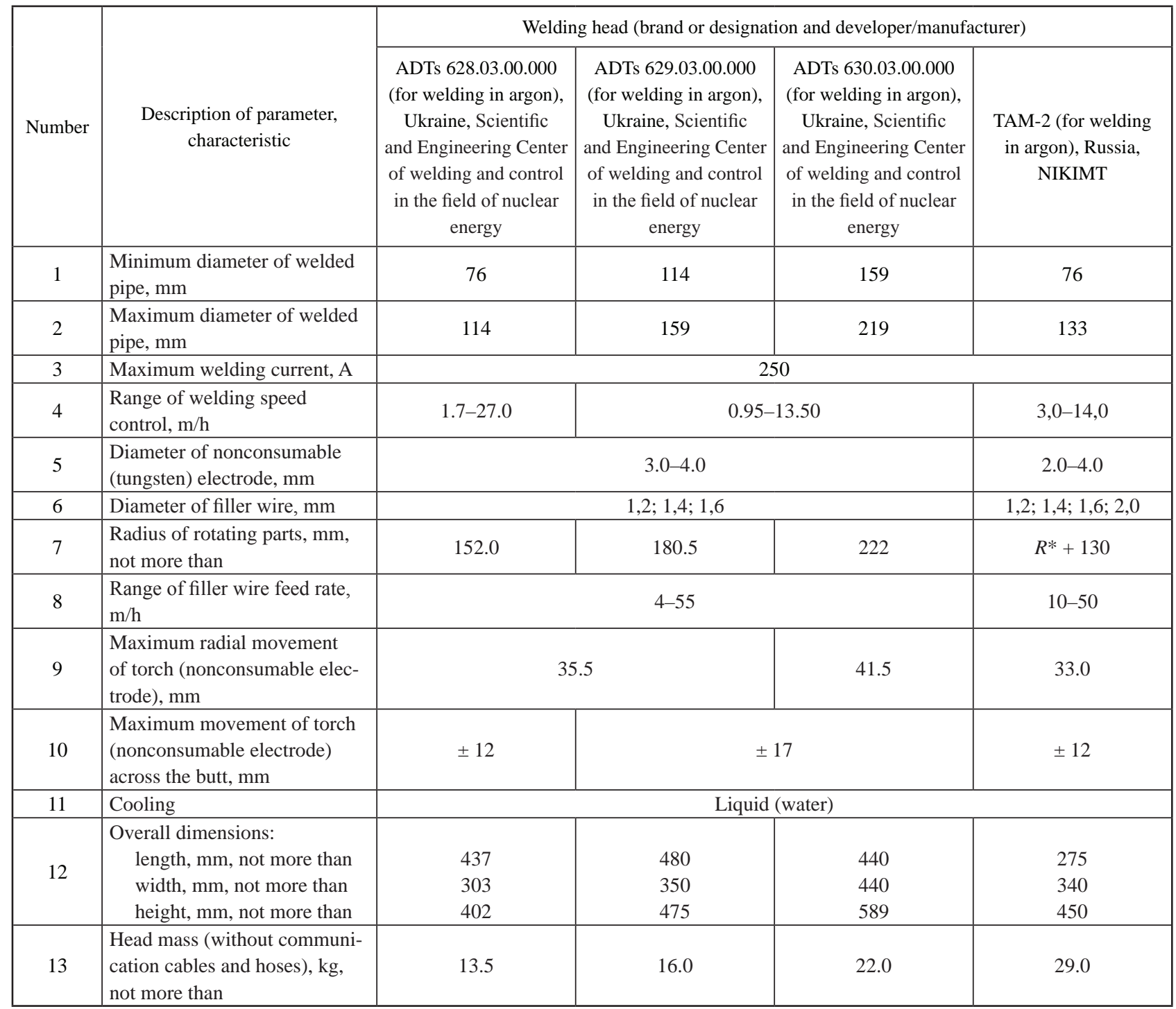

AAVR mechanisms and mechanisms of transverse torch (nonconsumable electrode) movement, channel of filler wire feed), on each faceplate, the sensor of spatial position of electrode (accelerometer) is installed and rigidly fixed. The mechanisms for rotation of welding heads ADTs 628.03.00.000, ADTs 629.03.00.000 and ADTs 630.03.00.000 and their clamping mechanisms provide realization of the same options as the similar mechanisms of welding heads ADTs 627.03.00.000, ADTs 627.03.00.000-01, ADTs 625.03.00.000 and ADTs 626.03.00.000. In the mechanism of rotation of welding heads ADTs 628.03.00.000, ADTs 629.03.00.000 and ADTs 630.03.00.000, as the main components of the drive, the reverse gear motor 3257G 024 CR $32 / 3$ of the Company «Faul Haber» and the encoder 05.2420.1211.0128 of the Company «Kübler» are used.

The design base of the torch of welding heads ADTs 628.03.00.000, ADTs 629.03.00.000 and ADTs 630.03.00.000 represents a rectangular metal body with two inner sealed cavities, one of which is intended for filling with cooling liquid (water) in order to realize its heat exchange with the mentioned casing, and the second is intended to function as a chamber of shielding (inert) gas entering the torch through the corresponding branch-pipe from the gas supply line of automatic machines for GTAW and flowing out of it through 10 holes with a diameter of $1.2 \mathrm{~mm}$, which in combination with a gas filter, installed in the inner lower part of the torch body, provides a laminar flowing of shielding (inert) gas in the direction of welding zone through the ceramic torch nozzle.

The AAVR mechanism in welding heads ADTs 628.03.00.000, ADTs 629.03.00.000 and ADTs 630.03 .00 .000 is designed to provide maintaining the preset (programmed) length of welding arc and as to its design it is similar to the AAVR mechanism of welding heads ADTs 625.03.00.000 and ADTs 626.03.00.000. The peculiarity of the AAVR mech- 
Table 2. Cont.

\begin{tabular}{|c|c|c|c|c|}
\hline \multirow[b]{2}{*}{ Number } & \multirow[b]{2}{*}{$\begin{array}{l}\text { Description of parameter, } \\
\text { characteristic }\end{array}$} & \multicolumn{3}{|c|}{ Welding head (brand or designation and developer/manufacturer) } \\
\hline & & $\begin{array}{c}\text { TAM-3 (for welding in argon), } \\
\text { Russia, NIKIMT }\end{array}$ & $\begin{array}{l}\text { MU-IV 76/195 P with built-in } \\
\text { mechanism of filler wire feed } \\
\text { (for welding in argon), } \\
\text { France, Polysoude }\end{array}$ & $\begin{array}{c}\text { MU-IV114/275 P with built-in } \\
\text { mechanism of filler wire feed } \\
\text { (for welding in argon), } \\
\text { France, Polysoude }\end{array}$ \\
\hline 1 & $\begin{array}{l}\text { Minimum diameter of welded pipe, } \\
\mathrm{mm}\end{array}$ & 133 & 76 & 114 \\
\hline 2 & $\begin{array}{l}\text { Maximum diameter of welded pipe, } \\
\text { mm }\end{array}$ & 219 & 195 & 275 \\
\hline 3 & Maximum welding current, $\mathrm{A}$ & \multicolumn{2}{|c|}{250} & 290 \\
\hline 4 & $\begin{array}{l}\text { Range of welding speed control, } \\
\mathrm{m} / \mathrm{h}\end{array}$ & $3.0-14.00$ & \multicolumn{2}{|c|}{$0.5-20.0$} \\
\hline 5 & $\begin{array}{l}\text { Diameter of nonconsumable } \\
\text { (tungsten) electrode, mm }\end{array}$ & $2.0-4.0$ & \multicolumn{2}{|c|}{$2.0-3.2$} \\
\hline 6 & Diameter of filler wire, $\mathrm{mm}$ & 1,$2 ; 1,4 ; 1,6 ; 2,0$ & \multicolumn{2}{|c|}{0.8} \\
\hline 7 & $\begin{array}{l}\text { Radius of rotating parts, mm, } \\
\text { not more than }\end{array}$ & $R^{*+155}$ & 205 & 205 \\
\hline 8 & Range of filler wire feed rate, $\mathrm{m} / \mathrm{h}$ & $10-50$ & \multicolumn{2}{|c|}{$0.5-55$} \\
\hline 9 & $\begin{array}{l}\text { Maximum radial movement of torch } \\
\text { (nonconsumable electrode), } \mathrm{mm}\end{array}$ & 33.0 & \multicolumn{2}{|c|}{20} \\
\hline 10 & $\begin{array}{l}\text { Maximum movement of torch } \\
\text { (nonconsumable electrode) across } \\
\text { the butt, } \mathrm{mm}\end{array}$ & \pm 12 & \multicolumn{2}{|c|}{ \pm 15} \\
\hline 11 & Cooling & \multicolumn{3}{|c|}{ Liquid (water) } \\
\hline 12 & $\begin{array}{l}\text { Overall dimensions: } \\
\text { length, mm, not more than } \\
\text { width, mm, not more than } \\
\text { height, mm, not more than }\end{array}$ & $\begin{array}{r}90 \\
520 \\
550\end{array}$ & $\begin{array}{l}500 \\
410 \\
500\end{array}$ & $\begin{array}{l}616 \\
500 \\
530\end{array}$ \\
\hline 13 & $\begin{array}{l}\text { Head mass (without communication } \\
\text { cables and hoses), kg, not more than }\end{array}$ & 35.0 & 32.0 & 35.0 \\
\hline $\begin{array}{l}\text { Notes. } 1 . \\
\text { 2. Torche } \\
\text { gas lense }\end{array}$ & is the nominal outer radius of weld & pipelines, mm. & . & with ceramic nozzles and \\
\hline
\end{tabular}

anism in welding heads ADTs 628.03.00.000, ADTs 629.03.00.000 and ADTs 630.03.00.000 consists in the fact that this mechanism is rigidly connected with the mechanism of transverse movement of the torch (nonconsumable electrode), intended for directing («aiming») of nonconsumable electrode to a welded butt and correcting the spatial position of this electrode across the mentioned butt joint, as well as for performing oscillations of nonconsumable electrode across the butt in accordance with the programmed values of the amplitude and oscillation frequency with electrode movements on the straight $[4,9]$. As a drive in the AAVR mechanism of welding heads ADTs 628.03.00.000, ADTs 629.03.00.000 and ADTs 630.03.00.000, a reversive gear motor $2224 \mathrm{U} 024$ SR 20/1 of «Faul Haber» is used, and in the mechanism of transverse movement of nonconsumable electrode (oscillator mechanism) - the reversive gear motor 2642 W 024 CR of «Faul Haber» with a built-in encoder 05.24.20.1111.0128 of «Kübler» is used, which makes it possible not only to regulate the amplitude and frequency of electrode oscillations and to main- tain their programmed values stable during the welding process, but also to automatically determine the moving direction of nonconsumable electrode.

As to their design, the mechanisms of AAVR and the oscillator of nonconsumable electrode in welding heads ADTs 628.03.00.000, ADTs 629.03.00.000 and ADTs 630.03.00.000 are combined in a one unit and in order to optimize the overall dimensions of these heads, the AAVR mechanism is installed perpendicular relative to the faceplate plane, and the oscillator mechanism is installed parallel to it.

The unit of the filler wire feed channel (liner unit) provides directing (feeding) of the filler wire to the zone of welding arc (weld pool zone), correcting the spatial position of filler wire relative to the nonconsumable torch electrode, changing and fixation of the spatial position of the liner when changing welding directions (directions of faceplate rotation).

The presence of a three-coordinate spatial position sensor (of accelerometer type) with electronic output installed on the faceplate of each of welding heads ADTs 628.03.00.000, ADTs 629.03.00.000 and ADTs 
630.03.00.000 makes it possible to automatically determine the angular position of nonconsumable electrode in the plane (cross-section) of a welded butt relative to the gravity vector, which provides the performance of a programmed welding cycle regardless of the initial spatial position of nonconsumable electrode, and also obtaining a reliable information about its angular position for performance of welding cycle program in accordance with adequate control axes.

The mechanism for filler wire feed of welding heads ADTs 628.03.00.000, ADTs 629.03.00.000 and ADTs 630.03.00.000 is designed to provide movement of filler wire into the welding zone at a programmed speed and is made as a separate external unit, which allows using a standard reel for filler wire having a diameter of up to $300 \mathrm{~mm}$. As a drive for this mechanism, DC electric motor was used, having a rated power of $100 \mathrm{~W}$ and a built-in encoder that generates 500 pulses per one full revolution of the output shaft of the electric motor. The main units of the filler wire feeding mechanism are two reducing gears and a standard four-roller clamping mechanism manufactured in Ukraine. The first among the reducing gears, which is a single-stage cylindrical one, provides the initial reduction with a ratio of $1: 3$ and with the help of the second reducing gear of a worm type, a reduction with a ratio of $1: 100$ is carried out. The output shaft of the second reducing gear is connected to a four-roller clamping mechanism, in which by means of spring-loaded feeding rollers clamping to the filler wire and its direction into the feeding channel is provided. The feed rate is controlled by means of the filler wire feed drive controller, which is a part of the control system (CS) interface of the automatic machines ADTs 628 UKhL4, ADTs 629 UKhL4 and ADTs 630 UKhL4 for GTAW [8]. The controller generates a voltage at the motor armature and provides regulation and maintenance of a stable value of the programmed filler wire feed rate due to a feedback carried out by processing a sequence of pulses entering this controller from an information output of the optoelectric encoder built-in in the electric motor.

The water cooling system of welding heads ADTs 628.03.00.000, ADTs 629.03.00.000 and ADTs 630.03.00.000 is built on the principle of a closed liquid cooling system and is based on the use of autonomous water cooling units of domestic serial production designed to provide cooling and circulation of the working liquid in the cavities of torches with water cooling of machines for TIG welding at a welding current of up to $500 \mathrm{~A}$.

The control of operation of the mechanisms and systems of automatic machines ADTs 628 UKhL4, ADTs 629 UKhL4 and ADTs 630 UKhL4, includ- ing the actuating mechanisms of welding heads ADTs 628.03.00.000, ADTs 629.03.00.000 and ADTs 630.03 .00 .000 is carried out by one and the same CS by means of its hardware and software. An obligatory component of CS is a standard personal computer. The software for GTAW automatic machines designed at the Scientific and Engineering Center of welding and control in the field of nuclear energy is based on the use of the integrated environment Lab VIEW and a personal computer with operating systems Windows XP-SP2 or Windows 7 either Windows 10.

\section{Conclusions}

1. Designing, manufacture, testing and results of pilot operation of experimental models of automatic machines ADTs 627 U3.1, ADTs 625 U3.1 and ADTs 626 U3.1 for orbital welding using nonconsumable electrode in inert gas or mixtures of gases (mainly by the methods of autopressing, successive penetration and antipressing) and designing, manufacture and testing of experimental models of automatic machines ADTs 628 UKhL4, ADTs 629 UKhL4 and ADTs 630 UKhL4 for orbital welding with oscillations of nonconsumable electrode and filler wire feed and the further development of the industrial manufacture of these machines and their components create all the necessary preconditions for equipping the assembly organizations, repair detachments and enterprises of power engineering and other sectors of the Ukrainian economy with domestic modern equipment, which makes it possible to realize both used as well as new technologies for automatic welding of position butt joints of thin-walled pipelines with a nominal outer diameter ranging from 7 to $76 \mathrm{~mm}$, as well as pipelines with a nominal outer diameter ranging from 76 to $219 \mathrm{~mm}$ with a wall thickness of up to $12 \mathrm{~mm}$ and edges preparation from austenitic, pearlitic and martensitic classes of steels, high alloys, nonferrous metals and alloys (except aluminum and its alloys).

2. The presence of a personal computer in the CS of the developed automatic machines ADTs 628 UKhL4, ADTs 629 UKhL4 and ADTs 630 UKhL4 makes it possible not only to perform adaptive control of GTAW processes and equipment for its realization, but also to document the actual values of parameters of these processes and conditions of welding, to conduct their retrospective analysis and comparison with practiced computer models, to obtain initial information for carrying out reliable non-destructive testing, diagnostics and predictive calculations of reliability of welded position butt joints of pipelines.

3. The further development of domestic technologies for GTAW of position butt joints of pipelines 
and equipment for their realization in the direction of increasing the level of automation approached to robotization is possible due to the modernization of some actuating mechanisms of welding heads for GTAW, use of video sensors, creation of a bank of typical welding conditions, advanced use of modern (for example, signal) microprocessors and nonvolatile memory.

4. The mechanisms of automatic machines for GTAW considered and described in this work can be successfully used in automatic welding machines and installations for producing rectilinear and curvilinear welds using nonconsumable electrode in the inert gas shielding and in mixtures of gases.

1. Bukarov, V.A. (2002) Technology of automatic shieldedarc welding. In: Welding in nuclear industry and power engineering.Trudy NIKIMT. Moscow, AT, Vol. 1, 149-210 [in Russian].

2. Grinenko, V.I., Roshchin, V.V., Khavanov, V.A., Poloskov, S.I. (2008) To problem of automation of welding of field joints in nuclear plant piping. Tekhnologiya Mashinostroeniya, 8, 48-51 [in Russian].

3. Poloskov, S.I., Bukarov, V.A., Ishchenko, Yu.S. (2000) Effect of parameter deviations of argon-arc welding of pipe position butt joints on quality of welded joints. In: Proc. of All-Russian
Sci.-Techn. Conf. on Welding and Related Technologies. Moscow, MEI (TU), 22-25 [in Russian].

4. (1986) Arc welding equipment: Refer. Book. Ed. by V.V. Smirnov. Leningrad, Energoatomizdat [in Russian].

5. Makhlin, N.M., Korotynsky, A.E., Bogdanovsky, V.A. et al. (2011) Single- and multioperator systems for automatic welding of position butt joints of nuclear plant piping. The Paton Welding J., 11, 28-36.

6. Makhlin, N.M., Korotynsky, O.E., Svyrydenko, A.O. (2013) Hardware and software complexes for automatic welding of position butt joints of nuclear plant pipings. Nauka ta Innovatsii, 9(6), 31-45 [in Ukrainian].

7. Makhlin, N.M., Popov, V.E., Fedorenko, N.S. et al. (2013) Application of automatic orbital welding in manufacture of housings of neutron measurement channels of nuclear reactors. The Paton Welding J., 6, 28-33.

8. Makhlin, N.M., Buryak, V.Yu. (2019) Drives of mechanisms of automatic machines for orbital TIG welding of metal pipeline butt joints in NPP power units. Ibid., 9, 47-52.

9. Gladkov, E.A. (2006) Control of processes and equipment in welding: Manual for students of higher education inst. Moscow, Akademiya [in Russian].

10. Grinenko, V.I., Khavanov, V.A., Belousov, A.N., Poloskov, S.I. (2002) Experience of NIKIMT on creation of equipment for orbital welding of pipes in site. In: Welding in nuclear industry and power engineering.Trudy NIKIMT. Moscow, AT, Vol. 2, 310-339 [in Russian].

11. (2019) http://www.polysoude.com

Received 05.08.2019

\section{iiw YOUNG PROFESSIONALS Isscourtoverr INTERNATIONAL CONFERENCE ON WELDING AND RELATED TECHNOLOGIES}
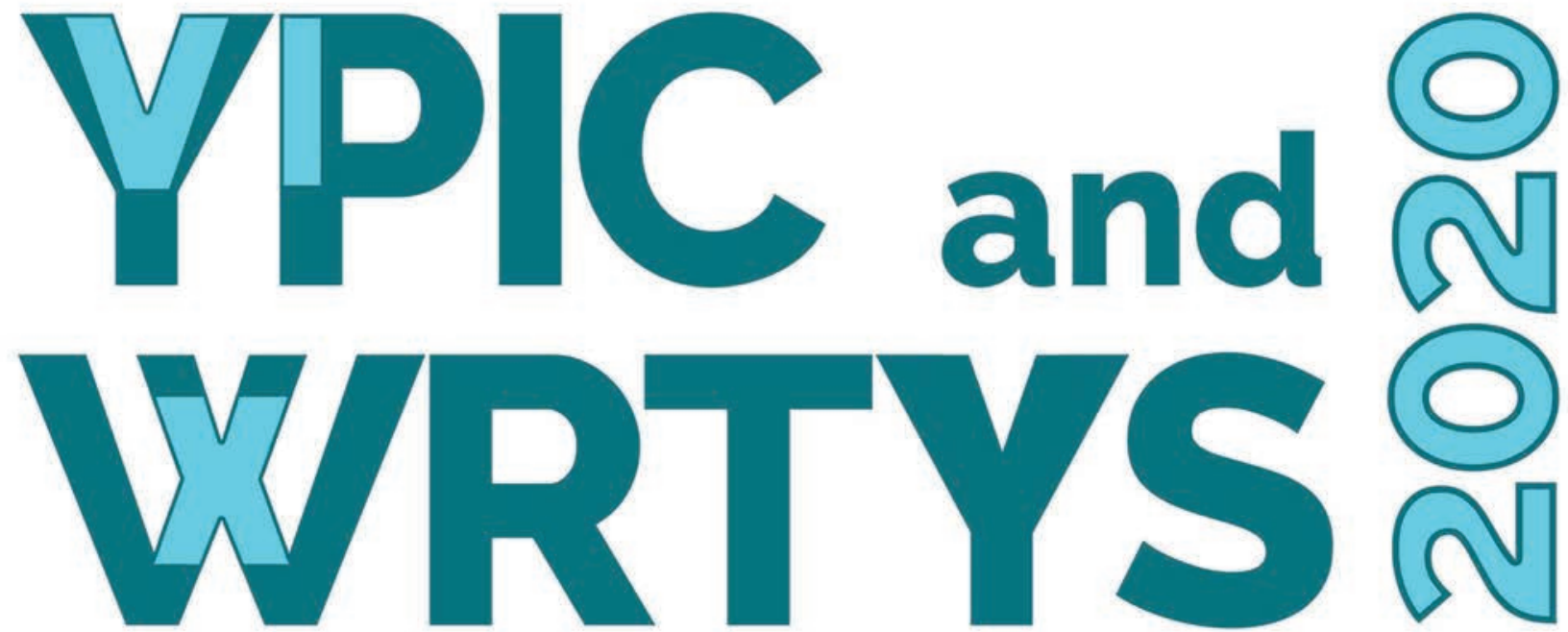

19-22 MAY 2020 


\title{
EFFECT OF EXTRUSION MODIFIERS OF COATING MIXTURE ON ELECTRODE COATING THICKNESS DIFFERENCE*
}

\author{
A.E. MARCHENKO ${ }^{1}$, M.F. GNATENKO ${ }^{2}$ and N.V. SKORINA ${ }^{1}$ \\ ${ }^{1}$ E.O. Paton Electric Welding Institute of the NAS of Ukraine \\ 11 Kazymyr Malevych Str., 03150, Kyiv, Ukraine. E-mail: office@paton.kiev.ua \\ ${ }^{2}$ WELMA LLC \\ 3 Kaunasskaya Str., 02160, Kyiv, Ukraine
}

\begin{abstract}
The method of oscillographing the signals generated by electromagnetic sensor, through the channel of which the electrodes pass at the outlet of the press coating head, was used to study the effect of extrusion modifiers of the coating mixture on thickness difference in manufacture of test electrodes UONI 13/55 of $4 \mathrm{~mm}$ diameter. The phenomenon of reduction of coating thickness difference under the effect of modifiers (CMC, alginates, cellulose or soda ash) is explained by that the dose of liquid glass added to the mixture gradually increases with the change of the type and increase of the content of modifier. Hydrating of modifying additive particles as a result of absorption of liquid glass moisture leads to thickening of the glass, and of its intergranular layers in the coating mixture, and to weakening of Hamaker interaction of filler grains. Probability of generation and accumulation of elastic stresses during extrusion application of the mixture on the rods becomes lower. The ability of the coating mixture flow to cover the rods in a uniform concentric layer at crimping of the electrodes becomes higher, accordingly. 6 Ref., 1 Table, 11 Figures.
\end{abstract}

Keywords: coated electrode manufacturing, coating mixture, coating thickness difference, extrusion modifiers, liquid glass, coating viscosity, electrode quality

Technological additives of natural origin or synthesized chemically are used in order to maintain a stationary pressure flow of coating mixtures during their extrusion deposition on the rods and ensuring a uniform concentric coating layer. They include silicates (kaolin, bentonite, muscovite mica), chemicals (soda, potash) or powders of organic hydrocolloids (cellulose, CMC, alginates). Plasticizing impact of the above modifiers is attributable to their densifying effect on the liquid glass binder in the coating mixture composition or suppression of the chemical reaction between the liquid glass and marble of the coating mixture. It is known that the silicates have structural moisture in their composition, and the base of alkali hydrocolloids consists of carbohydrates. It is important that their use does not lead to deterioration of metallurgical and other technological qualities of the manufactured electrodes.

The range of modifiers is quite broad, and the mechanism of their anticipated action began to be clarified only at the end of 1980s. This study provides analysis of its physico-chemical features and substantiation of rational methods of its realization.

Objects and procedure of investigation. Powders of organic hydrocolloids in the form of Na-CMC of 85CO grade from Namangan Chemical Plant and Na-alginate of Manutex RK/F grade of Alginate In- dustries Ltd. (Great Britain), and of EC cellulose, as well as soda ash, were studied. Each of them was tested individually, just its content in the coating mixture was changed. Coating mixture not containing the above additives was studied for comparison. Investigation procedure described in detail in [1] was used.

Characteristics of grain composition of the charge were as follows: passing through 0063 mesh $34.0 \%$, specific surface of $3700 \mathrm{~cm}^{2} / g$; grain packing density -0.790 .

NaK liquid glass with 3.05 module, $\rho=$ $=1435 \mathrm{~kg} \cdot \mathrm{m}^{-3}$ and $\eta=910 \mathrm{mPa} \cdot \mathrm{s}$ was used in all the experiments, and the one with $\eta=500 \mathrm{mPa} \cdot \mathrm{s}$ was used in the experiment with the alginate. The coating mixture was prepared in single roller mixer.

The conditions of coating mixture preparation are given in the Table. The designations accepted in the Table are as follows:

- $t_{\mathrm{cm}}, P_{\mathrm{cr}}$ is the duration of preparation of coating mixture and pressure developed in the press head at electrode crimping;

- $e_{i}, e_{\mathrm{sm}}, R_{\mathrm{rms}}, S_{r}$ are the individual, sample mean, ranges and standard deviations of the values of coating thickness difference, calculated by the $x_{i}$ and $y_{i}$ coordinate components of coating thickness difference vector (CC CTDV) recorded on the oscillograms; 
Experimental conditions and results

\begin{tabular}{|c|c|c|c|c|c|c|c|c|c|}
\hline \multirow{2}{*}{$\begin{array}{c}\text { Experiment } \\
\text { number }\end{array}$} & \multicolumn{3}{|c|}{ Glass, coating mixture } & \multicolumn{5}{|c|}{ Selective parameters of coating thickness difference, mm } & \multirow{2}{*}{$\begin{array}{r}\text { Reject } \\
\text { rate, \% }\end{array}$} \\
\hline & Dose, \% & $t_{\mathrm{cm}}, \min$ & $P_{\mathrm{pr}}, \mathrm{MPa}$ & $\begin{array}{l}\text { Charge } \\
\text { number }\end{array}$ & $N$, pcs & $e_{\mathrm{sm}}$ & $R_{\mathrm{rms}}$ & $S_{\mathrm{r}}$ & \\
\hline \multicolumn{10}{|c|}{$0 \%$ CMC of $85 \mathrm{CO}$ grade in the charge } \\
\hline \multirow{4}{*}{1188} & \multirow{4}{*}{23.0} & \multirow{4}{*}{10.5} & \multirow{4}{*}{$55.0^{1}$} & 1.1 & 100 & 0.18 & 0.055 & 0.025 & 57.0 \\
\hline & & & & 1.2 & 100 & 0.23 & 0.050 & 0.015 & 61.0 \\
\hline & & & & 1.3 & 100 & 0.15 & 0.060 & 0.025 & 35.0 \\
\hline & & & & 2 & 90 & 0.16 & 0.060 & 0.030 & 26.0 \\
\hline \multicolumn{10}{|c|}{$0.5 \%$ CMC of $85 \mathrm{CO}$ grade in the charge } \\
\hline \multirow{3}{*}{1205} & \multirow{3}{*}{24.4} & \multirow{3}{*}{7.0} & \multirow{3}{*}{52.0} & 1 & 100 & 0.07 & 0.060 & 0.025 & 0 \\
\hline & & & & 2 & 100 & 0.08 & 0.040 & 0.015 & 0 \\
\hline & & & & 3 & 100 & 0.09 & 0.035 & 0.015 & 0 \\
\hline \multicolumn{10}{|c|}{$1.0 \%$ CMC of $85 \mathrm{CO}$ grade in the charge } \\
\hline \multirow{3}{*}{1306} & \multirow{3}{*}{27.0} & \multirow{3}{*}{5.0} & \multirow{3}{*}{52.0} & 1 & 100 & 0.11 & 0.035 & 0.025 & $2.0^{2}$ \\
\hline & & & & 2 & 80 & 0.14 & 0.025 & 0.010 & 0 \\
\hline & & & & 3 & 90 & 0.12 & 0.025 & 0.010 & 0 \\
\hline \multicolumn{10}{|c|}{$1.5 \%$ CMC of 85CO grade in the charge } \\
\hline 1407 & 30.1 & 3.5 & 52.0 & 1 & 120 & 0.06 & 0.025 & 0.015 & 0 \\
\hline \multicolumn{10}{|c|}{$1.0 \%$ alginate in the charge } \\
\hline \multirow{3}{*}{8848} & \multirow{3}{*}{28.7} & \multirow{3}{*}{7.0} & \multirow{3}{*}{53.0} & 1 & 100 & 0.03 & 0.035 & - & 0 \\
\hline & & & & 2 & 100 & 0.04 & 0.040 & - & 0 \\
\hline & & & & 3 & 80 & 0.02 & 0.025 & - & 0 \\
\hline \multicolumn{10}{|c|}{$2.0 \%$ cellulose in the charge } \\
\hline \multirow{3}{*}{2313} & & & & 1 & 65 & 0.04 & 0.030 & 0.015 & 0 \\
\hline & 28.8 & 8.0 & 44.0 & 2 & 50 & 0.06 & 0.030 & 0.017 & 0 \\
\hline & & & & 3 & 90 & 0.04 & 0.043 & 0.056 & 0 \\
\hline & & & & $5 \%$ cellul & the cha & & & & \\
\hline & & & & 1 & 70 & 0.01 & 0.009 & 0.004 & 0 \\
\hline 1814 & 28.8 & 8.0 & 48.0 & 2 & 55 & 0.01 & 0.018 & 0.009 & 0 \\
\hline & & & & 3 & 45 & 0.02 & 0.023 & 0.017 & 0 \\
\hline & & & & $1.2 \% \operatorname{sod}$ & he charg & & & & \\
\hline 2408 & 316 & 40 & 400 & 1 & 100 & 0.04 & 0.040 & 0.015 & 0 \\
\hline 2408 & 31.6 & 4.0 & 40.0 & 4 & 100 & 0.07 & 0.015 & 0.010 & 0 \\
\hline & & & & $2.4 \%$ sod & he charg & & & & \\
\hline & & & & 1 & 60 & 0.01 & 0.015 & 0.005 & 0 \\
\hline 2409 & 37.5 & 5.0 & 40.0 & 5 & 60 & 0.03 & 0.023 & 0.010 & 0 \\
\hline
\end{tabular}

- $N=100$ is the number of $e_{t}$ measurements in the total population accumulated during $60 \mathrm{~s}$. The oscilloscope tape speed is $10 \mathrm{~mm} \cdot \mathrm{s}^{-1}$, electrode crimping rate is 420 pcs per minute ( 2 measurements of $x_{i}$ and $y_{i}$ per three electrodes).

The $e_{\mathrm{sm}}, R_{\mathrm{rms}}, S_{\mathrm{r}}$ values were calculated by the moving averages technique, which is used to study the time series, when predicting, for instance the weather, currency rate, market prices, etc. With this purpose, similar to [1], the total data set was conditionally divided into 20 consecutive samples, each consisting from five $e_{t}$ values following each other. Sample values of $e_{\mathrm{sm}}, R_{\mathrm{rms}}, S_{r}$, eliminating the noise, better reflect trends than $e_{\text {. }}$.

Investigation results. Difference of thickness of coating from coating mixture without modifiers. As was anticipated, unfavourable technological properties were found in the coating mixture without extrusion modifiers, designated by index 1188 . Electrodes could only be pressed from it, when the gap between the tip of the rod guide and the calibrating sleeve, i.e. press chamber volume, was doubled, compared to its standard size. Still, the mixture coats the rods in a nonuniform layer, and the crimping process essentially can not be adjusted. CC CTDV values in this experiment were registered continuously for $240 \mathrm{~s}$. It follows from the data given in the Table that the produced electrodes had inadmissibly high and rather unstable values of coating thickness difference. The reject rate, i.e. the quantity of electrodes with above-norm values of coating thickness difference, is greater than $60 \%$.

The shape of oscillograms reveals that extrusion deposition of coating from mixture 1188 on the rods is a stochastic and multifactorial process. During crimping, both the horizontal and the vertical coordinate components of CTDV vary randomly. In this experiment, the amplitude and duration of $x_{i}$ deviations from zero values is greater than that of $y_{i}$. 


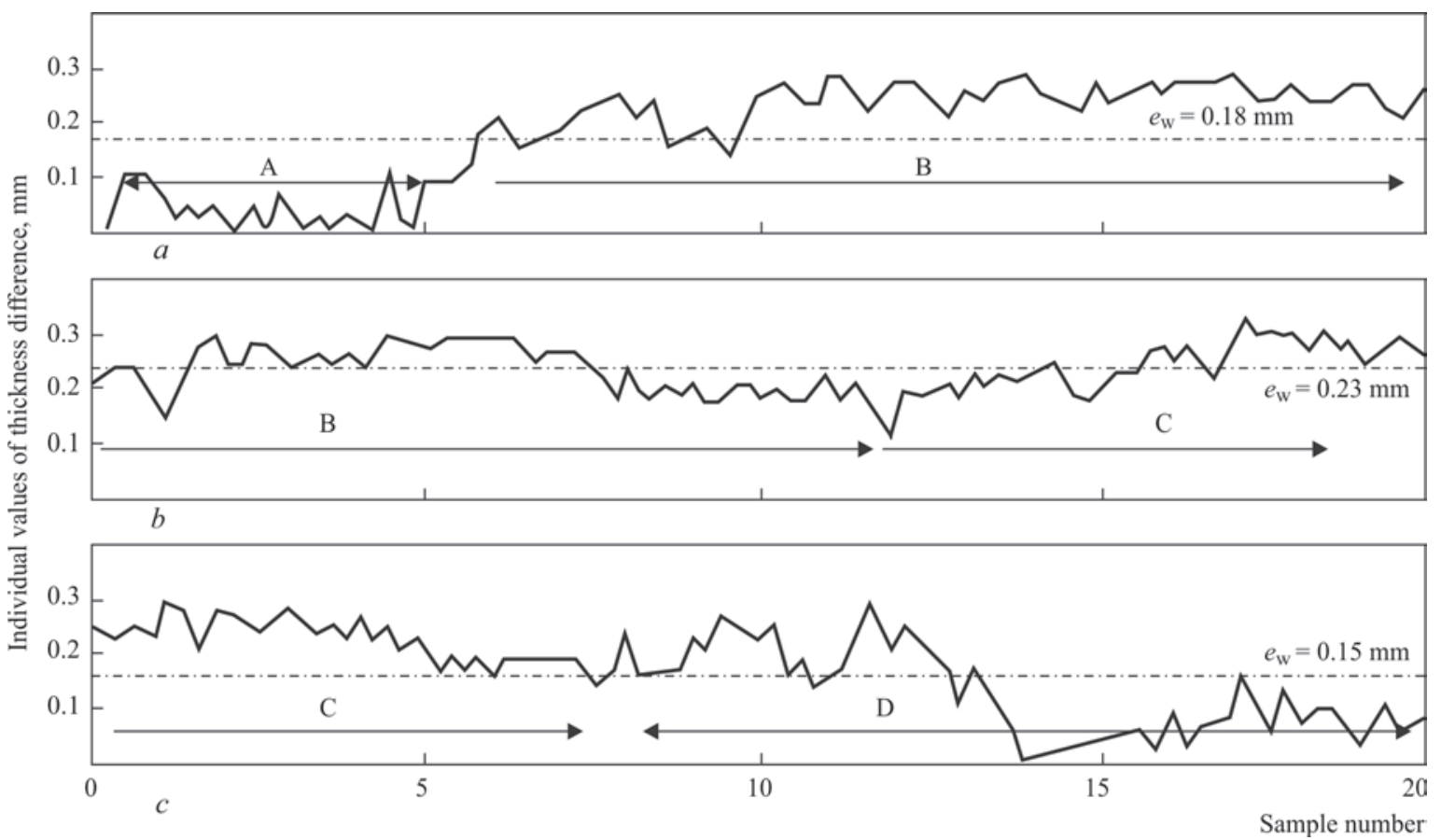

Figure 1. Evolution of $e_{i}$ in electrodes pressed out of mixture 1188 (batch 1); $a-c$ - designations of the starting (denoted by index 1.1 in the Table), medium (1.2) and end (1.3) portions of CTDV oscillograms

Judging by the orientation of stochastic deviations of $x_{i}$ from $x_{0}$ from zero lines, they, most probably, are caused by the impact on the rod of the pressure of the column of coating mixture, injected from the cylinder into the press head. Mixture slipping on the rotating plate surface is obviously superposed on it.

The motive of periodical short-term and low-amplitude deviations prevails in the profile of CTDV vertical component. They can be caused by pulsating
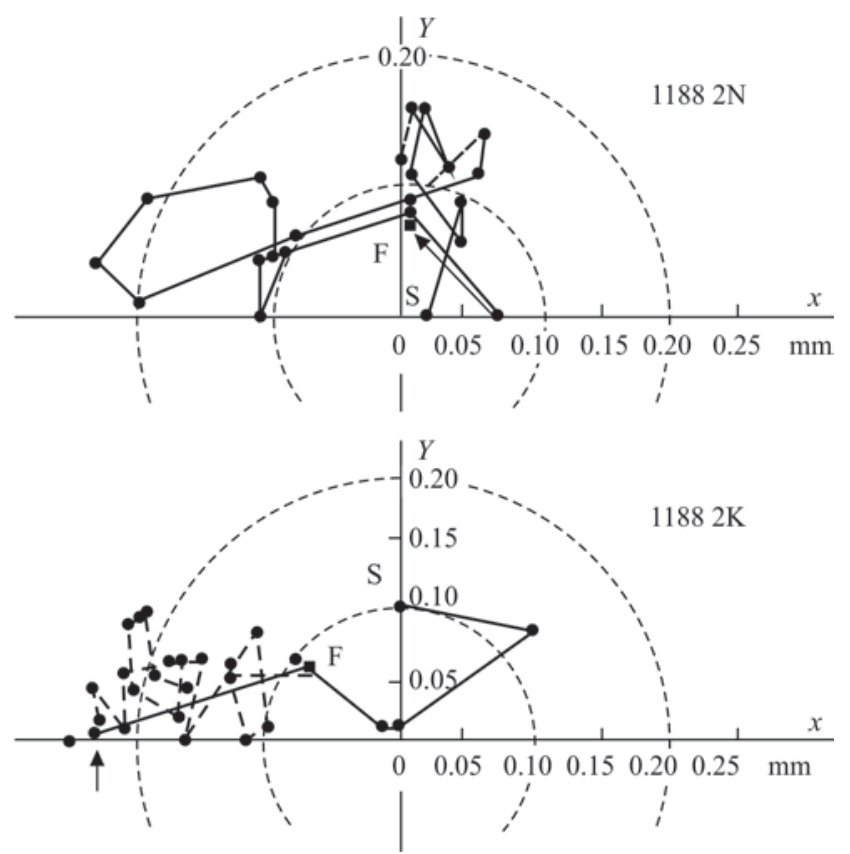

Figure 2. View of phase trajectories of CTDV obtained at crimping electrodes from batch 2 of mixture 1188 (for designations see the text) passage of the mixture through vertically located divider windows in front of the press chamber.

Figure 1 shows the evolution of the calculated individual values of the difference of coating thickness of electrodes pressed from 1188 mixture. Arrows indicate the starting section of oscillogram $\mathrm{A}$, sections of over-normative values of thickness difference $\mathrm{B}$ and $\mathrm{C}$, as well as transition section $\mathrm{D}$, within which the direction of evolution of thickness difference values changes. The wavelike elements of thickness difference evolution with a longer (A), and shorter (B) period and approximately the same amplitude are clearly visible.

One can see stochastic ripple with the frequency by orders of magnitude greater than that of the waves with periods $\mathrm{A}$ and $\mathrm{B}$.

Figure 2 gives the shape of the trajectory of displacement of the projection of electrode core on the plane normal to the electrode axis. Indices $2 \mathrm{~N}$ and $2 \mathrm{~K}$ denote the initial and final branches of the phase diagram, and indices $\mathrm{S}$ and $\mathrm{E}$ show the beginning and end of each branch. A spiral broken in appearance is unwound between them, with the change of the right twist (solid line) into the opposite one (dash line), and simultaneous ripple of its longitudinal and transverse dimensional parameters. Initial branch designated by index $2 \mathrm{~N}$, pulsates along the direction of electrode displacement for approximately $30 \mathrm{~s}$, remaining, mainly, within $0.20 \mathrm{~mm}$, and the finish point of CTDV displacement almost coincided with the starting one. The final branch of the spiral, denoted by index $2 \mathrm{~F}$, contrarily reflects the low-amplitude ripple of CTDV 
tip, which during the same period of time, gradually shifting in the radial direction, finally goes beyond the circumference of admissible values of thickness difference of $0.20 \mathrm{~mm}$ diameter.

By the nature of the curves, given in Figures 1 and 2 it can be argued that during the crimping, which they reflect, it is impossible to regulate the process using the means available to the operator.

Impact of modifiers on coating thickness difference. At addition of organic hydrocolloids in the form of CMC (from 0.5 up to $1.5 \%$ ) and alginate (1\%) to the coating mixture, it becomes possible to produce electrodes from it with a standard gap in the press head, and mean sample values and characteristics of scatter of coating thickness difference decrease (see Table).

Coating mixtures with CMC. Starting from $0.5 \%$ CMC, the profile of oscillograms of CC CTDV evolution, as well as the curves of $e_{i}$ variation during crimping are smoothed the more, the greater is the proportion of CMC in the coating mixture (Figure 3).

Here, large-scale trends become stronger in $e_{\mathrm{sm}}, R_{\mathrm{rms}}$, $S_{r}$ evolution, which are indicative of increase of electrode uniformity by $e_{i}$ characteristic, and cases of over-normative thickness difference are not observed at all.

Naturally the histograms of $e_{i}$ distribution and trajectories of CTDV phase diagrams are essentially densified, although the latter do preserve their spiral shape, not going beyond a circle of $0.15 \mathrm{~mm}$ diameter.

Coating mixtures with alginate. Judging by absolute values of $e_{\mathrm{sm}}$, the technological properties of coating mixture with alginate are better than those of the mixture with the same CMC content. This is attributable to lower viscosity of the used liquid glass and its higher content, than in the coating mixture with index 1188, selected as the analog. By the characteristics of $e_{i}$ value scatter, the electrodes from coating mixtures with the same content of alginate and CMC are identical.

Coating mixtures with soda. In terms of the ability to suppress the coating thickness difference, soda ash is a more effective extrusion modifier than CMC. In confirmation, it is sufficient to refer to Figure 4, from which it follows that in electrodes made from these coating mixtures, coating thickness difference does not exceed $0.10 \mathrm{~mm}$. During one hour soaking, $e_{\mathrm{sm}}$ value somewhat rose. Therefore, soda particle swelling went on. Scattering of $e_{i}$ value decreased, and none of the results exceeded $0.10 \mathrm{~mm}$ value.

Coating mixtures with cellulose. The data obtained at testing mixtures with 2.0 and $2.5 \%$ cellulose are given in Figure 5. In electrodes from coating mixture designated by index 2313 (2\% cellulose), the scattering region of $e_{i}$ values does not go beyond $0.10 \mathrm{~mm}$, and for those pressed from coating mixture 1814 it

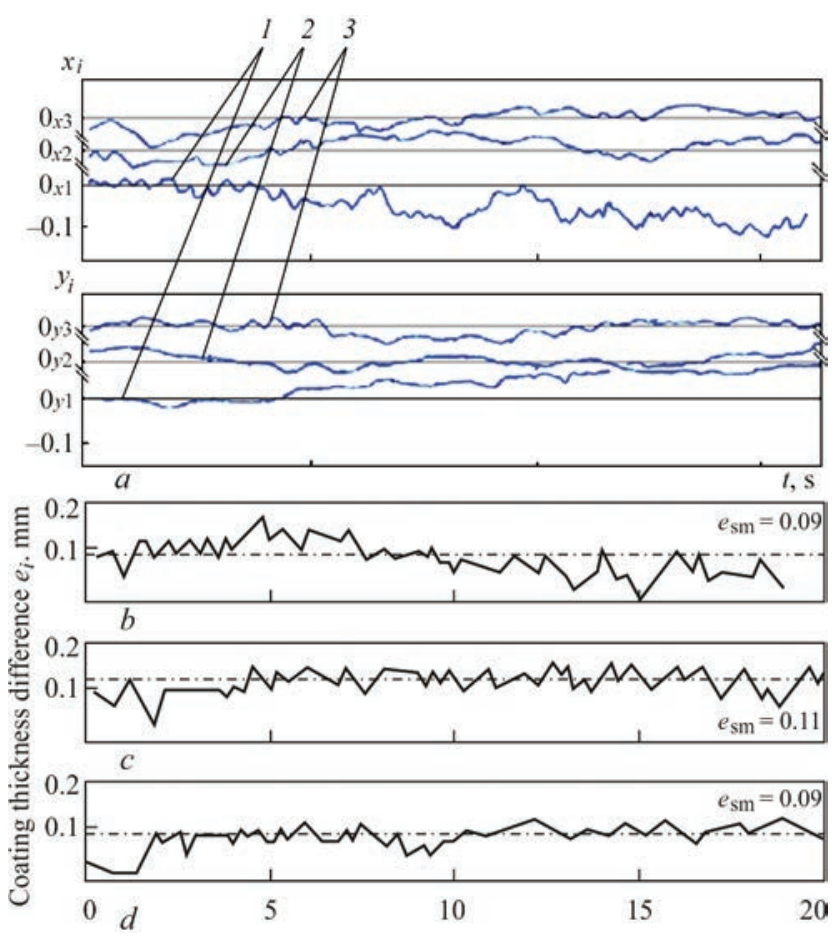

Figure 3. Copied portions of CC CTDV oscillograms ( $x_{i}$ and $\left.y_{i}\right)$ (a) and evolution of $\mathrm{e}_{i}$ during crimping of electrodes from mixtures $1205(b), 1306(c)$ and $1407(d)$, containing $0.5(1), 1.0$ (2) and 1.55 (3) CMC, respectively

does not exceed $0.05 \mathrm{~mm}$. Soaking of coating mixture 2313 changes the scattering profile of $e_{i}$, which, nonetheless, does not go beyond $0.10 \mathrm{~mm}$. Soaking of coating mixture 1814 changes both the profile and the width of $e_{i}$ scattering region. It, however, does not go beyond $0.05 \mathrm{~mm}$ even in the worst case.

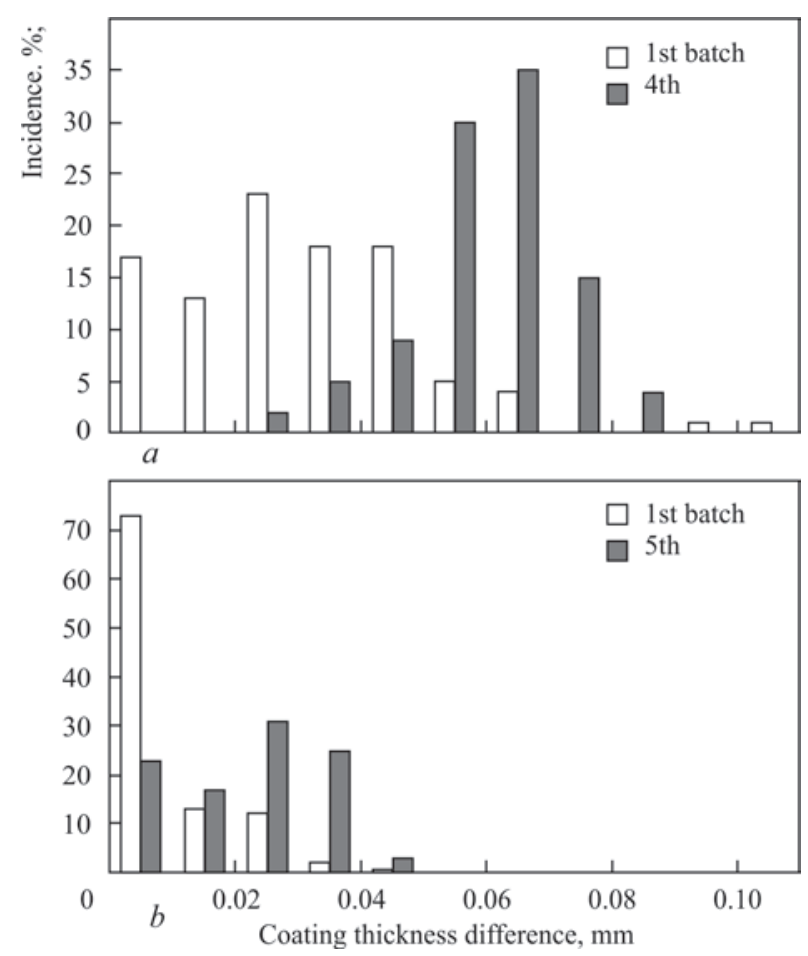

Figure 4. Density of distribution of $e_{i}$ in electrodes made from coating mixtures 2008 (2 \% soda, $a$ ) and 2009 (2.4\% soda, $b$ ) 

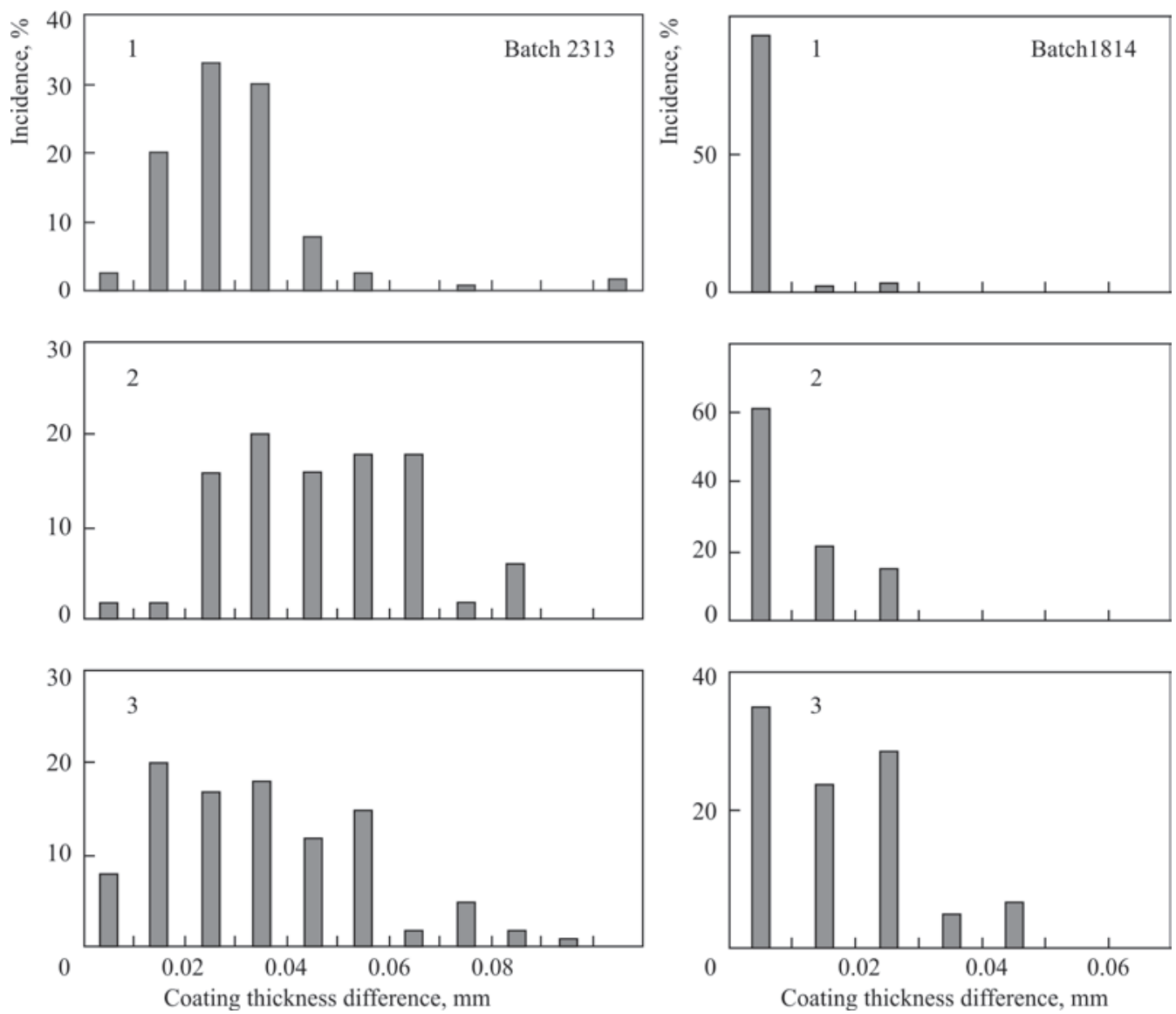

Figure 5. Density of $e_{i}$ distribution in electrodes made from mixtures 2313 (2 \% EC) and 1814 (2.5 \% EC). 1-3 - batch number

Discussion. The shape of CC CTDV oscillograms, nature of variation of individual values of coating thickness difference, as well as the shape of CTDV trajectories, show that variation of the coating thickness difference during its extrusion application on the rods is a stochastic and multifactorial process.

The broken shape of curves $e_{i}=f(t)$ and chaotic displacement of the projections of CTDV trajectories to the plane, normal to electrode movement, bear the signs of fractality, inherent to the turbulent flow of liquids and Brownian motion of suspended particles, respectively. Randomly changing deviations from zero position of the horizontal, vertical, and in the case of low adaptability to fabrication of the coating mixture, of both the CC CTDV components can be regarded as the consequence of not only turbulent flow of the coating mixture, but also the complex power interaction of elastic (rod) and visco-elastic (enveloping coating mixture) elements of its flow in the press chamber. Elasticity is the cause, and viscosity is the means of damping of its relaxation process. The modulus of elasticity of the rod is constant. The results of our studies lead to the conclusion that the ratio of the modulus of elasticity and viscosity becomes smaller, and the probability of appearance of elastic turbulence of the mixture as the source of coating thickness difference in the pressure flow condition becomes high- er as the coating mixture flow consistency becomes more rigid and its configuration becomes more complex, because of the change of its direction, degree, as well as the reduction rate.

The studied extrusion modifiers of coating mixtures are hydrophilic materials. CMC particles, dispersed in liquid glass, while sorbing moisture from it, swell and are wetted, by our data, up to $115-125 \%$; alginate particles - to a smaller degree and those of cellulose, apparently, to the smallest degree. Soda particles, while hydrating, can, by similar calculations, sorb up to $200 \%$ of $\mathrm{H}_{2} \mathrm{O}$ from liquid glass.

As a result of liquid glass dehydrating in the intergranular space, its viscosity and, accordingly, coating mixture extrusion resistance $P_{e x}$, as well as its plastic strength $P_{m}$, should increase. This is in agreement with the data given in Figure 6.

It follows from the Table that with the change of the kind and increase of modifier content, the dose of liquid glass added to the mixture increases as follows: from $23.0 \%$ (mixture without plasticizer, designated by index 1188) up to $37.5 \%$ (mixture with $2.45 \%$ soda, index 2409). This is exactly how coating mixture thickening under the impact of the plasticizer is compensated. Here, the degree of the volume filling by charge grains is lowered, intergranular film of the binder becomes thicker, filler grain interaction be- 


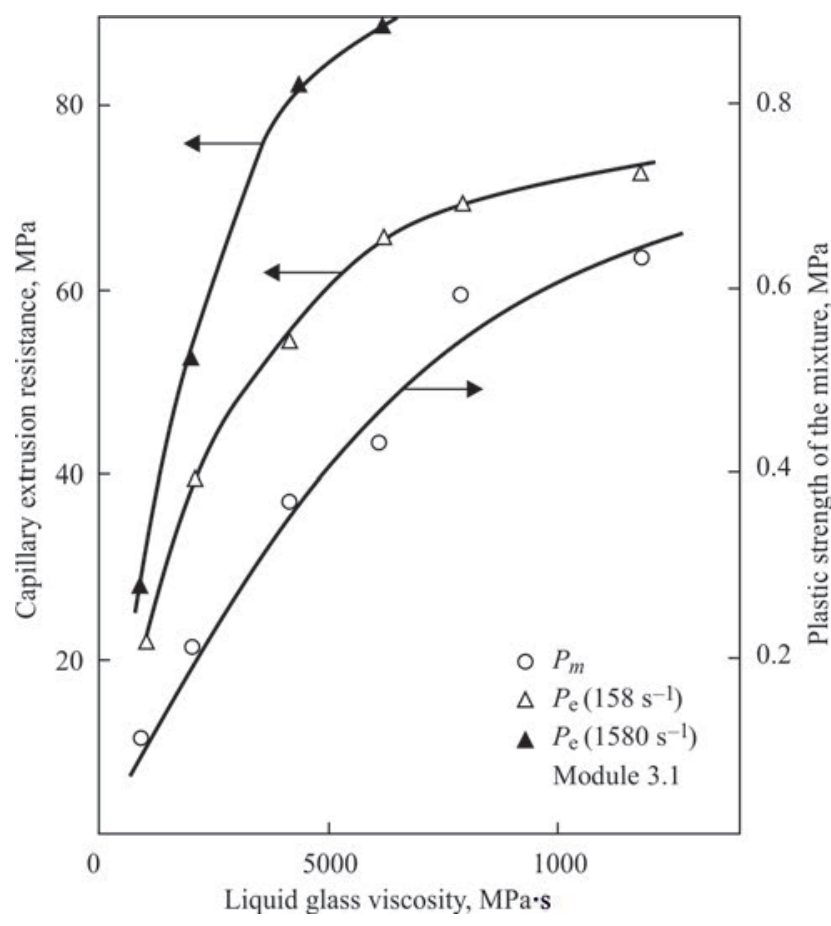

Figure 6. Variation of $P_{\mathrm{m}}$ and $P_{\mathrm{ex}}$ of coating mixture for UONI $13 / 55$ electrodes, caused by increase of NaK liquid glass viscosity (25 wt.\%)

comes weaker, that, eventually, should facilitate the activation nucleation of vacancies, required for shear displacement of grains of extruded mixture filler.

The probability of accumulation of elastic stresses in the coating mixture flow during its deposition on the rod is reduced. There is no need for their relaxation, for instance, by spontaneous transition of pressure flow of the mixture from a symmetrical one to eccentric circular cross-section, more favourable in energy terms [2].

It is important that weakening of the mixture consistency, due to increase of liquid glass content in it, just as the modifiers proper, did not become the cause for other defects of the coating and welds.

Production experience shows that the probability of appearance of coating thickness difference due to unfavourable extrusion characteristics of the mixture, as a rule, becomes lower, whereas its proneness to mechanical damage, because of its weak consistency, becomes higher. This is, in particular, indicated by the given in Figure 7 systematized and generalized by us annual results of acceptance testing of electrode products, performed by the State Acceptance Service of one of the electrode manufacturing enterprises.

Variation of the composition, characteristics and dose of liquid glass, on the one hand, and kind and concentration of the modifier, on the other, allows adjusting the mixture consistency, thus achieving favourable ratios of its extrusion properties $\left(P_{\mathrm{ex}}\right.$ as a measure of energy intensity of the process of coating deposition by extrusion on the rods) and plastic

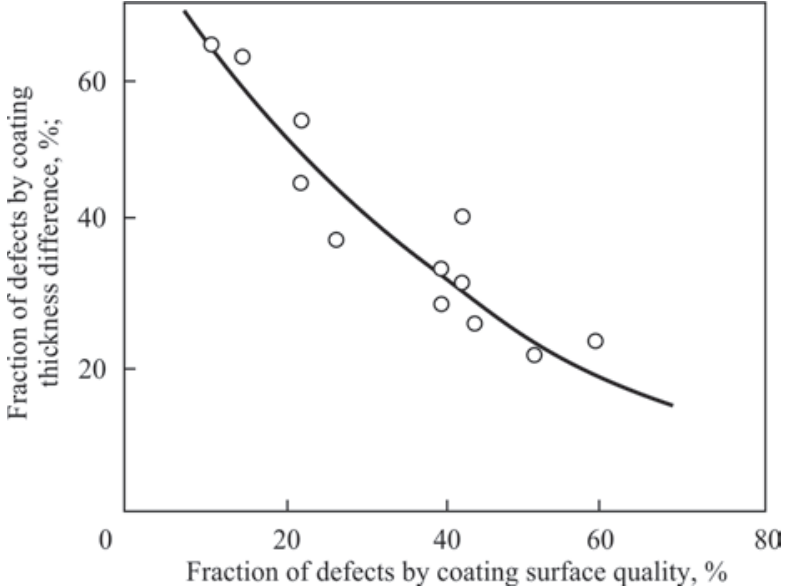

Figure 7. Interrelation of the fraction of electrodes rejected by thickness difference and surface quality of the coating (total reject rate of $3.5 \%)$

strength $\left(P_{\mathrm{m}}\right.$ as a measure of raw coating resistance to mechanical damage). It follows from the data, given in Figure 8, that high-modulus liquid glasses, particularly those with a low viscosity, provide a larger range of $P_{\mathrm{m}}$ values of the mixture at the same variations of $P_{\mathrm{ex}}$ (hatched zone), than the low-modulus glasses. This is confirmed also by the given in the Table results of the experiment with electrode crimping from alginate-containing mixture.

Modifying effectiveness of the considered additives significantly depends not only on thickening ability, but also on their impact on the nature of physico-chemical interaction of the surface of filler grains with liquid glass. Polymer anions of asymmetrical molecules of CMC and alginates, dispersed in the intergranular film of the binder, as well as isomorphous

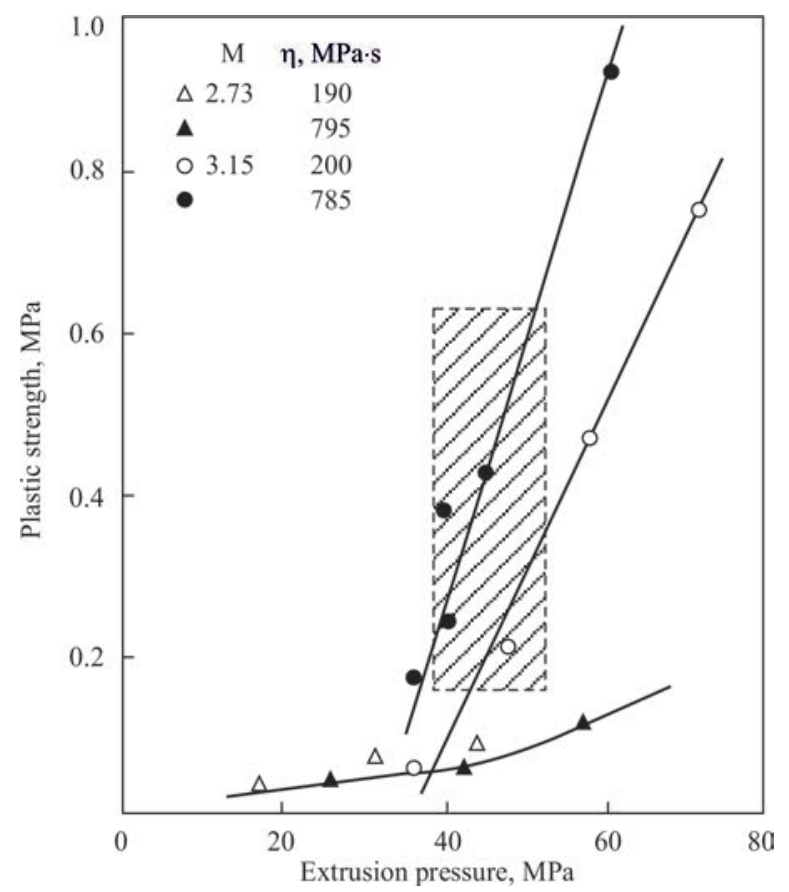

Figure 8. Impact of modulus and viscosity of KNa liquid glass on plastic strength of the coating mixture for ANO-27 electrodes 


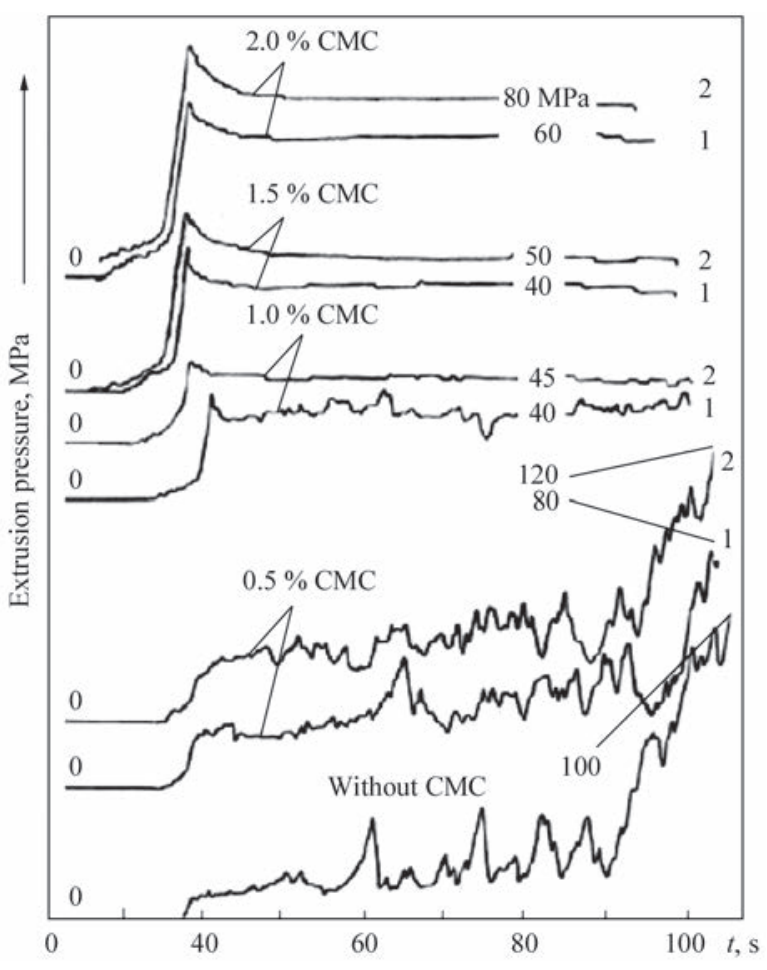

Figure 9. Curves of extrusion of coating mixture UONI 13/55 with different content of low-viscosity (1) and high-viscosity (2) CMC (NaK-liquid glass with 2.9 modulus and viscosity of $175 \mathrm{mPa} \cdot \mathrm{s}, 22.5 \mathrm{wt} . \%)$

carbonate anions, formed as a result of dissociation of soda molecules in it, are selectively sorbed by the hard surface of mixture filler particles. Similar to other surfactants, they block access of liquid-glass silicon-oxygen anions to it. This prevents the unpredictable thickening of the mixture, caused by increase of solvation barrier, and, therefore, hydrodynamic size of the grains, as well as ion-exchange transition into it of Ca from marble particles into the intergranular liquid-glass film.

The confrontation of alkali silicate and Na-CMC in an attempt to sorb on the surface of calcite grains is

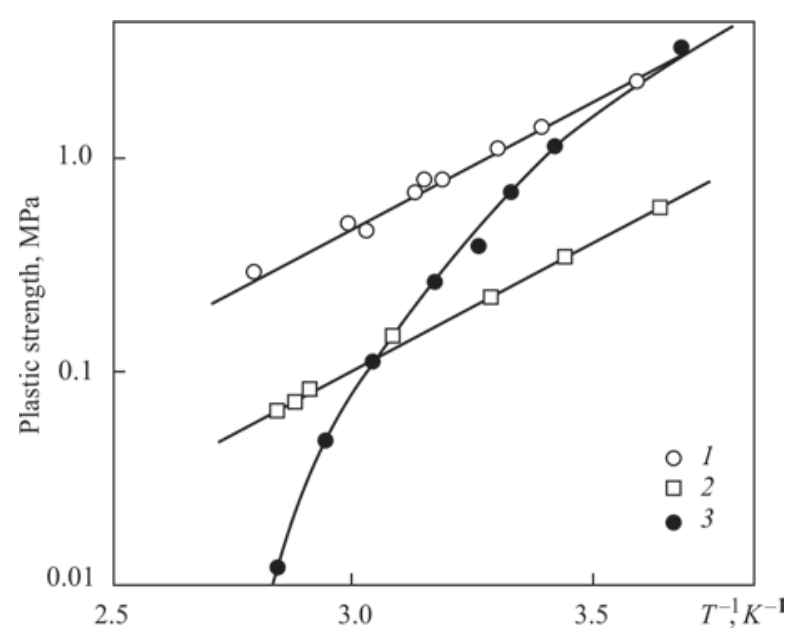

Figure 10. Temperature impact on softening of coating mixtures ANO-4 (1) and UONI 13/55 without soda (2) and with addition of $1.5 \%$ soda (3) confirmed by IR-spectroscopic and rheological studies. Results of IR-spectroscopic studies are considered by us in $[3,4]$. Rheological results are given in Figure 9 in the form of extrusion curves, recorded by plastometer OB-1435 when studying UONI 13/55 mixtures, containing from 0 to $2 \%$ of low-viscosity (68/350) and high-viscosity (68/920) Na-CMC. Capillaries of $4 \mathrm{~mm}$ diameter, and $40 \mathrm{~mm}$ length were used at average gradient of shear rate of $158 \mathrm{~s}^{-1}$.

One can see that in mixtures without CMC and with $0.5 \% \mathrm{CMC}$ the nature of outflow is highly unstable - pressure pulsates and rises as the mixture is used, as a result of its dilatancy and liquid phase extraction. At such low concentrations the compared CMC compositions are incapable of blocking the processes of SOA sorption and calcium ion transition into liquid glass. This is in agreement with the given in the Table results of determination of coating thickness difference.

Flowing of the mixture containing $1 \%$ of high-viscosity CMC, is stabilized and remains stable at concentrations, exceeding $1 \%$. Its low-viscosity modification is capable of ensuring stable extrusion only at $1.5 \%$ and higher content.

At present several production variants of modifying the extrusion properties of mixtures are used, namely individually (CMC, alginate, soda and cellulose), CMC in combination with soda, as well as CMC in combination with cellulose.

In order to increase their technological effectiveness, it is recommended to use intensive mixers of counterflow type for mixture preparation. Up to $2 \%$ water are added to the mixer, together with glass, slightly «dusting» the mixture with hydrocolloid powder before unloading from the mixer.

Kind, content and ratio of the proportions of extrusion modifiers of the mixture, in combination with the kind, module, viscosity and dose of liquid glass, optimum in terms of minimizing the coating thickness difference, are selected taking into account the features of the applied heat treatment and requirements to consumer properties of the electrodes.

So, for instance, it should be taken into account that at the beginning of electrode drying, soda increases the mixture proneness to thermal softening, which promotes formation of surface defects of the coating [5]. This is confirmed by shown in Figure 10 impact of temperature on $P_{m}$ of ANO-4 and UONI 13/55 coating mixtures. The most intensive $P_{m}$ lowering at heating was found exactly in the mixture containing soda, which was due to releasing (starting from $T=40^{\circ} \mathrm{C}$ ) of moisture absorbed by soda during the process of charge mixing with liquid glass. In mixtures containing organic hydrocolloids, the rate of thermal soft- 
ening, contrarily, decreases, particularly, when their coarse modifications are used [4].

Felt tapes 3-5 mm thick have to be pasted on working surfaces of metal frames used for electrode transportation in continuous-operation drying furnaces, in order to prevent formation of dents or sticking of coatings, containing soda as extrusion modifier [6].

Moreover, soda is hygroscopic, and it lowers the hydrosorption resistance of the coating (Figure 11). This drawback cannot be removed by trivial technological measures.

Unlike soda, organic hydrocolloids in the coating are completely destructured in the standard mode of low-hydrogen electrode baking. Hygroscopicity of the coating, due to the formed pores and their ash residue, is much lower than that caused by soda, even in the most unfavourable case (see Figure 11). Nonetheless, it should be taken into account that hygroscopicity can increase, if the dose of glass required for compensation for mixture thickening by the modifier is exceeded too much.

\section{Conclusion}

Analysis of the results of the performed studies leads to the conclusion that powders of CMC, alginates, cellulose and soda ash really modify the coating mixture of low-hydrogen electrodes. Dispersed in the intergranular layer of liquid glass hydrophyllic particles of modifiers sorb moisture from it that results in increase of mixture viscosity. Increase of liquid glass dose is a means, «thinning» the mixture due to increasing the volume not taken up by the filler, and concentration of vacancies in it, which form during flowing.

While competing with silicon-oxygen anions (SOA) of liquid glass, the hydrated molecules of organic modifiers or soda carbonate ions of the same name drive SOA out of the interphase layer on the surface of grains of marble and other filler ingredients. The thus favourably transformed nature of the interphase layer, blocking of the transition of calcium ions into the liquid-glass film, reduction of the hydrodynamic particle size and EDL charge on filler grain surface, weaken the mixture consistency, as a result of

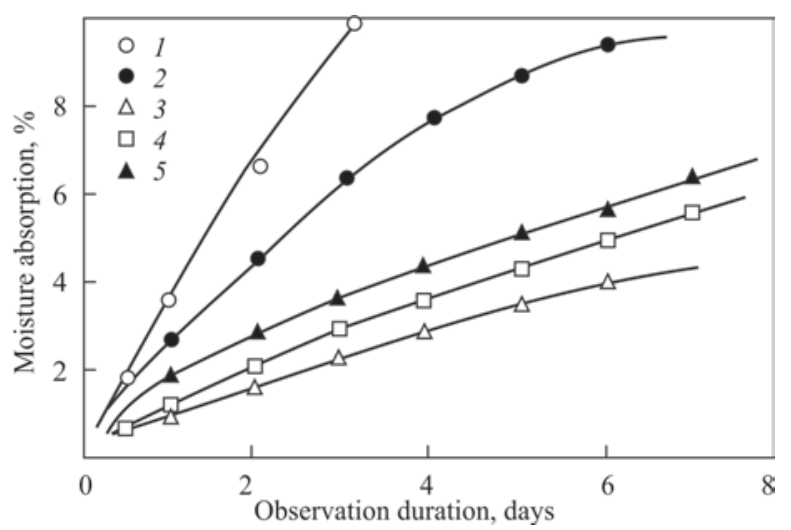

Figure 11. Comparison of hygroscopicity of coating of UONI 13/55 electrodes, made from mixture with 2.4 (1), 1.6 (2) soda, 1.5 (3), 1.0 (4) and 0 (5) \% NaCMC

addition of liquid glass to it. Hydrated particles of the modifiers proper can be regarded as additional vacancies for mixture flow filler grains.

Combining certain kinds and concentrations of modifiers, on the one hand, with the needed characteristics and dose of liquid glass in the mixture, on the other, allows improving its consistency to the level, necessary for rheological support of the required quality of electrodes in terms of thickness difference, without detracting from their quality as regards other kinds of coating defects.

1. Marchenko, A.E. (2017) Experimental studies of electrode coating thickness variation at pressing. The Paton Welding J., 1, 20-27.

2. Bernhardt, E. (1965) Recycling of thermoplastic materials. Moscow, Khimiya [in Russian].

3. Lavrenov, L.V., Marchenko, A.E., Shkurko, S.A (1975) Peculiarities of adsorption of alkaline silicates from liquid glass by marble and fluorite in electrode coatings. Avtomatich. Svarka, 3, 34-38 [in Russian].

4. Marchenko, A.E., Skorina, N.V. (2013) Influence of technological factors in manufacture of low-hydrogen electrodes on hydrogen content in the deposited metal. The Paton Welding J., 8, 13-24.

5. Marchenko, A.E., Gnatenko, M.F., Gorshkova, S.D. (1984) Method of evaluation of thermal softening of electrode paste. In: Inform. documents, CMEA, 1, 66-69 [in Russian].

6. Shelepov, E.P. (2000) Furnace of G-232 model for heat treatment of welding electrodes. In: Proc. of Sci.-Techn. Seminar on Electrode Manufacture on the Threshold of New Millennium (St.-Petersburg, 22-26 May, 2000). Cherepovets, 170-175 [in Russian].

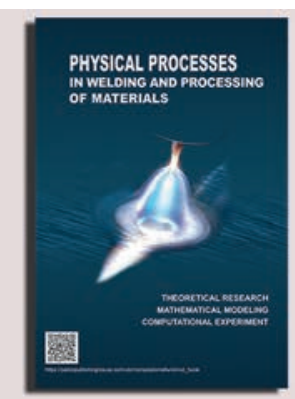

\section{NEW BOOK}

Physical processes in welding and material treatment. Theoretical investigation, mathematical modelling, numerical simulation collection of articles and reports: Collection of articles and reports edited by Prof. I.V. Krivtsun. Kyiv: International Association «Welding», 2018. - 642 p. ISBN 978-617-7015-74-0 (in Russian, English, Ukrainian).

Collection in the open acces:

https://patonpublishinghouse.com/compilations/Krivtsun_Sbornik_2018_small.pdf

Orders for the collection, please send to the Editorial Board. 


\title{
EXPERIENCE OF REPAIR OF PARTS OF TPS POWER UNIT EQUIPMENT
}

\section{A.V. GRUZEVICH ${ }^{1}$ and D.L. NIKIFOROV ${ }^{2}$}

${ }^{1}$ Trypillya TPS

08720, Ukrajinka, Ukraine. E-mail: gruzevich@bigmir.net

${ }^{2} \mathrm{PSJC}$ «Tsentrenergo»

120/4 Kozatska Str., 03022, Kyiv, Ukraine. E-mail: d.i.nikiforov.jsc.ce@gmail.com

\begin{abstract}
Technology of welding and recovery of performance of the shaft of regulator of limiting number of revolutions in automatic safety device of turbo feed pump in No.1 power unit of Trypillya TPS is presented. Operating conditions of automatic safety device of regulator shaft and causes for its damage have been analyzed. Parameters of the mode of welding and heat treatment of the regulator shaft from steel $40 \mathrm{Kh}$ were optimized. Microstructure and mechanical properties of witness-samples were studied, and optimum technological conditions of producing a sound repair welded joint were determined. Obtained results were confirmed by successful operation of the turboset for $2743 \mathrm{~h}$. 7 Ref., 3 Tables, 5 Figures.
\end{abstract}

Ke y w ord s : reconditioning repair of power equipment, TIG welding, welded joints, heat treatment, microstructure, mechanical properties

Feed pump PN-1135-340 with turbo drive OR-12PM is used in TPS power units of 300 MW power for supplying the feed water from deaerator to boiler TPP210A through high pressure heaters [1]. The driving turbine of the feed pump consumes steam of III extraction $\left(P=1.56 \mathrm{MPa}, T=440{ }^{\circ} \mathrm{C}\right)$.

Regulator of critical number of revolutions is one of the main elements of the automatic safety device, which is installed on the turbo feed pump (TFP) and is used for its protection from exceeding the rotor speed (Figure 1).

Purpose, operating conditions and causes for damage. Regulator of critical number of revolutions of circular type is located on driving turbine rotor and is set to the number of revolutions of $5700 \mathrm{rpm}$.

During the service period of TFP automatic safety device, cases of both partial damage of the regulator shaft and of its complete destruction were observed. During the scheduled repair period of the power unit in 2016, after the regulator has operated for $75000 \mathrm{~h}$,

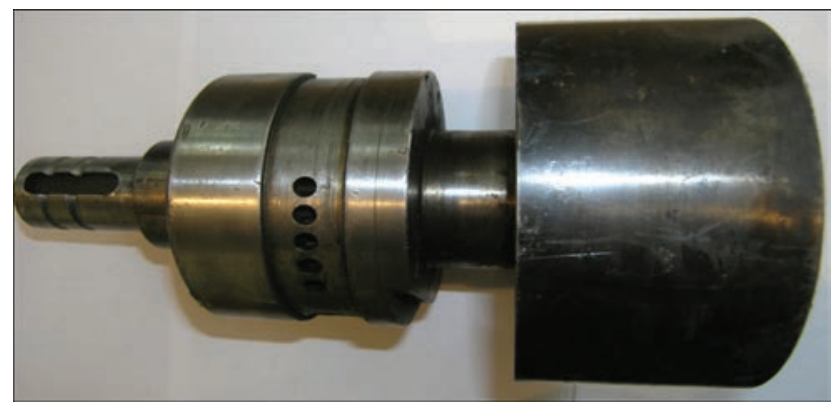

Figure 1. General view of the regulator of critical number of revolutions of automatic safety device in TFP of K-300-240 turbine damage of regulator shaft in the area of fillet transition was detected in the form of a not through-thickness circular crack. The damage site is shown in Figure 2.

The crack was eliminated by turning the neck shaft to the depth of $3.1 \mathrm{~mm}$. After cutting out the crack, a metal layer was further removed to the depth of $0.5 \mathrm{~mm}$ for guaranteed elimination of undetected microcracks. The completeness of crack removal was

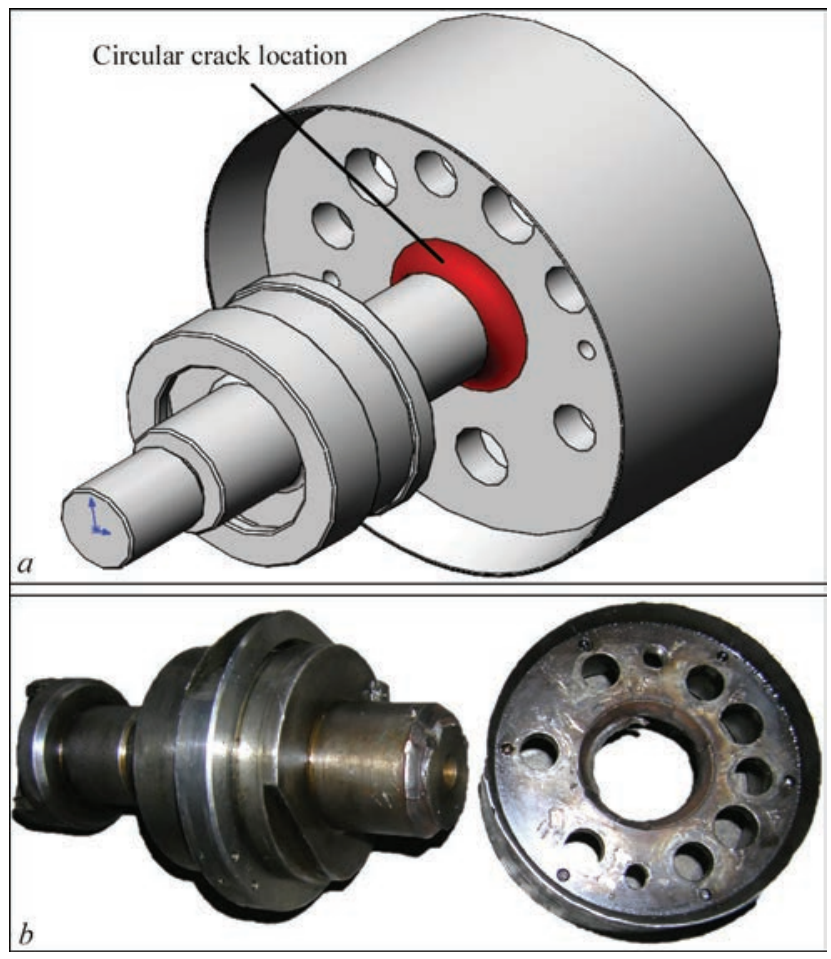

Figure 2. Location of fatigue damage of regulator shaft $(a)$ and case of total destruction of the shaft as a result of cyclic loading $(b)$ 
Table 1. Chemical composition of 40Kh steel according to GOST 4543-71 and determined by PMI Master Pro chemical composition of 40Kh steel and Sv-04Kh19N11M3 deposited metal

\begin{tabular}{|c|c|c|c|c|c|c|c|c|}
\hline Material & $\mathrm{C}$ & $\mathrm{Si}$ & $\mathrm{Mn}$ & $\mathrm{Ni}$ & $\mathrm{S}$ & $\mathrm{P}$ & $\mathrm{C} \Gamma$ & $\mathrm{Cu}$ \\
\hline 40Kh (GOST 4543-71) & $0.36-0.44$ & $0.17-0.37$ & $0.5-0.8$ & Before 0.3 & $\begin{array}{c}\text { Before } \\
0.035\end{array}$ & $\begin{array}{c}\text { Before } \\
0.035\end{array}$ & $0.8-1.1$ & Before 0.3 \\
\hline 40Kh (PMI Master Pro) & 0.451 & 0.277 & 0.977 & 0.0824 & - & - & 1.09 & 0.0962 \\
\hline Sv-04Kh19N11M3 deposited metal & 0.216 & 0.288 & 1.19 & 5.41 & - & - & 8.10 & 0.201 \\
\hline
\end{tabular}

Table 2. Mechanical properties of $40 \mathrm{Kh}$ steel at $T=20^{\circ} \mathrm{C}$

\begin{tabular}{|c|c|c|c|c|c|c|c|}
\hline Product range & $\begin{array}{c}\text { Size, } \\
\mathrm{mm}\end{array}$ & $\sigma_{\mathrm{t}}, \mathrm{MPa}$ & $\sigma_{\mathrm{y}, \mathrm{MPa}}$ & $\delta, \%$ & $\Psi, \%$ & $\begin{array}{c}\mathrm{KCU}, \\
\mathrm{kJ} / \mathrm{m}^{2}\end{array}$ & Heat treatment \\
\hline Forging GOST 8479-70 & 150 & 655 & 490 & 13 & 40 & 540 & $\begin{array}{c}\text { Hardening } 860{ }^{\circ} \mathrm{C} \text {, oil; tempering } 550{ }^{\circ} \mathrm{C}, \\
\text { water }\end{array}$ \\
\hline \multicolumn{8}{|c|}{ 40Kh hardness after tempering } \\
\hline
\end{tabular}

controlled by visual examination and conducting dye penetrant testing.

Analysis of the conditions of regulator shaft operation (intensive alternating loads in the stress concentration area) and fractographic studies of fracture of a similar shaft, which was replaced by a new one, are indicative of a transcrystalline type of fracture and fatigue nature of damage.

After taking into account all the factors (absence of experience of performing repair of such parts by welding, precision of geometrical dimensions of the shaft and rather high requirements to their deviations, short time frame of the repair campaign and absence of the required spare parts), a decision was taken to perform the repair operations under the conditions of the enterprise shop.

The objective of the work is development and testing of the technology of repair of TFP regulator shaft in the area of fatigue damage by welding under shop conditions with application of electrode material of austenitic class, performance of thermal tempering of the item and application of special technological fixtures.

Investigation procedure. Regulator shaft is made from structural alloyed steel 40Kh to GOST 8479-70. Addition of chromium promotes reduction of the critical hardening rate, and, thus, improvement of hardenability. Tables 1, 2 present the chemical composition and mechanical properties of $40 \mathrm{Kh}$ steel, accordingly.

Considering the limited weldability of $40 \mathrm{Kh}$ steel [2-4], the need for preheating and finish heat treatment of part, the procedure of optimization of weld- ing technology and selection of mode parameters was performed on witness-samples.

Conducted investigations were realized with application of the following equipment:

- spectral analysis was conducted using optical-emission spectrometer PMI-MASTER Pro;

- mechanical testing was performed in tensile testing machine UMM-10;

- Brinell and Rockwell hardness was determined in UT hardness meter TKM-459;

- microstructure was assessed in Metam RV-21-2 microscope with x100-500 magnification.

Table 3 gives the welding process and mode parameters. VD-306D was used as the welding source.

TIG welding was performed in the downhand position, in two layers. After welding the samples were subjected to general heating in an electric furnace up to $300{ }^{\circ} \mathrm{C}$ temperature. At the next stage, the samples were cooled with the furnace for two hours and controlled. Examination of outer surface of welded joints after polishing with subsequent etching in acid showed absence of defects.

Conducted macroexaminations revealed a dense structure of the deposited metal of the weld and near-weld zone. Microstructure of the zone of Sv04Kh19N11M3 deposited metal consists of austenite with finely-dispersed carbide particles (Figure 3).

Results of mechanical testing of samples with welded joints for ultimate strength $\sigma_{t}$ and relative reduction in area $\psi$ meet the requirements to base metal and are equal to $\sigma_{\mathrm{t}}=806.7 \mathrm{MPa}, \psi=40 \%$. Sample fracture was of tough type and ran in the HAZ.

Table 3. Parameters of the modes of welding witness-samples from steel 40Kh

\begin{tabular}{|c|c|c|c|c|c|c|c|c|c|}
\hline \multirow{2}{*}{$\begin{array}{l}\text { Sample } \\
\text { number }\end{array}$} & \multirow{2}{*}{$\begin{array}{l}\text { Welding } \\
\text { process }\end{array}$} & \multirow{2}{*}{ Filler material } & \multirow{2}{*}{$\begin{array}{c}\text { Electrode } \\
\text { diameter, } \\
\text { mm }\end{array}$} & \multirow{2}{*}{$I, \mathrm{~A}$} & \multirow{2}{*}{$U_{\text {o.-c, }}, \mathrm{V}$} & \multirow{2}{*}{$\begin{array}{c}\text { Heat } \\
\text { treatment } \\
\text { tempera- } \\
\text { ture, }{ }^{\circ} \mathrm{C}\end{array}$} & \multicolumn{3}{|c|}{ Initial and final hardness, $H B$} \\
\hline & & & & & & & Base metal & Weld & HAZ \\
\hline 1 & TIG & Sv-04Kh19N11M3 & 2 & 80 & Not more than 95 & 300 & 183-192 & $270-275$ & $290-295$ \\
\hline
\end{tabular}



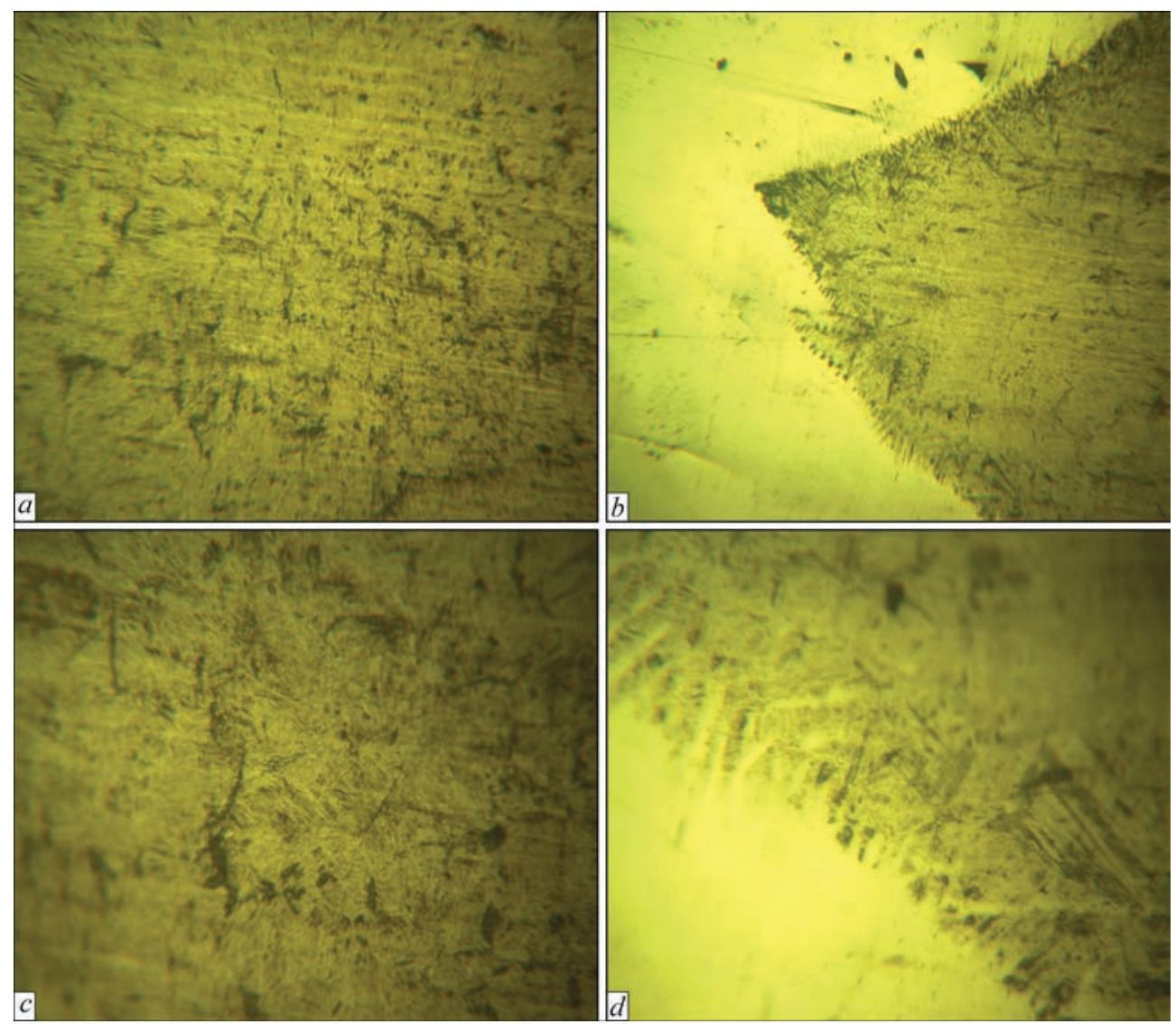

Figure 3. Microstructure of areas of 40Kh steel welded joint: $a-$ Sv-04Kh19N11M3; HAZ; $\times 100$, TIG; $b-$ weld; $\times 100$, TIG; $c$ Sv-04Kh19N11M3, HAZ, $\times 500$, TIG; $d$ - weld, $\times 500$, TIG

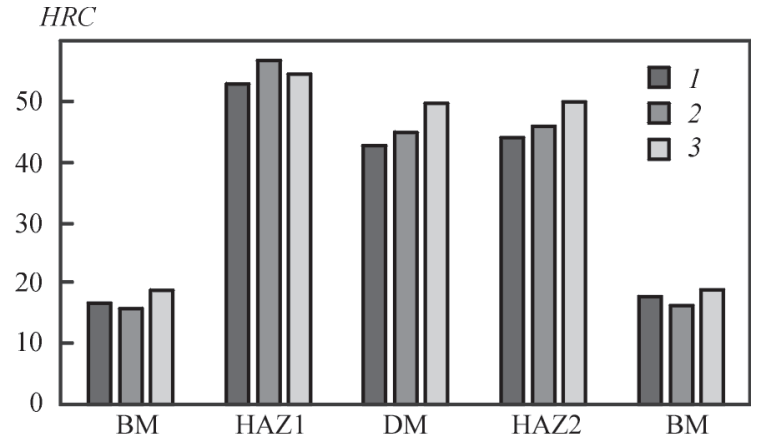

Figure 4. Graphs of Rockwell hardness distribution in welded samples made by Sv-04Kh19N11M3; 1 - plane 1; 2 - 2; 3 - 3
Welded samples were tested for hardness. Measurements were taken in three longitudinal planes with reference point on welded joint central axis and 1.5-2.0 mm step.

Test results showed that welding of $40 \mathrm{Kh}$ steel by the specified technology changes the structure and hardness of base metal in the HAZ (Figure 4). The scheme of edge beveling in fillet transition of the shaft and the fixture used during repair welding, are shown in Figure 5. After performance of repair welding with all the stages of heat treatment, vibration-based diagnostics of the shaft was performed with success.

Analysis of the results. Results of post-operational inspection show the possibility of application
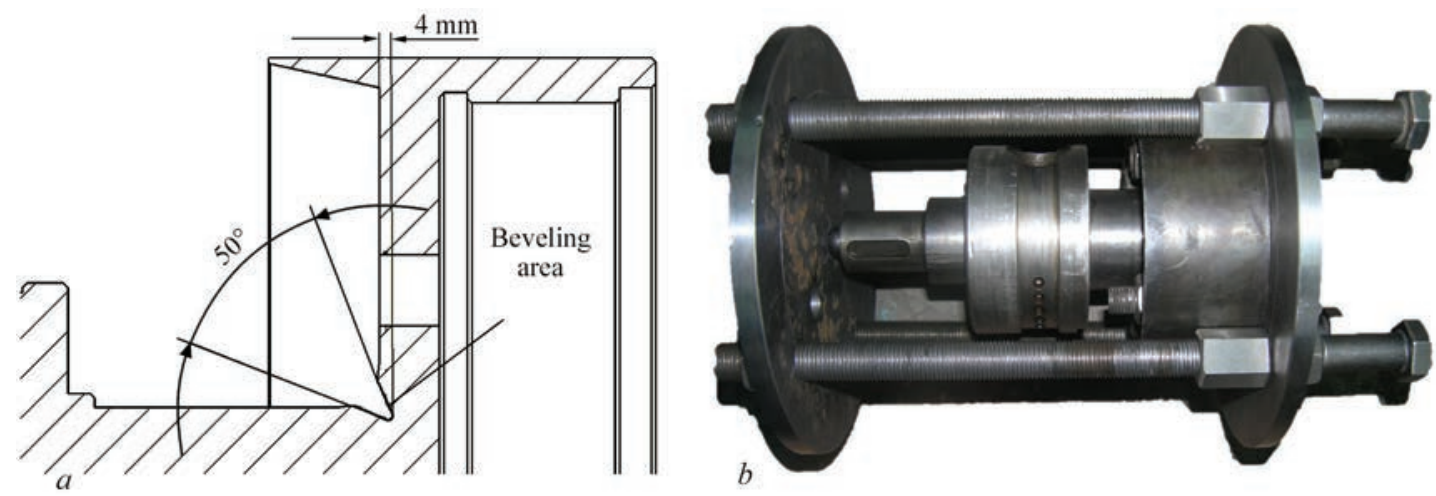

Figure 5. Scheme of beveling the edges of regulator shaft fillet transition $(a)$ and fixture for realization of the technology of shaft welding $(b)$ 
of austenitic filler material for repair of the regulator shaft with simultaneous preheating $\left(200-300^{\circ} \mathrm{C}\right)$ and thermal recovery $\left(250^{\circ} \mathrm{C}\right)$. Thus, application of technological measures (special fixture for shaft fastening) in combination with optimized welding technology, ensured successful operation of regulator shaft of TFP PN-1135-340 with turbo drive OR-12PM during the overhaul period of $300 \mathrm{MW}$ power unit.

It should be noted that there is a rather long-time experience of repair of power equipment (particularly, large-sized) with application of dissimilar (austenite + pearlite) materials $[5,6]$. The main advantages of this approach are the possibility to avoid performance of finish heat treatment, owing to the ductility margin of the deposited metal, as it is technologically impossible in TPS in some cases. In order to reduce hydrogen embrittlement and lower the diffusion level of mobile hydrogen in the shaft weld metal, thermal tempering was applied after welding, which leads to lowering of hydrogen content in the welded joints [7], and a certain lowering of the level of residual welding stresses.

The short-term effect and low reliability of this kind of repair, because of the above-mentioned factors, should be regarded as its disadvantages.

\section{Conclusions}

Selection of austenitic class of the deposited metal, despite the obvious disadvantages, such as chemical and structural inhomogeneity, allowed minimizing the mode of finish heat treatment and reducing the risk of part deformation and, as a result, deviations of the high-precision geometry of the shaft after the welding operations, from the requirements of the drawing that is confirmed by the results of vibration diagnostics.

1. Kosyak, Yu.F. (1982) Steam turbine K-300-240 KhTGZ. Moscow, Energoizdat [in Russian].

2. Filippov, A.A., Pachurin, G.V., Kuzmin, N.A. (2014) Stability of austenite at different temperatures and mechanical properties of hot-rolled steel 40Kh. Int. J. of Applied and Fundamental Research, 10, 27-32.

3. Pchelintsev, V.O., Govorun, T.P., Rab, V.M., Berladir, Kh.V. (2012) Thermocyclic treatment of 40Kh steel shaft of centrifugal pump of NKV type. Visnyk Sum. Derzh. Un-tu. Seriya Tekhnichni Nauky, 4, 123-132 [in Ukrainian].

4. Vasin, P.A., Vinokurov,V.A. (2013) Deposition of protective and hardening coatings on $40 \mathrm{Kh}$ steel by electric-spark alloying. In: Proc. of XIX Int. Sci.-Pract. Conf. on Modern Engineering and Technologies. Tomsk, 26-27.

5. (1988) RD 108.021.112.88: Repair of defects in cast housing parts of steam turbines and fittings using welding-up method without heat treatment. St.-Petersburg, NPO CKTI [in Russian].

6. (1990) $R D$ 34.17.205-90: Instruction on welding of connecting branches to collectors from 12Kh1MF steel by austenitic electrodes without heat treatment. Moscow, VTI [in Russian].

7. Kasatkin, S.B., Musiyachenko, V.F., Smiyan, O.D. (1974) Effect of preheating on hydrogen distribution in welded joint of high-strength steel. Avtomatich. Svarka, 5, 72-73 [in Russian].

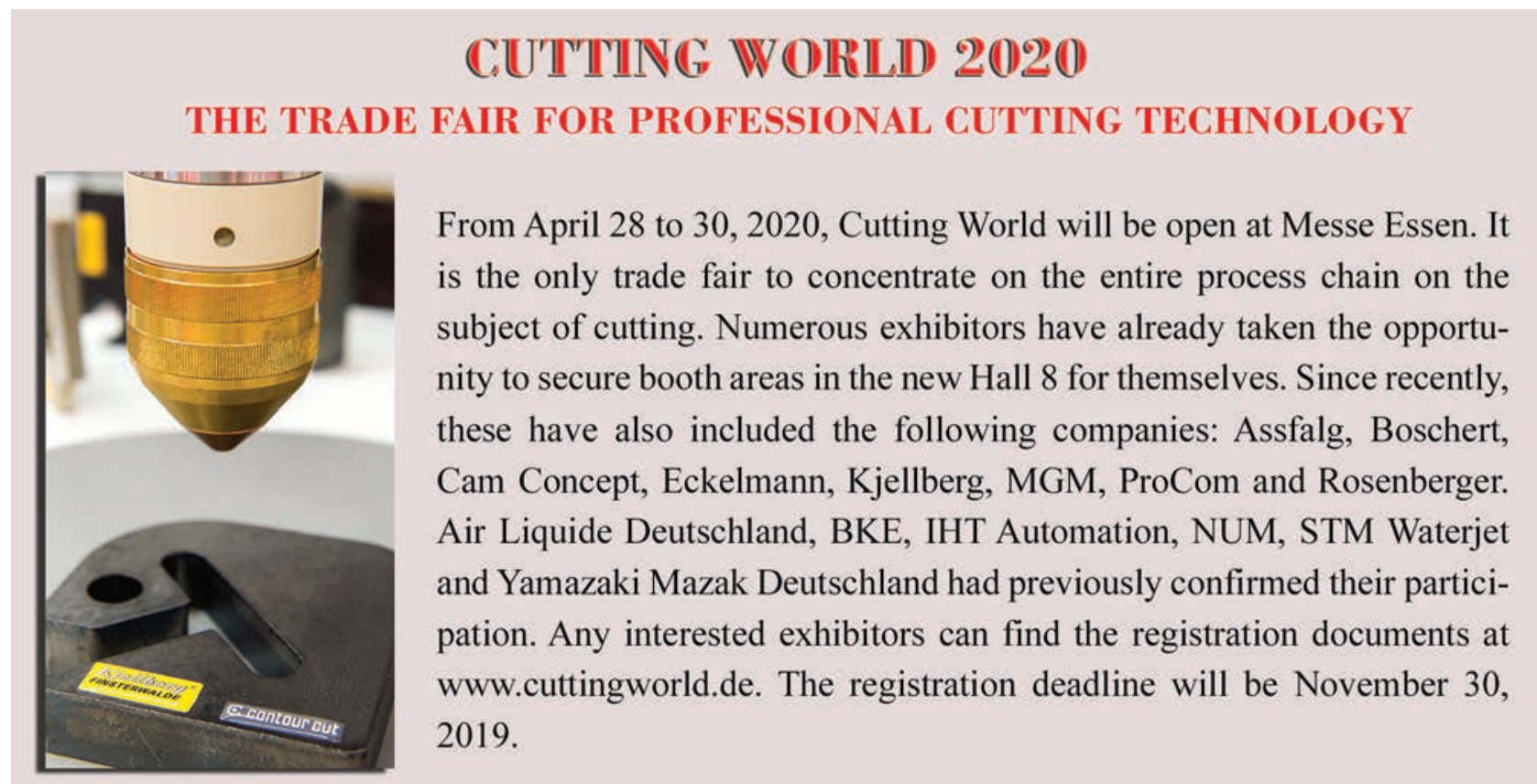




\section{SUBSCRIPTION}

The Patg9o

«The Paton Welding Journal» is Published Monthly Since 2000

in English, ISSN 0957-798X, doi.org/10.15407/tpwj.

«The Paton Welding Journal» is Cover-to-Cover Translation to English

of «Automatic Welding» Journal Published Since 1948 in Russian

and Ukrainian.

«The Paton Welding Journal» can be also subscribed worldwide from catalogues subscription agency EBSCO.

If You are interested in making subscription directly via Editorial Board, fill, please, the coupon and send application by Fax or E-mail.

12 issues per year, back issues available.

$\$ 384$, subscriptions for the printed (hard copy) version, air postage and packaging included.

$\$ 312$, subscriptions for the electronic version (sending issues of Journal in pdf format or providing access to IP addresses).

Institutions with current subscriptions on printed version can purchase online access to the electronic versions of any back issues that they have not subscribed to. Issues of the Journal (more than two years old) are available at a substantially reduced price.

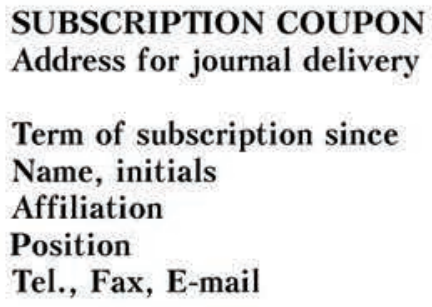

\begin{tabular}{lll}
\hline 20 & till & 20 \\
\hline & & \\
\hline & & \\
\hline
\end{tabular}

The archives for 2009-2018 are free of charge on www://patonpublishinghouse.com/eng/journals/tpwj
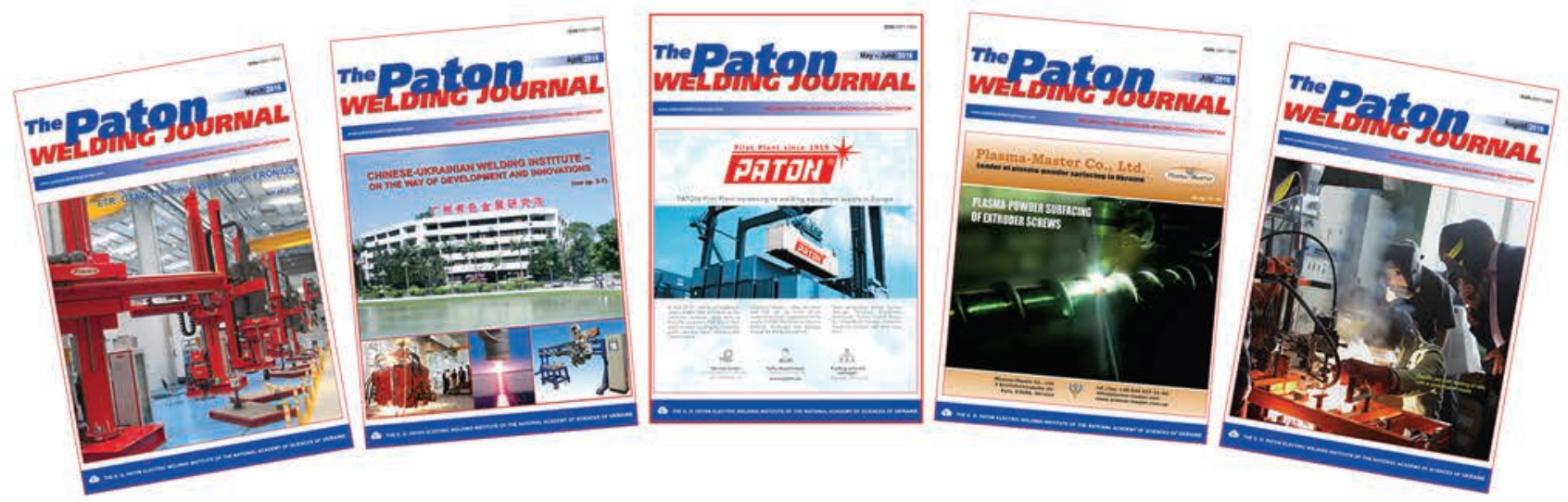

\section{ADVERTISING \\ in «The Paton Welding Journal»}

External cover, fully-colored:

First page of cover $(200 \times 200 \mathrm{~mm})-\$ 700$ Second page of cover $(200 \times 290 \mathrm{~mm})-\$ 550$ Third page of cover $(200 \times 290 \mathrm{~mm})-\$ 500$ Fourth page of cover $(200 \times 290 \mathrm{~mm})-\$ 600$
Internal cover, fully-colored:

First/second/third/fourth page

$(200 \times 290 \mathrm{~mm})-\$ 400$

Internal insert:

$(200 \times 290 \mathrm{~mm})-\$ 340$

$(400 \times 290 \mathrm{~mm})-\$ 500$
- Article in the form of advertising is $50 \%$ of the cost of advertising area

- When the sum of advertising contracts exceeds \$1001, a flexible system of discounts is envisaged

- Size of Journal after cutting is $200 \times 290 \mathrm{~mm}$

\section{Address}

11 Kazymyr Malevych Str. (former Bozhenko Str.), 03150, Kyiv, Ukraine

Tel.: (38044) 20060 16, 2008277

Fax: (38044) 2008277

E-mail: journal@paton.kiev.ua

www://patonpublishinghouse.com/eng/journals/tpwj 


\section{Calendar of December ${ }^{*}$}

DECEMBER 1, 1884 Alonzo Pawling and Henry Harnischfeger established P\&H Mining Equipment Inc. In 1933 the Company developed the first in the world all-welded excavator. Regardless, low market demand, the management of the Company continuously introduced innovations and improved production. Rivets were replaced for all-welded structure. Methods of welding were also improved by own patents. Creating the cranes and excavators, which were more robust, lighter and cheaper, P\&H Mining Equipment Inc. confidently took its place on the market.

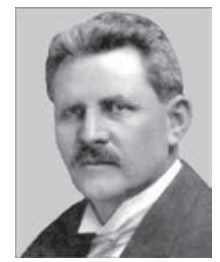$$
\text { dently took its place on the market. }
$$

DECEMBER 2, 2008 Monument to V.G. Shukhov (1853-1939), engineer and architect, was unveiled. He invented a hyperboloid structures, overlap gridshells and commercial units for thermal cracking of oil. He was an author of projects and technical manager during construction of the first Russian oil pipelines (1878) and oil refining plant with the first Russian oil crackers (1931). He made an outstanding contribution in the technologies of oil industry and pipeline transport, in development and construction of welded frames of buildings of open-hearth and converter shops, gas mains of hot blowing and blast furnace heater.

\begin{abstract}
DECEMBER 3, 1959 A national flag was hoisted on ice-breaker «Lenin» that commemorated beginning of new age in a civil ship-building of USSR. Development of qualitatively new type of ship requires mastering of principally new technologies. For the first time, already in the process of nuclear ship construction, there were developed and implemented new methods of welding of stainless steels. Workers of QC department, checking the quality of welds, thoroughly followed the welding operations. The most critical welds were subjected up to 11 tests. $4 \mathrm{~km}$ of X-ray film were used for X-ray testing of welds. Leakage of weld of not more than 4-5 drops per year was allowed. The ice-breaker worked around 30 years under heavy arctic conditions.
\end{abstract}

DECEMBER 4, 1945 A method of stud welding was published. The method was developed by Ted Nelson back in 1936, but even many years on it is still the most efficient and reliable for welding of fastening devices. The process of stud welding by Nelson includes the same basic metallurgical principles as any other type of technology of electric arc welding, namely use an arc discharge in order to melt the bolt (stud) end or electrode with part of main structure of metallic billet. Today the company, established by Nelson, continues to carry its name and is one of the largest suppliers of equipment for stud welding.

DECEMBER 5, 2014 It was a successful launch of «Orion» spaceship, replacing the Space Shuttles. The peculiarity of this space ship is application of friction stir welding. Engineers of Marshall Space Flight Center of NASA developed an innovative instrument for friction stir welding. In addition to space technologies the new technologies is used in manufacture of ship hulls, car roofs, wings and fuselage of the airplanes.

DECEMBER 6, 1963

The patent for ultrasonic method of welding of thermoplastics was applied by Robert Soloff and Seymour Linsley. Appearance and initial development of ultrasonic welding refers to $1930-1940^{\text {th }}$. During the investigation of ultrasonic oscillations it was discovered that simultaneous effect on a welding zone of specific compression force and ultrasonic oscillations provokes joining of the samples without passing through them electric current.

DECEMBER 7, 1995 Descent probe Galileo entered Jupiter atmosphere. This automatic space apparatus of NASA was developed for exploration of Jupiter and its satellites. During the flight it was on-board problems due to welded to each other in vacuum parts of its antenna. This event received wide publicity in 2006. European Space Agency issued a document, in which the possibility of application of cold welding in vacuum was considered as specific damage for space apparatuses. In order not to allow something similar, the designers should reduce the number of moving parts, produce them of different materials or cover their surface with a protective layer.
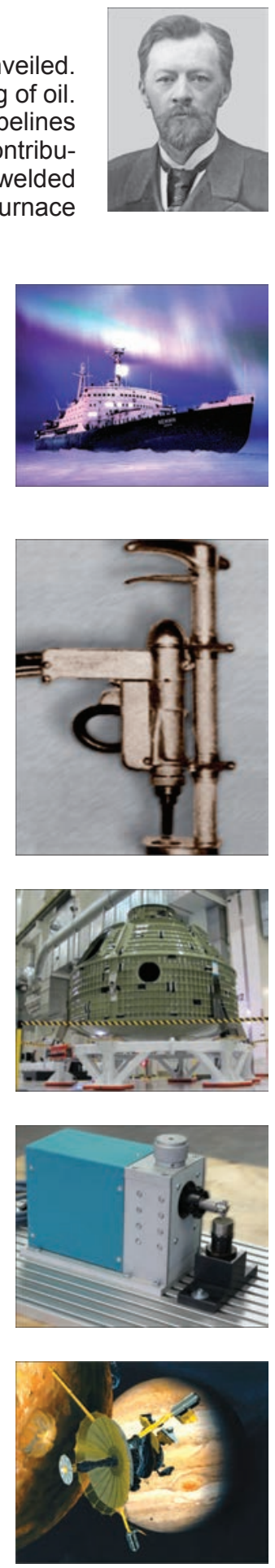

\footnotetext{
*The material was prepared by the Steel Work Company (Kryvyi Rih, Ukraine) with the participation of the editorial board of the Journal. The Calendar is published every month, starting from the issue of «The Paton Welding Journal» No.1, 2019.
} 
DECEMBER 9, 1937 Nils Gustaf Dalen died (1869-1937). He was a Swedish inventor, founder of AGA Company, No-

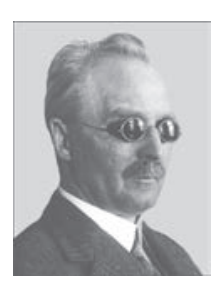
bel Prize winner on physics in 1912. The researcher lost his sight during the experiment and still could get a prize «for invention of automatic regulators, used in combination with gas accumulators for light sources on lighthouses and buoys». AGA Company (before the mergence in 2000 with Linde Company) was the largest manufacturer of commercial gases.

DECEMBER 10, 1964 C. Townes (50\%, USA), N.G. Basov (25\%, USSR) and A.M. Prokhorov (25\%, USSR) was awarded with the Nobel Prize for discovery of new principle of generation and amplification of light, i.e. laser. Based on these works in the beginning of 1960th in the USA it was developed the first optical quantum generator - ruby laser used in welding. The laser was titled by the first letters of English phrase - «Light - Amplification by Stimulated Emission of Radiation».

DECEMBER 11, 1954 «Forrestal», an American aircraft carrier, the main ship of its type was laid. It was the first aircraft carrier designed in the postwar period, in which the experience, gained during the World War II, was fully taken into account, and also the requirements of jet aviation were taken into account. During construction of an aircraft carrier of the «Forrestal» type, about 700 tons of welding materials were consumed, which was a record of such materials application in shipbuilding.

DECEMBER 12, 1961 A new method of welding pipes was patented. The installation was designed on the basis of a specific request for the construction of power plants, the technical characteristics of which required the provision of perfect repetitive welds in order to guarantee the maximum level of safety. For the development of a new method in industrial production, the French welding company «Polysoude» was founded.. Today, «Polysoude» designs, manufactures and sells equipment and installations for orbital and mechanized welding and surfacing.

DECEMBER 13, 1816 Date of birth of Werner Siemens (1816-1892), a famous German engineer, inventor, scientist. Together with Johann Halske (1814-1890), he created the company "TelegraphenBauanstalt Siemens \& Halske», which was engaged in a wide range of works in the field of precision mechanics and optics, as well as the creation of electro-medical devices. As the basic area of activity, the company chose the electro-telegraphy. Namely the telegraph with its huge number of wires needed to be connected, became the catalyst for the development of resistance welding. Thus, the ends of the telegraph wires with a specially made oblique cut of the ends were assembled with an overlap and joined by «incandescence» of the passing direct current.

DECEMBER 14, 1922 Opening of the underground metro line in Glasgow, Scotland took place. The line is the third oldest underground system in the world after the London and Budapest metro. This is the only metro in the British Isles outside London, which is located completely underground. During the construction of the metro, arc welding was used.

DECEMBER 15, 1932 The Soviet mainline cargo-passenger DC locomotive VL19, produced since 1932 to 1938 , was put into service. It was the first all-welded electric locomotive, and among the serial ones (until March 1953) it was the only electric locomotive, the design of which was made in the USSR. In 1931, at almost all the locomotive-building and car-building plants of the Soviet Union the production was transferred to welding of parts, assemblies and structures.

DECEMBER 16, 1947 Experimental physicist Walter Brattein, who worked with the theorist John Bardin, assembled the first serviceable spot transistor. Later, due to creation of the p-n-junction theory by William Shockley (1948-1950), a junction transistor, later a planar transistor (1959) was produced, which became the basis for creating monolithic integrated circuits, including those, used in welding inverters.
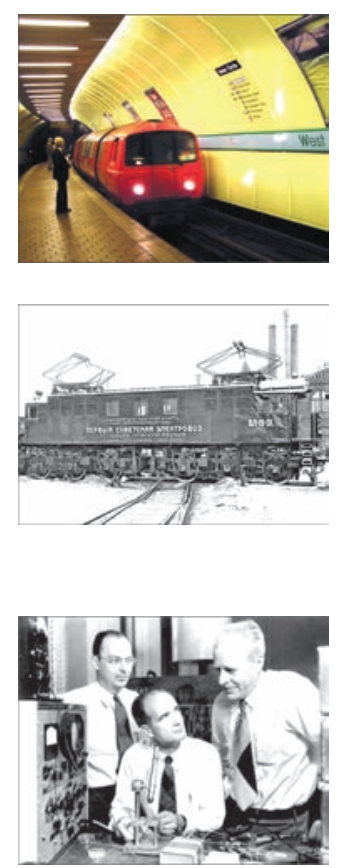
DECEMBER 17, 1946 Gravity welding was patented. This type of welding is not widely spread. It is used, for example, in shipbuilding during welding of panels, but in some cases it is convenient and necessary. During welding in hard-to-reach places, a fire-cracker welding is used. Its advantage consists in the fact, that due to a simple mechanization, the process becomes easily controllable. One worker can serve several installations at once. Strong light radiation of the arc during ignition of electrodes negatively affects the welder and those, who work nearby. Automation of both the process of ignition of the arc (from the control panel) as well as the whole process of gravity welding allows the welder to be removed from the zone of light radiation and harmful dust evolutions.

DECEMBER 18, 1959 The first in the world nuclear-powered submarine K-162 with a titanium hull was laid. The Soviet nuclear-powered submarine of the second generation was the fastest submarine in the world, reaching the speeds over $80 \mathrm{~km} / \mathrm{h}$ (42 knots) in a submerged state. Welding of titanium structures had to be carried out in argon (about 1 million $\mathrm{m}^{3}$ of argon was consumed). In the process of works an extremely high precision and a surgical cleanliness were required.

DECEMBER 19, 1939 The medium tank T-34, was added to the armament of the Red Army and in March, 1940 it was approved for serial production. In total during the years of war, more than 35 thous T-34 of all modifications were produced. Initially, the hull and the turret of T-34 were welded manually by electrodes with a special coating.. In total, a few dozen of welds were produced. Simultaneously with the development of technology, two installations for automatic welding of the hull side with a wing guard of the tank T-34 were designed and manufactured. In January 1942, the first experimental model was welded. The technology and equipment passed a successful testing. On the initiative of E.O. Paton the first in the world' line for production of armored tanks was put into operation, which equipped with about 20 installations for automatic submerged-arc welding. The efficiency of automatic welding was 10 times higher than that of manual welding (photo of the tank T-34 at the territory of the E.O. Paton Electric Welding Institute).

DECEMBER 20, 1898 O. Kleinshmidt published a patent on one of the developments of spot welding. Kleinschmidt replaced carbon electrodes in the "devices» of Benardos by copper electrodes. Also Kleinshmidt invented an improved device for welding, having mounted the transformer directly into the tongs. Since that time, the spot welding left the stage of laboratory experiments and the work on improvement of the process efficiency began.

DECEMBER 21, 1928 John Calvin Coulidge, US President (1872-1933) signed a Bill, approving realization of the project of construction of gravity dam on Colorado River. The first electricity was generated by the station generators already after eight years. Hoover Dam is a unique hydraulic construction in the USA, which is a concrete arch-gravity structure $221 \mathrm{~m}$ high and hydroelectric station located in the lower reaches of Colorado River. The water comes to the turbines from $100 \mathrm{~m}$ height through steel cylindrical wells assembled from welded segments.
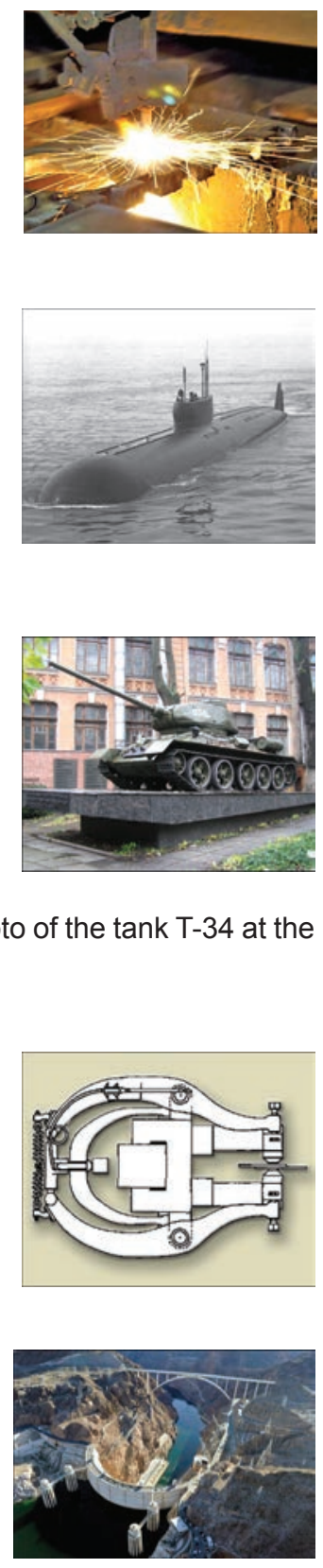

DECEMBER 22, 2007 French carrier rocket Ariane 5 launched the first ever African satellite. To create Ariane 5, the engineers supervising welding of the fuel tank for the rocket, made it from aluminium $3 \mathrm{~mm}$ thick. The welding unit was rotating inside the tank that allowed conducting seamless welding. The weld integrity is of critical importance, as cryogenic tanks form the load-carrying structure of the carrier rocket first stage. In addition, KUKA welding robots were used to build the rocket, which also ensured seamless welding.

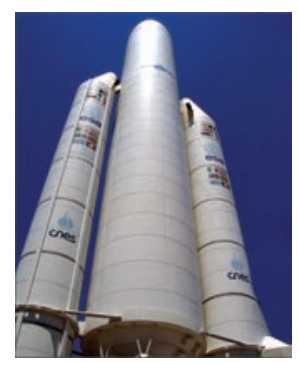

DECEMBER 24, 1818 Birthday of James Joule (1818-1889) - English physicist, who made a significant contribution to formation of thermodynamics. In 1853-1854, together with W. Thompson, English physicist, he discovered the phenomenon of gas cooling at its slow flowing through a porous partition. During electricity studies, wire bundles were fused in a coal box, due to passage of electric current through the wire, i.e. resistance welding was performed in principle. 
DECEMBER 25, 1901 On Christmas night, 1901, the land bank in Hannover was attacked. Robbery attempt failed, and it would not be worth remembering, had it not been for one circumstance: here the criminals used the "gas cutter» - autogenous cutting torch for the first time for opening the safe. The unknown robbers, who can be called «technically illiterate», failed. The point is that a large amount of oxygen is required for iron to burn, while they were only able to get through the eight millimeter casing of the safe made from plain sheet steel.

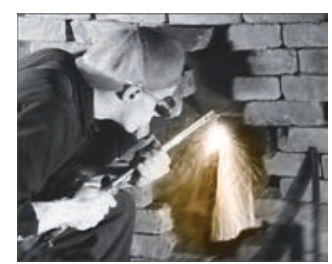

DECEMBER 26, 1922 Robert Nobel from General Electric Company developed automatic direct current welding using arc voltage for regulation of feed rate. This method was mainly applied for repair of worn engine shafts and crane wheels. This process used bare electrode wire, the feed rate of which depended on arc voltage.

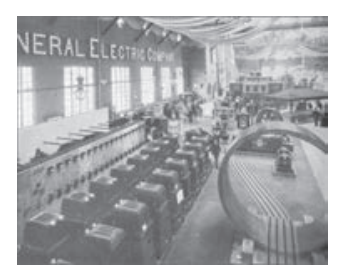

DECEMBER 27, 1968 The flight of Apollo-8, the second manned spacecraft within the US Apollo space program, was completed. During this flight, men reached the another celestial body, the Moon, for the first time. This was the first manned start of Saturn-5 rocket. Saturn- 5 rocket remains to be the most lifting and powerful, the heaviest and largest of the rockets putting payloads to orbit, which has been developed so far. Electron beam, laser and plasma-arc welding processes were used for welding the rocket aluminium tanks.

DECEMBER 28, 1927 One of the patents of D.A. Dulchevsky (1879-1961), Soviet inventor in the field of electric welding, was published. The inventor scientist created an automatic machine of an ingenious design. By its principle of operation, it is a transition from intermittently operating automatic machines to continuously operating automatic machines. This automatic machine has found practical application in railway transport, mainly for performance of surfacing operations. Starting from 1940, this process began to be actively introduced into industry and construction.

DECEMBER 29, 1920 A floating assembly workshop «ESAB IV» was accepted by the Lloyd's register. Two welding stations with DC generator were installed on the ship. ESAB Company was able to perform repair-welding operations "afloat». In many cases such technique of repair operations performance turned out to be indispensable. ESAB IV vessel functioned for 60 years.

DECEMBER 30, 1957 James Byron patented the apparatus for ultrasonic welding. In welding engineering the ultrasound can be used for various purposes. By applying it to the weld pool during crystallization, we can improve the mechanical properties of the welded joint, owing to refinement of weld metal structure and better removal of gases. The ultrasound can be the source of energy for producing spot and seam joints. Ultrasonic welding of metals is becoming ever wider applied, as this method has several advantages and special features, compared to resistance and cold welding. Ultrasound welding is particularly promising for application for microelectronics products.
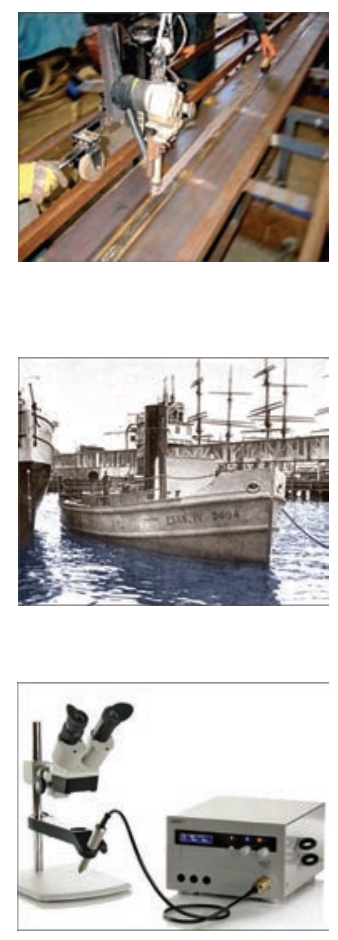

DECEMBER 31, 1986 N.N. Benardos (1842-1905) got a patent on spot resistance welding. It is not known when and under what circumstances N.N.Benardos came to the principle of spot resistance welding. World's first patent for this process (and «apparatus» for its realization) was issued in his name in Germany. Used as electrodes in it were graphite rods, inserted into tongs, compressed manually. 